Aus der Klinik für Gynäkologie und Geburtshilfe

(Prof. Dr. med. J. Gallwas)

der Medizinischen Fakultät der Universität Göttingen

\title{
Glucolyse- und Glutaminase-Inhibition zur \\ Therapieoptimierung von Tamoxifen bei
}

ER-positivem Mammakarzinom

\author{
INAUGURAL-DISSERTATION \\ zur Erlangung des Doktorgrades \\ der Medizinischen Fakultät der \\ Georg-August-Universität zu Göttingen \\ vorgelegt von \\ Friederike Anna-Amalia Susanne Steifensand \\ aus \\ Frankfurt am Main
}


Dekan:

\section{Betreuungsausschuss}

Betreuer/in

Ko-Betreuer/in:

\section{Prüfungskommission}

Referent/in

Ko-Referent/in:

Drittreferent/in:

Datum der mündlichen Prüfung:
Prof. Dr. med. W. Brück

Prof. Dr. rer. nat. C. Gründker

Prof. Dr. rer. nat. D. Kube

Prof. Dr. rer. nat. C. Gründker 
Hiermit erkläre ich, die Dissertation mit dem Titel " Glucose- und Glutaminase-Inhibition zur Therapieoptimierung von Tamoxifen bei ER-positivem Mammakarzinom" eigenständig angefertigt und keine anderen als die von mir angegebenen Quellen und Hilfsmittel verwendet zu haben.

Göttingen, den

(Unterschrift) 


\section{Inhaltsverzeichnis}

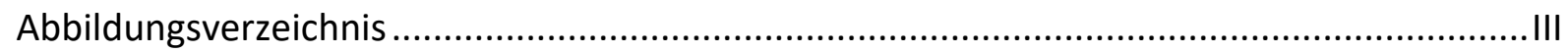

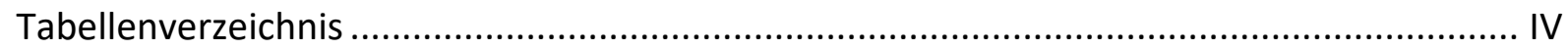



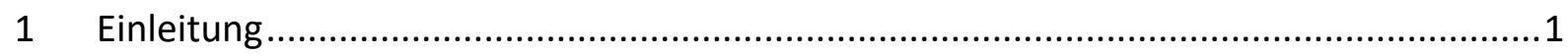

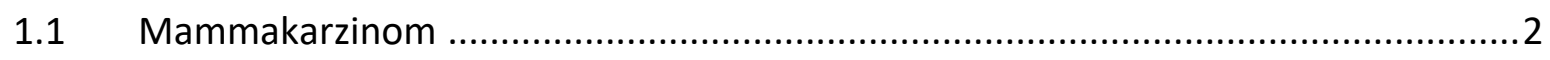

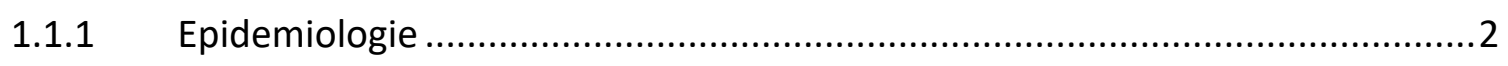

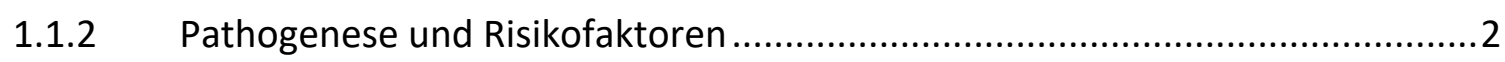

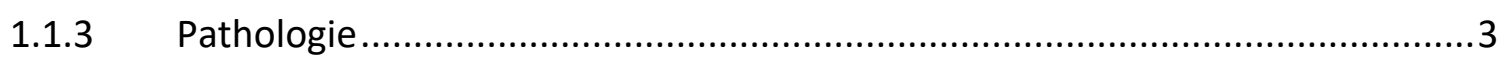

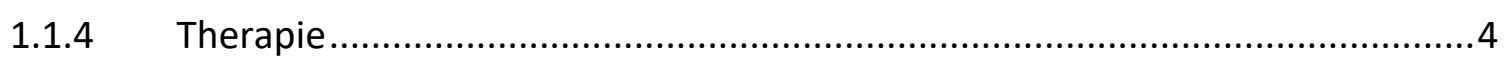

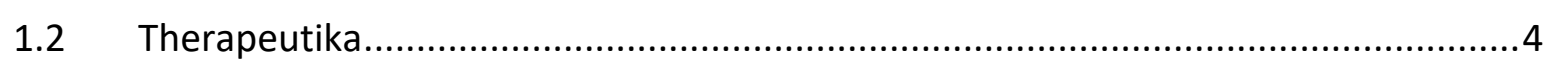

1.2.1 Tamoxifen als anti-hormonelles Therapeutikum .............................................4

1.2.2 2-Deoxy-D-Glucose als anti-metabolisches Therapeutikum............................6

1.2.3 Tumor-Metabolismus und Warburg-Effekt ................................................... 7

1.2.4 CB-839 als anti-metabolisches Therapeutikum ...........................................

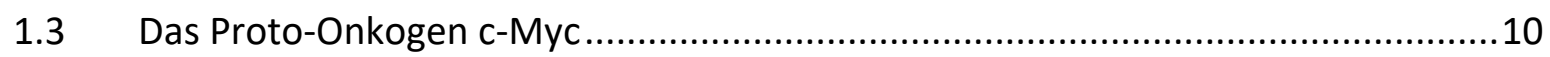

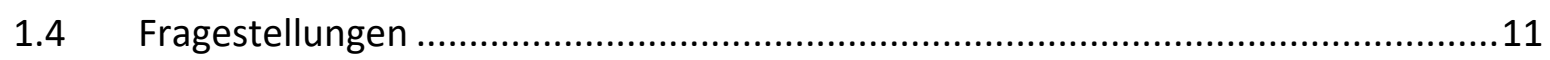

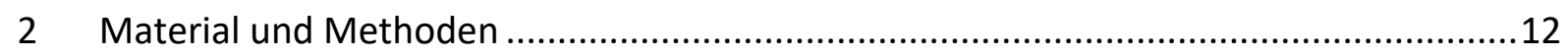

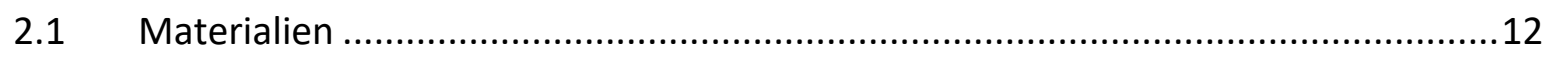

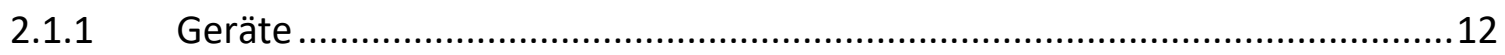



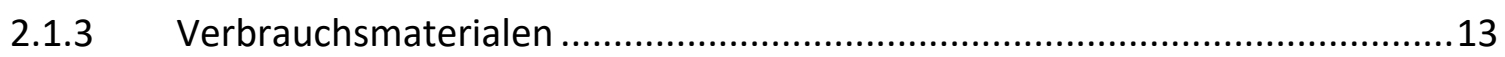

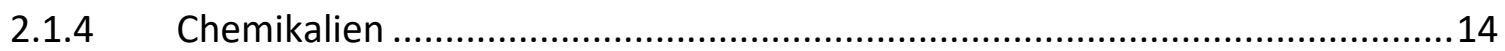

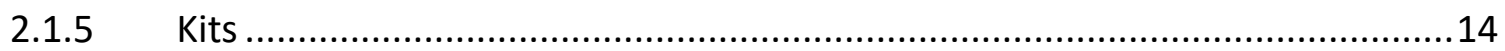

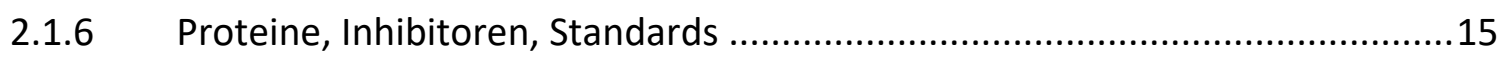

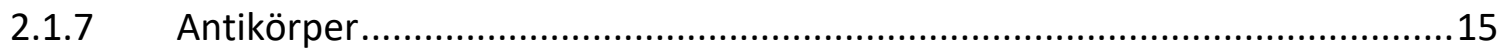

2.1.8 Versuchssubstanzen und Konzentrationen ................................................15

2.1.9 Zelllinien und Kulturbedingungen........................................................ 17

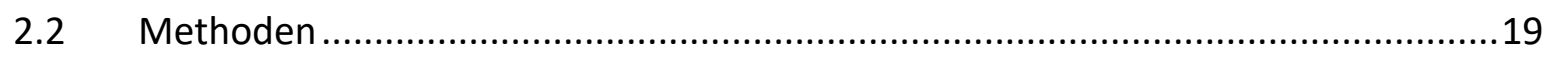

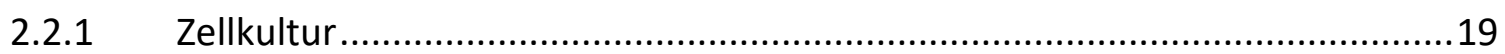

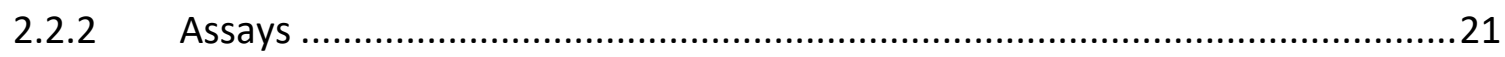

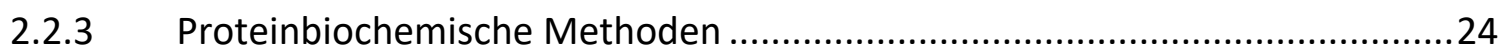

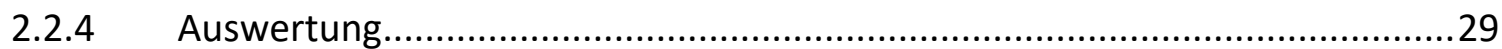


3 Ergebnisse

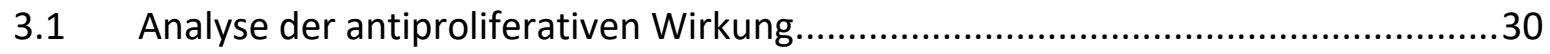

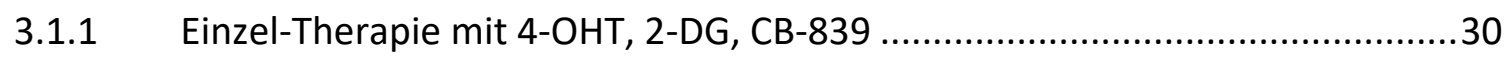

3.1.2 Kombinationstherapie aus 4-OHT, 2-DG, CB-839 …..................................... 37

3.2 Untersuchung der Apoptoseinduktion ............................................................... 45

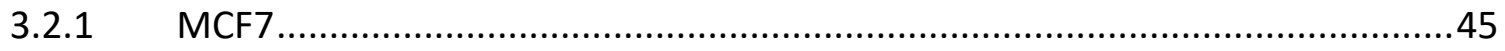



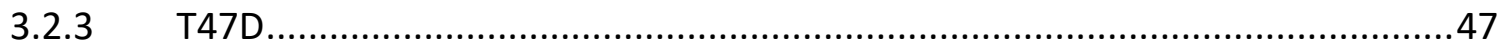

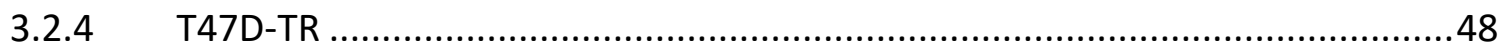

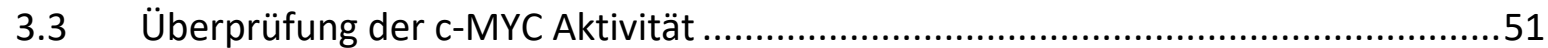

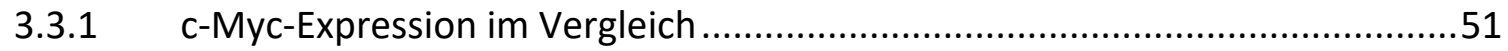

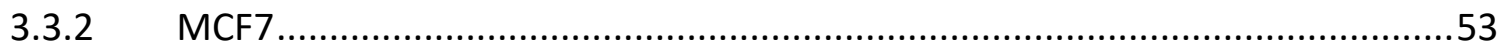

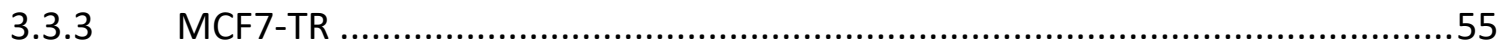

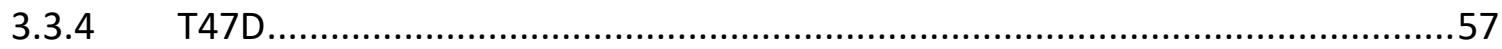

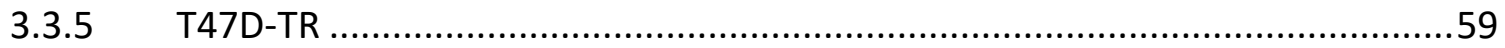

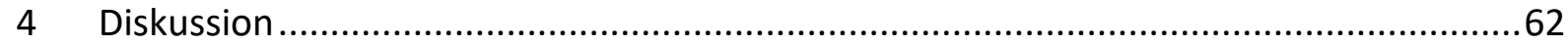

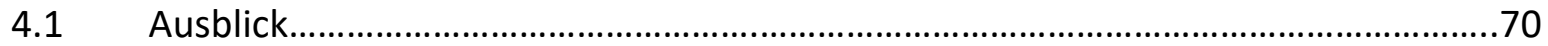

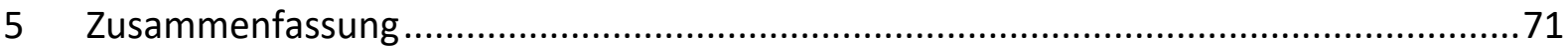

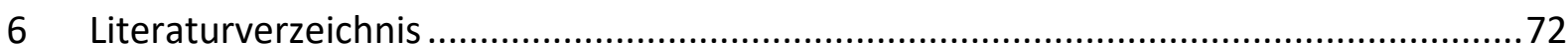




\section{Abbildungsverzeichnis}

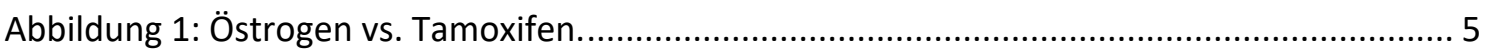

Abbildung 2: Strukturformel von Glucose im Vergleich zu 2-Deoxy-D-Glucose ............................ 6

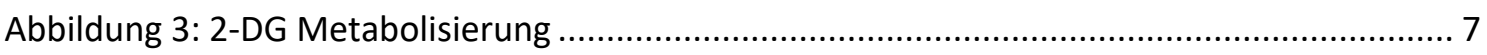

Abbildung 4: Warburg-Effekt bei Krebszellen im Vergleich zu gesunden Zellen.......................... 8

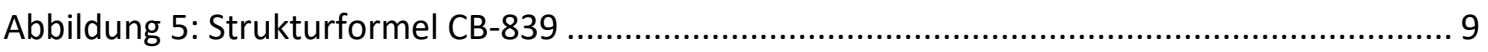

Abbildung 6: Schematische Darstellung der Glutaminolyse....................................................... 9

Abbildung 7: Schematische Darstellung der Reaktionen von AlamarBlue ................................. 22

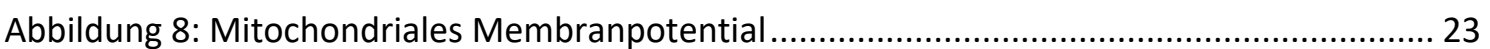

Abbildung 9: Viabilitätsinhibition der Mammakarzinomzelllinie MCF7 ……........................ 32

Abbildung 10: Viabilitätsinhibition der Mammakarzinomzelllinie MCF7-TR ................................ 32

Abbildung 11: Viabilitätsinhibition der Mammakarzinomzelllinie T47D ……....................... 34

Abbildung 12: Viabilitätsinhibition der Mammakarzinomzelllinie T47D-TR $\quad$.............. 35

Abbildung 13: Viabilitätsinhibition der Mammakarzinomzelllinie MCF7 ……...................... 38

Abbildung 14: Viabilitätsinhibition der Mammakarzinomzelllinie MCF7 …............................. 40

Abbildung 15: Viabilitätsinhibition der Mammakarzinomzelllinie T47D …............................ 41

Abbildung 16: Viabilitätsinhibition der Mammakarzinomzelllinie T47D-TR $\quad$ …........................ 43

Abbildung 17: Apoptoseinduktion der Mammakarzinomzelllinie MCF7 ............................... 46

Abbildung 18: Apoptoseinduktion der Mammakarzinomzelllinie MCF7-TR $\quad$ …......................... 47

Abbildung 19: Apoptoseinduktion der Mammakarzinomzelllinie T47D …............................. 48

Abbildung 20: Apoptoseinduktion der Mammakarzinomzelllinie T47D-TR _......................... 49

Abbildung 21: Western-Blot-Analyse von c-Myc bei MCF7, MCF7-TR, T47D und T47D-TR und quantitative Analyse der c-Myc-Expression

Abbildung 22: Western-Blot-Analyse von c-Myc bei MCF7

und quantitative Analyse der Effekte der einzelnen Behandlungen auf c-Myc 54

Abbildung 23: Western-Blot-Analyse von c-Myc bei MCF7-TR

und quantitative Analyse der Effekte der einzelnen Behandlungen auf c-Myc 56

Abbildung 24: Western-Blot-Analyse von c-Myc bei T47D

und quantitative Analyse der Effekte der einzelnen Behandlungen auf c-Myc 58

Abbildung 25: Western-Blot-Analyse von c-Myc bei T47D-TR

und quantitative Analyse der Effekte der einzelnen Behandlungen auf c-Myc 60










\section{Tabellenverzeichnis}

Tabelle 1: Molekulare Subtypen des Mammakarzinoms ........................................................ 3

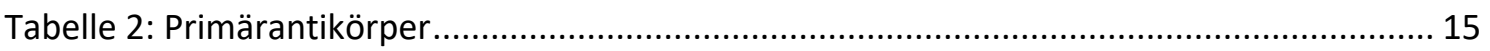

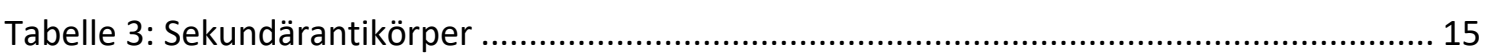

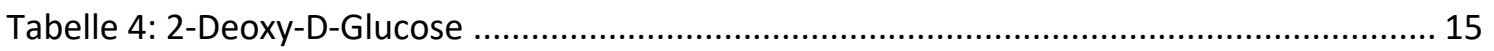

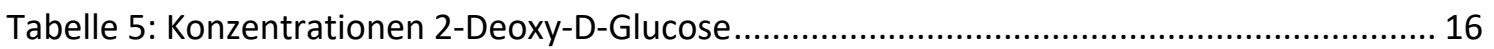

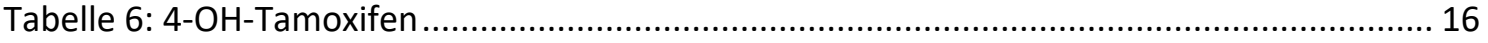



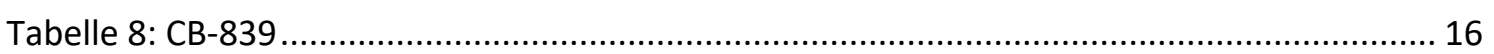

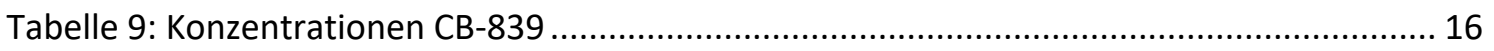

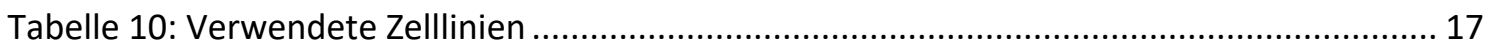

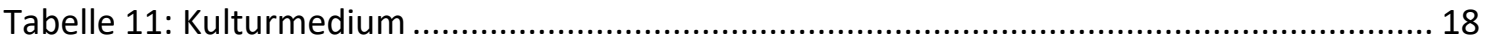

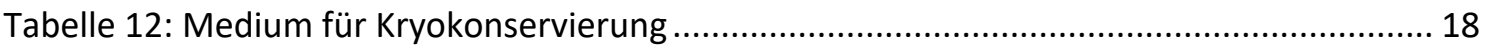

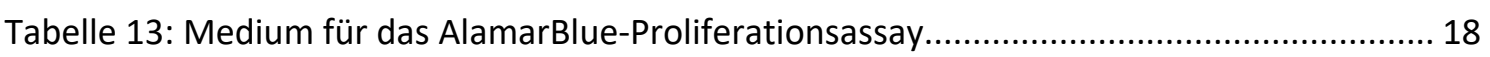

Tabelle 14: Aussaatdichte für das AlamarBlue-Proliferationsassay .......................................... 22

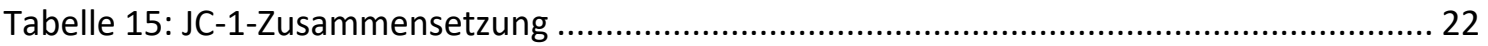

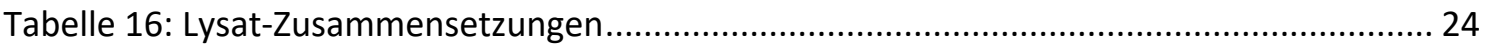

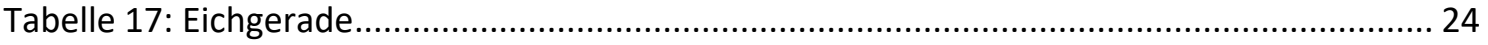

Tabelle 18: Substanzen zur Proteinbestimmung nach Bradford ............................................ 25

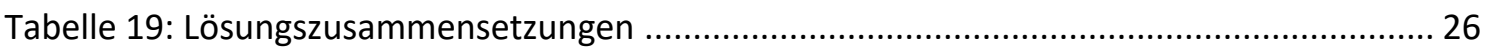

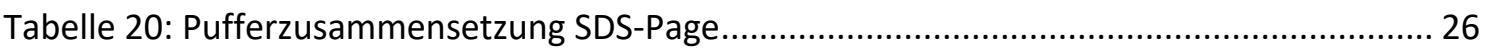

Tabelle 21: Zusammensetzung von Sammel- und Trenngel ...................................................... 26

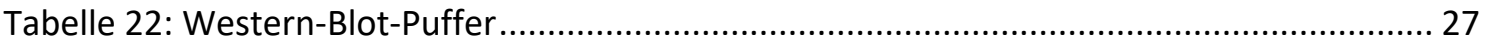

Tabelle 23: Bestandteile und Zusammensetzung für Immunodetektion ................................... 28

Tabelle 24: Statistische Auswertung des Viabilitäts-Assays unter Einzelbehandlungen ............. 36

Tabelle 25: Statistische Auswertung des Viabilitäts-Assays unter Kombinationsbehandlungen 44

Tabelle 26: Statistische Auswertung des JC-1-Assays unter Kombinationsbehandlungen .......... 50

Tabelle 27: Statistische Auswertung von c-Myc unter Kombinationsbehandlungen ................. 61 


\section{Abkürzungsverzeichnis}

ATP

bidest.

BSA

2-DG

DMEM

DMSO

DNA

ER

FCS

$x \mathrm{~g}$

MEM

4-OHT

PAGE

PBS

$\mathrm{P} / \mathrm{S}$

rpm

RT

TR
Adenosintriphosphat

2-fach destilliert

engl.: bovine serum albumin (Rinderserumalbumin)

2-deoxy-D-Glukose

Dulbecco's Modified Eagle Medium

Dimethylsulfoxid

engl.: deoxyribonucleic acid (Desoxyribonukleinsäure)

Östrogen-Rezeptor

engl.: fetal calf serum (fetales Rinderserum)

$\mathrm{x}$-fache Erdbeschleunigung

engl.: minimal essential medium

4-Hydroxytamoxifen

Polyacrylamid-Gelelektrophorese

engl.: phosphate-buffered saline (phosphatgepufferte Salzlösung)

Penicillin/Streptomycin

engl.: rounds per minute (Umdrehungen pro Minute)

Raumtemperatur

Tamoxifen-resistent 


\section{Einleitung}

Allein in Deutschland sind im Jahr 2018 schätzungsweise über 70.000 Menschen an einem Mammakarzinom erkrankt (GEKID 2019). Damit stellt es die häufigste Krebserkrankung der Frau dar.

Die Therapie von soliden Mammakarzinomen baut auf drei Säulen auf, bestehend aus Operation, Strahlentherapie und Chemotherapie. Letztere stellt einen wichtigen Bestandteil in der Therapie dar, allerdings ist sie auch mit Nebenwirkungen behaftet, da nicht nur Krebszellen, sondern auch gesunde Zellen angegriffen werden. Daher ist es besonders wichtig die Unterschiede zwischen gesunden und entarteten Zellen zu betrachten. Einen wichtigen Unterschied zu gesundem Gewebe stellt die Sensibilität gegenüber körpereigenen Hormonen dar. Es konnte gezeigt werden, dass Hormone häufig proliferationssteigernd auf gynäkologische Tumore wirken.

Ein weiterer wesentlicher Unterschied ist der Metabolismus. Bei entarteten Zellen findet sich eine vermehrte Glukoseaufnahme, verbunden mit gesteigerter Glykolyse und Glutaminolyse, sowie eine Hochregulierung der ATP-Synthese (Warburg 1956). Aufgrund dieser Erkenntnis bietet sich der Tumormetabolismus als therapeutisches Target in der Therapie entarteter Mammakarzinom-Zellen an.

Im Folgenden wurde daher untersucht, ob die anti-hormonelle Therapie unter der Verwendung von 4-Hydroxy-Tamoxifen mit einer Anti-Metabolismus-Therapie mit dem Glykolyse-Inhibitor 2-Deoxy-D-Glucose oder dem Glutaminase-Inhibitor CB-839 kombiniert werden kann. 


\subsection{Mammakarzinom}

\subsubsection{Epidemiologie}

2014 konnte zuletzt eine Brustkrebs-Prävalenz von über 312.000 und eine Inzidenz von circa 69.000 verzeichnet werden. Die Schätzung für das Jahr 2018 durch das Robert Koch-Institut beläuft sich auf eine Prävalenz von über 560.000 und eine Inzidenz von mehr als 72.000 Patientinnen und Patienten. Damit ist Brustkrebs mit Abstand die häufigste Krebserkrankung der Frau, jede Achte wird laut der Inzidenzzahlen im Laufe ihres Lebens an einem Mammakarzinom erkranken. Dabei liegt der Altersgipfel bei 65 bis 69 Jahren, über $30 \%$ der Erkrankten befinden sich unterhalb dieses Gipfels (GEKID 2019).

\subsubsection{Pathogenese und Risikofaktoren}

Als heterogene Erkrankung ist die Entstehung des Brustkrebses noch nicht vollständig geklärt, allerdings korrelieren genetische Prädispositionen und bestimmte Risikofaktoren mit einer erhöhten Wahrscheinlichkeit im Laufe des Lebens an einem Mammakarzinom zu erkranken. Dabei unterscheidet man ätiologisch genetische, hormonelle und toxische Risikofaktoren. Zu den genetischen Risikofaktoren gehören unter anderem eine familiäre Prädisposition für Mamma- oder Ovarialkarzinom, eine erhöhte Dichtigkeit des Brustdrüsengewebes und gutartige Brustveränderungen oder Keimbahnmutationen wie BRCA1/2-Gen-Mutationen.

Auf hormoneller Ebene kann das Risiko durch eine frühe erste bzw. späte letzte Menarche, Nullparität und ein höheres Alter bei der ersten Geburt sowie durch das metabolische Syndrom mit Adipositas oder eine postmenopausale Hormonersatztherapie erhöht werden (Amant et al. 2005).

Zu den Risikofaktoren auf toxischer Ebene zählen Nikotinabusus, Alkoholabusus sowie eine Radiatio-Therapie im Kindes- oder Jugendalter (Moskowitz et al. 2014). 


\subsubsection{Pathologie}

Es werden beim Mammakarzinom vier molekulare Subtypen unterschieden (siehe Tab. 1) (Carey et al. 2006; Prat et al. 2010).

Tabelle 1: Molekulare Subtypen des Mammakarzinoms

\begin{tabular}{ll}
\hline Molekularer Subtyp & Definition \\
\hline Luminal A & ER $\alpha / P R+$ \\
Luminal B & HER2 -, Ki67 niedrig \\
& ER $\alpha+$ \\
HER2-gesteuert & PR- oder HER2 +, Ki67 hoch \\
& ER $/ \mathrm{PR}-$ \\
Basal-like & HER2 + \\
\hline
\end{tabular}

$\begin{array}{llll}E R \alpha & = & & \text { Östrogen-Rezeptor alpha } \\ P R & = & \text { Progesteron-Rezeptor } \\ \text { HER2 } & = & \text { Human Epidermal Growth Factor Receptor 2 }\end{array}$

Dabei wird die Definition nach dem Rezeptorstatus der Krebszellen getroffen.

Luminal-A-Zellen sind durch die Ausprägung von Hormonrezeptoren definiert, wozu die Östrogenrezeptoren (ER) und Progesteronrezeptoren (PR) gehören. Es findet sich hier keine Ausbildung des sogenannten Human Epidermal Growth Factor Receptor 2, kurz HER2. Insgesamt ist bei den Zellen des molekularen Subtyps Luminal A die Proliferationsrate, beschrieben durch den Ki67-Index, gering. Die Zellen dieses Subtyps haben insgesamt eine gute therapeutische Prognose mit einem guten Outcome der Patienten. $70 \%$ der Mammakarzinome zählen hierzu (Anderson et al. 2002).

Bei den Luminal-B-Zellen findet man ebenfalls ER, jedoch kann hier der PR-Status negativ und/oder der HER2-Rezeptor-Status positiv ausfallen, der Proliferationsindex Ki67 ist ebenfalls höher.

HER2-gesteuerte Zellen zeichnen sich durch einen negativen Hormonrezeptorstatus (ER $\alpha /$ PR-negativ) und der Ausbildung von HER2-Rezeptoren aus.

Die schlechteste Prognose mit dem invasivsten und sehr proliferativen Wachstum haben die basal-like bzw. triple-negativen Mammakarzinom-Zellen. Hier fällt der oben genannte Rezeptorstatus insgesamt negativ aus. Das bedingt schlechte Therapieoptionen, da keine rezeptorischen Angriffspunkte gegeben sind. 


\subsubsection{Therapie}

Zu den Therapieoptionen des Mammakarzinoms zählen Operation, Bestrahlung und die medikamentöse Therapie (S3-Leitlinie Mammakarzinom 2017).

Insgesamt basiert die Therapie des Mammakarzinoms jedoch auf einem komplexen Algorithmus mehrerer Faktoren, bei dem individuell die jeweiligen Optionen kombiniert werden.

\subsection{Therapeutika}

\subsubsection{Tamoxifen als anti-hormonelles Therapeutikum}

Tamoxifen wirkt als selektiver ER-Modulator am ER und wird bei Mammakarzinom-Zellen des Subtyps Luminal A eingesetzt, da diese einen ER vom Subtyp $\alpha$ exprimieren. Natürlicherweise wirkt am ER das Östrogen.

Östrogen (Östradiol, Estron) ist ein in den Ovarien produziertes lipophiles Hormon, welches durch die Zellmembran diffundieren und intrazellulär an den ER binden kann. Gebunden bildet dieser Dimere und löst eine Konfirmationsänderung aus. Dadurch kann der Komplex an Ko-Aktivatoren binden, die wiederum als großer Komplex die DNA an den Estrogen Response Elements (EREs) modulieren und die Transkription sowie die Zellproliferation anregen können. Tamoxifen bindet als selektiver ER-Modulator kompetitiv an den ER, jedoch so, dass es zu einer Konfirmationsänderung kommt, die einen ER-Antagonismus zur Folge hat. Infolgedessen kommt es nämlich zu einer Komplexbildung mit Koaktivatoren, welche eine hemmende Wirkung auf die Estrogen Response Elements (EREs) der DNA haben und die ER-abhängige Transkription unterdrücken.

Tamoxifen wirkt also auf transkriptioneller Ebene. 75 \% der Mammakarzinome sind hormonsensibel und somit mit dem selektiven ER-Modulator Tamoxifen therapierbar (Perou et al. 2000). 


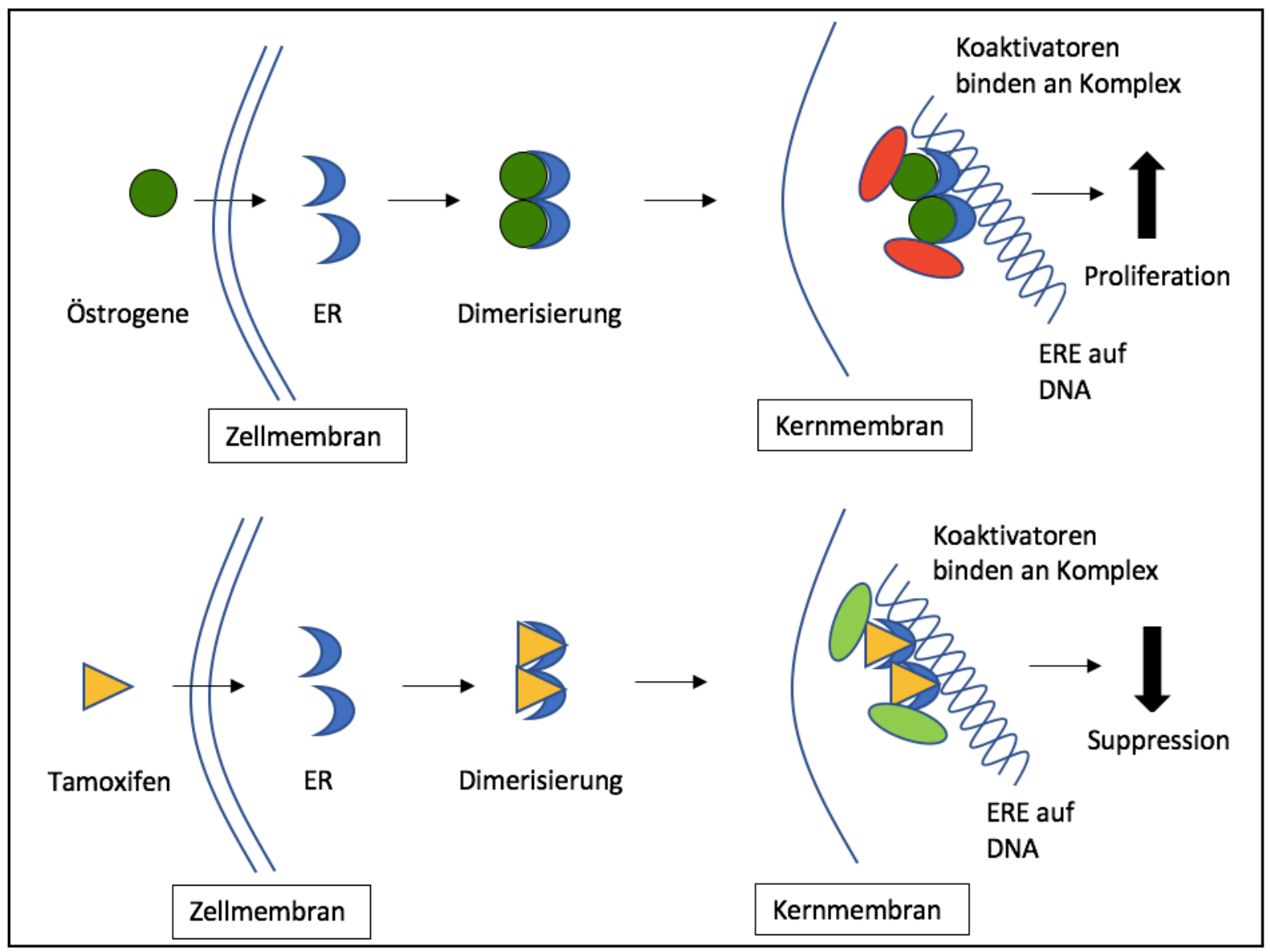

Abbildung 1: Östrogen vs. Tamoxifen (nach Patel und Bihani 2018).

Im menschlichen Gewebe lassen sich grundsätzlich zwei ER voneinander unterscheiden, ER $\alpha$ und ER $\beta$. Beide besitzen die gleiche Grundstruktur, werden jedoch in unterschiedlichen Geweben exprimiert und haben dort jeweils andere Auswirkungen.

Während man ER $\alpha$ hauptsächlich in der Mamma findet, wird ER $\beta$ von Knochen, Endometrium und Gefäßen exprimiert (Barkhem et al. 1998).

Tamoxifen ist ein Partialagonist. Es ist spezifisch für ER $\alpha$ und wirkt hier antiproliferativ. Auf ER $\beta$ hat Tamoxifen jedoch eine proliferative Wirkung, daher ergeben sich die Nebenwirkungen des Tamoxifens. Dazu gehören neben allgemeiner Symptomatik (Unwohlsein, Müdigkeit, Übelkeit, Ödeme, Hitzewallungen, Leuko- und Thrombozytopenien) eine Erhöhung des Risikos für Endometriumkarzinome (1\%), sowie die Ausbildung von Thromboembolien (1-3 \%) (EBCTCG 2011; Fisher et al. 2005).

Tamoxifen wird nach Aufnahme im menschlichen Körper über verschiedene CYP-Enzyme der Leber in die aktiven und deutlich wirksameren Metaboliten umgewandelt. Dazu gehört unter anderem 4-OH-Tamoxifen (Cronin-Fenton et al. 2014). 
Neben dem Auftreten möglicher Nebenwirkungen stellt die Entwicklung einer Tamoxifenresistenz in der klinischen Praxis ein großes Problem dar. In über $50 \%$ der mit Tamoxifen behandelten Patientinnen konnte eine primäre oder sekundäre Tamoxifenresistenz beobachtet werden (EBCTCG 2005). Der genaue Pathomechanismus hinter der Resistenzentwicklung ist noch nicht vollständig geklärt.

\subsubsection{2-Deoxy-D-Glucose als anti-metabolisches Therapeutikum}

2-DG ist ein Glykolyse-Hemmstoff. Es unterscheidet sich von Glucose durch eine Hydrogen-Gruppe anstatt einer Hydroxygruppe am $\mathrm{C}_{2}$-Atom (siehe Abb. 2).

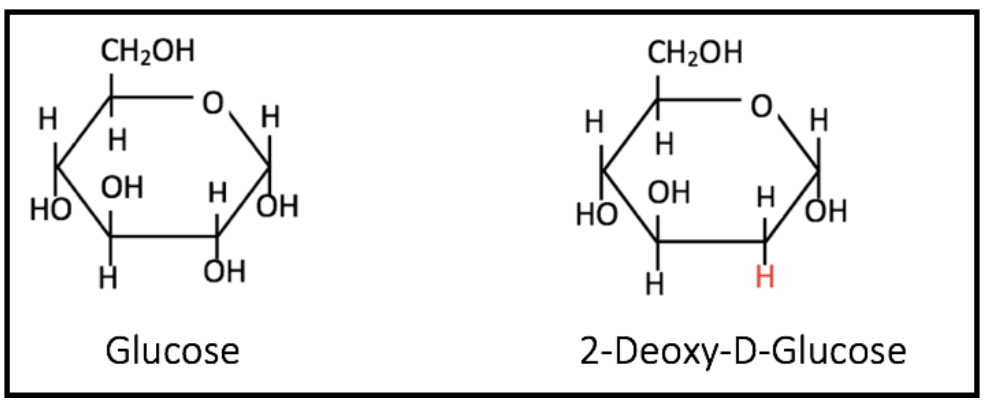

Abbildung 2: Strukturformel von Glucose im Vergleich zu 2-Deoxy-D-Glucose (nach Aft et al. 2002)

2-DG wird wie Glucose über Glucose-Transporter in die Zelle aufgenommen und ebenfalls wie die Glucose durch das Enzym Hexokinase phosphoryliert (siehe Abb. 3). 2-DG-6-Phosphat kann jedoch nicht isomerisiert werden und somit nicht weiter in der Glykolyse verarbeitet werden, sodass es akkumuliert (Pelicano et al. 2006).

Der Mangel an verarbeitungsfähiger Glucose bedingt einen Abfall der Energieproduktion und des Zellmetabolismuses, wodurch die Zelle in einen Zellzyklusarrest gerät (Maher et al. 2004). Daraus resultiert letztendlich der Untergang der Zelle. Es konnte bereits gezeigt werden, dass unter anderem die Therapie mit 2-DG zu einer Aktivierung von Caspase-3 führt, welche eine Apoptose der Zelle induzieren kann (Aft et al. 2002). 




Abbildung 3: 2-DG Metabolisierung (nach Aft et al. 2002)

Die Wirkung von 2-DG konnte sowohl in Mammakarzinom-Zellen nachgewiesen werden, als auch in anderen soliden Tumoren (Laszlo et al. 1960). In Mammakarzinom-Zellen konnte gezeigt werden, dass die Kombination aus 2-DG mit verschiedenen Chemotherapeutika zu signifikanten Wirkungseffekten führt (Zhang und Aft 2009).

In klinischen Phase I und II Studien an humanen Glioblastomen wurde ein Wirkungsprofit unter der Kombination von Strahlentherapie und der Gabe von 2-DG beobachtet (Mohanti et al. 1996).

\subsubsection{Tumor-Metabolismus und Warburg-Effekt}

Glucose gelangt in die Zelle und wird zunächst über die Glykolyse metabolisiert. Dabei unterscheidet man die aerobe Glykolyse, also unter Sauerstoff-Anwesenheit, von der anaeroben Glykolyse, also unter Sauerstoff-Abwesenheit. Bei der aeroben Glykolyse wird die Glucose über den Citratzyklus und die mitochondriale Atmungskette in die Produkte Kohlenstoff-Dioxid, Wasser und 36 ATP metabolisiert. Die anaerobe Glykolyse funktioniert über die Fermentation des Pyruvats in Lactat, der Energiegewinn in Form von ATP ist deutlich geringer. Eine wichtige Eigenschaft von Krebszellen bzw. "hallmark of cancer" ist der Warburg-Effekt, benannt nach den Beobachtungen durch Otto Warburg (1924).

Dieser beschreibt, wie in Abb. 4 dargestellt, das Verhalten von Krebszellen im Vergleich zu gesundem Gewebe einen erhöhten Glucosebedarf zu haben und trotz aerober Bedingungen ihre Energie durch aerobe Oxidierung und durch Lactat-Fermentation zu erzielen, anstatt allein durch aerobe Oxidierung (Warburg 1956). 
Verschiedene Erklärungsansätze versuchen dieses typische Verhalten von Tumorzellen zu begründen. Demnach sollen durch die erhöhte Glucoseaufnahme die Stoffwechselwege beschleunigt und eine schnellere ATP-Produktion ermöglicht werden, wodurch der Tumor schneller proliferieren kann (Van der Heiden et al. 2009; Locasale und Cantley 2011).

Außerdem soll das bei der anaeroben Glykolyse entstehende azidotische Milieu dem Tumor das invasive Wachstum ermöglichen (Estrella et al. 2013).

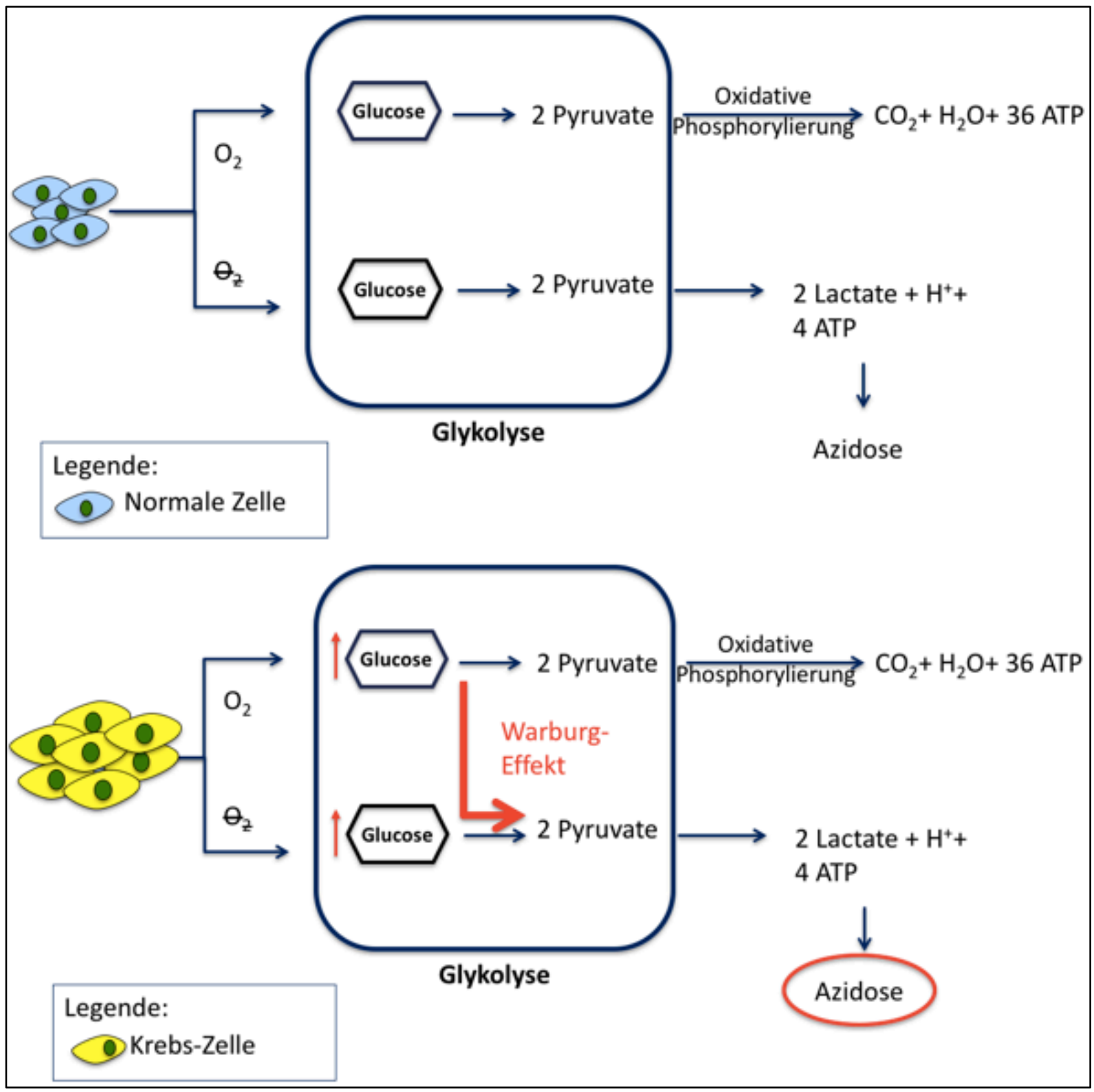

Abbildung 4: Warburg-Effekt bei Krebszellen im Vergleich zu gesunden Zellen (nach Damaghi et al. 2015).

Mittels Glykolyse-Inhibition durch 2-DG ist es möglich in diesen Warburg-Effekt einzugreifen. 


\subsubsection{CB-839 als anti-metabolisches Therapeutikum}

CB-839 (siehe Abb. 5) ist ein allosterischer Inhibitor der Glutaminase, ein Enzym der Glutaminolyse.

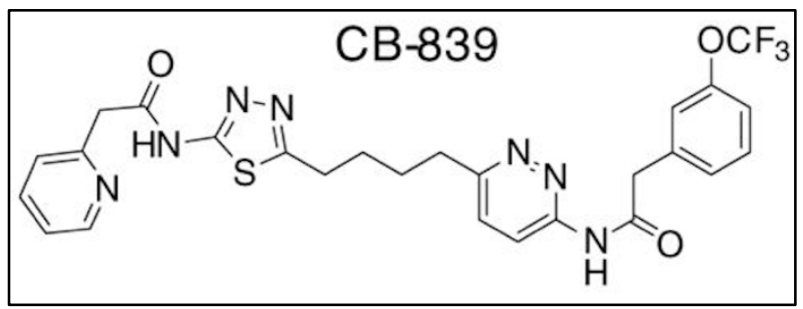

Abbildung 5: Strukturformel CB-839 (Gross et al. 2014)

Glutamin ist eine essentielle Aminosäure des menschlichen Körpers. Im Rahmen der Glutaminolyse wird es in der Zelle zu Glutamat, Aspartat, $\mathrm{CO}_{2}$, Pyruvat, Lactat, Alanin und Citrat metabolisiert (Wise und Thompson 2010).

Nach Aufnahme in die Zelle wird es durch das Enzym Glutaminase in Glutamat und Ammonium $\left(\mathrm{NH}_{4}^{+}\right)$umgewandelt. Durch die Glutamat-Dehydrogenase entsteht im nächsten Schritt aus Glutamat $\alpha$-Ketoglutarat, welches anschließend den Citratzyklus speisen kann. Alternativ kann das Glutamat durch die Alanin-Aminotransferase bzw. durch die AspartatAminotransferase in Alanin und Aspartat umgewandelt werden, welche Ausgangsstoffe der Nukleinsäuresynthese sind. Das im Zwischenschritt des Citratzyklus entstehende Malat kann in Pyruvat bzw. Lactat umgewandelt werden. Damit erschließt sich im Rahmen der Glutaminolyse neben der Glykolyse ein weiterer Prozess der Energiegewinnung (siehe Abb. 6) (DeBerardinis und Cheng 2010).

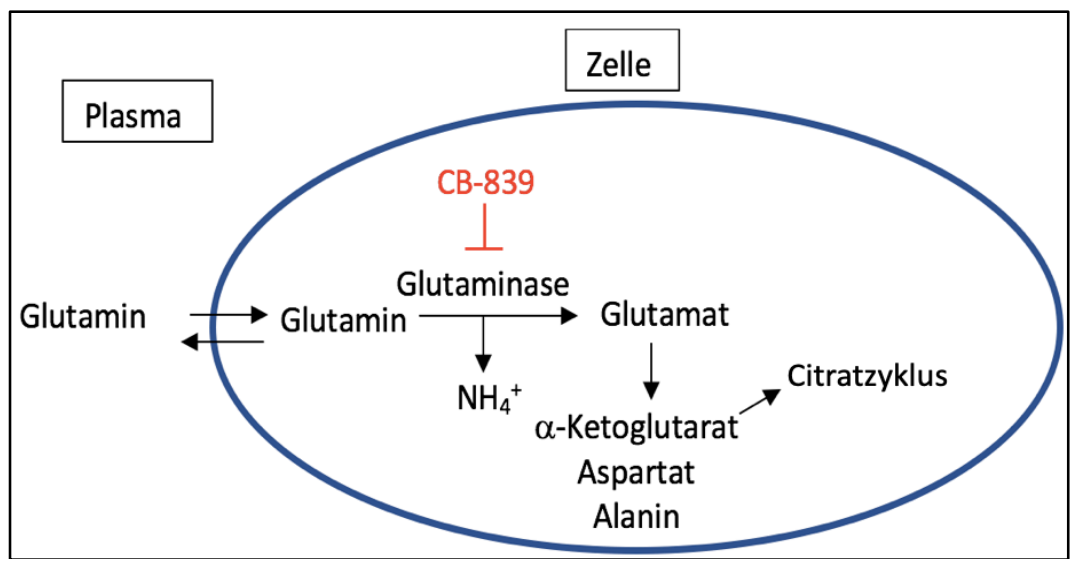

Abbildung 6: Schematische Darstellung der Glutaminolyse ( nach Hensley et al. 2013) 
Es konnte bereits beobachtet werden, dass Tumorzellen neben einer gesteigerten Glykolyse (Warburg-Effekt) einen verstärkten Glutamin-Stoffwechsel aufweisen (Hensley et al. 2013; Koppenol et al. 2011).

Der Nutzen für die Tumorzellen liegt einerseits in der Energiegewinnung und andererseits in der gesteigerten Nukleinsäure- und Serin-Synthese durch die Zwischen- bzw. Endprodukte Glutamat und Aspartat, ausgehend von der Aminosäure Glutamin. Dadurch wird das proliferative Wachstum der Tumorzelle ermöglicht (Hensley et al. 2013).

Das Wissen darüber stellt therapeutisch ein weiteres Target dar, indem auf die Glutaminolyse hemmend eingewirkt wird. Hierbei wird der Glutaminase-Hemmstoff CB-839 genutzt, der den ersten Schritt der Glutaminolyse durch eine selektive und irreversible Bindung des Enzyms Glutaminase hemmt (Gross et al. 2014).

Die Hochregulierung der Glutaminase konnte bereits unter anderem im Gliom (Seltzer et al. 2010), nichtkleinzelligem Lungenkarzinom (van den Heuvel et al. 2012), Pankreaskarzinom (Son et al. 2013) und triple-negativen Mammakarzinom-Zellen nachgewiesen werden (Timmerman et al. 2013). In Letzteren konnte zudem eine Wirkung des Glutaminase-Inhibitors CB-839 gezeigt werden (Gross et al. 2014).

Aktuell laufen klinische Phase I und II Studien bezüglich einer Mono- und Kombinationstherapie mit CB-839 in soliden Tumoren (Whiting 2014).

\subsection{Das Proto-Onkogen c-Myc}

Myc ist ein Proto-Onkogen, welches in 30-40 \% der malignen Tumoren zu finden ist und zu circa $16 \%$ im Mammakarzinom (Deming et al. 2000).

Myc ist als Proto-Onkogen an diversen Prozessen innerhalb des Zellstoffwechsels beteiligt, das Ausmaß dessen ist noch nicht vollständig geklärt (Schuhmacher et al. 1999).

Allerdings weiß man, dass c-Myc als Protein an die DNA binden und zu einer Aktivierung proliferationsanregender Gene führen kann (Jansen-Dürr et al. 1993).

Es konnte bereits gezeigt werden, dass Myc auch durch die EREs (estrogen response elements) reguliert wird, welche Östrogen-abhängig aktiviert werden (Dubik und Shiu 1992). 


\subsection{Fragestellungen}

In verschiedenen Studien konnten die Wirkstoffe 4-OHT, 2-DG und CB-839 einzeln bereits eine antiproliferative Wirkung auf Mammakarzinom-Zellen zeigen (Fisher et al. 2005; Wokoun et al. 2017; Gross et al. 2014). Allerdings ist noch nicht bekannt, inwiefern die Kombination der Wirkstoffe auf die Zelllinien MCF7 und T47D eine antiproliferative Wirkung haben und wie sich diese im Vergleich zu den entsprechenden Tamoxifen-resistenten Zelllinien MCF7-TR und T47D-TR verhält.

Daher wurde in dieser Arbeit untersucht, ob sich die Therapie mit dem niedrig dosiertem 4-OHT durch eine Anti-Metabolismus-Therapie mittels 2-DG und/oder CB-839 optimieren lässt und ob dabei Unterschiede zu den TR-Zelllinien zu beobachten sind. Es sollte überprüft werden, inwiefern sich die verschiedenen Behandlungen in der Zellviabilität und der Induktion von Apoptose widerspiegeln und welche Auswirkungen diese proteinbiochemisch auf c-Myc haben. 


\section{Material und Methoden}

\subsection{Materialien}

\subsubsection{Geräte}

\begin{tabular}{|c|c|}
\hline Absaugsystem EcoVac & Schütt Labortechnik, Göttingen \\
\hline Analysewaage & Sartorius, Göttingen, (Schütt Labortechnik) \\
\hline Autoklav 2540EL & Schütt Labortechnik, Göttingen \\
\hline Gasbrenner & Schütt Labortechnik, Göttingen \\
\hline \multicolumn{2}{|l|}{ Gefrieranlagen: } \\
\hline $\begin{array}{l}-\quad-150^{\circ} \mathrm{C} \text { (Schadstofftank) } \\
-\quad-80^{\circ} \mathrm{C} \\
-\quad-30{ }^{\circ} \mathrm{C}\end{array}$ & $\begin{array}{l}\text { Air Liquide, Düsseldorf } \\
\text { Forma Scientific, Braunschweig } \\
\text { Liebherr, Biberach }\end{array}$ \\
\hline LI-COR Odyssey Sa Imaging Systems & Biosciences, Bad Homburg \\
\hline \multicolumn{2}{|l|}{ Kühlschränke: } \\
\hline$-\quad-4{ }^{\circ} \mathrm{C}$ & Bosch + Liebherr, Biberach \\
\hline \multicolumn{2}{|l|}{ Mikroskop: } \\
\hline - $\quad$ Axiovert 25 & Zeiss, Jena \\
\hline Multidetection Microplate Reader & BIO-TEK, Bad Friedrichshall \\
\hline Neubauer-Zählkammer 0,0025 mm² & Brand Gläser, Wertheim \\
\hline \multicolumn{2}{|l|}{ Pipetten: } \\
\hline $\begin{array}{ll}\text { - } & \text { Pipetten } 10 / 200 / 1000 \mu l \\
\text { - } & \text { Multipette plus }\end{array}$ & $\begin{array}{l}\text { Eppendorf-Research } \\
\text { Eppendorf, Hamburg }\end{array}$ \\
\hline Sterilwerkbank Lamin air LFM 24725 & Heraeus, Osterode \\
\hline Vortex REAX top & Heidolph, Bremen \\
\hline Wasserbad 1083 & GFL, Burgwedel \\
\hline \multicolumn{2}{|l|}{ Zentrifuge: } \\
\hline - $\quad$ Labofuge 400R & Fisher Scientific, Schwerte \\
\hline
\end{tabular}




\subsubsection{EDV}

GraphPad Prism $^{\circledR} 7.0$ für Windows

Microsoft Office XP Version 20
GraphPad Software, San Diego California (USA)

Microsoft, Redmond (USA)

\subsubsection{Verbrauchsmaterialen}

\begin{tabular}{|c|c|}
\hline Combitips plus & Eppendorf, Hamburg \\
\hline Deckgläschen & Menzel Gläser, Braunschweig \\
\hline Einfrierboxen & Nalgene Labware, Rochester (USA) \\
\hline $\begin{array}{l}\text { Gewebekulturflaschen }\left(75 \mathrm{~cm}^{2}\right) \text { mit Be- } \\
\text { lüftungskappe }\end{array}$ & Sarstedt, Nümbrecht \\
\hline Multiwell-Platte: 96-Well-Platte & Falcon, Durham (USA) \\
\hline Multipetten-Spitzen, steril: $5 \mathrm{ml}$ & Eppendorf, Hamburg; TipOne StarLab, Hamburg \\
\hline Serologie-Pipetten: $5 \mathrm{ml}, 10 \mathrm{ml}, 25 \mathrm{ml}$ & Sarstedt, Nümbrecht \\
\hline Pipettenspitzen: $10 \mu \mathrm{l}, 200 \mu \mathrm{l}, 1000 \mu \mathrm{l}$ & StarLab, Hamburg \\
\hline Tubes: $0,5 \mathrm{ml}, 1,5 \mathrm{ml}, 2 \mathrm{ml}$ & Eppendorf, Hamburg; Sarstedt, Nümbrecht \\
\hline Kryoröhrchen: $1,8 \mathrm{ml}$ & Nalgene Labware, Rochester (USA) \\
\hline Röhrchen: $15 \mathrm{ml}, 50 \mathrm{ml}$ & $\begin{array}{l}\text { Greiner bio-one, Kremsmünster (Österreich); } \\
\text { Sarstedt, Nümbrecht }\end{array}$ \\
\hline Sterilfilter & Sartorius, Göttingen \\
\hline Spritze $2 \mathrm{ml}, 5 \mathrm{ml}$ & Becton Dickinson, Franklin Lakes (USA) \\
\hline Zellkulturflaschen & Sarstedt, Nümbrecht \\
\hline
\end{tabular}




\subsubsection{Chemikalien}

\begin{tabular}{|c|c|}
\hline alamarBlue $^{\circledR}$ & BioRad, Puchheim \\
\hline CellLytic ${ }^{\mathrm{TM}} \mathrm{M}$ Cell Lysis Reagent & Sigma-Aldrich, St. Louis (USA) \\
\hline Dimethylsulfoxid (DMSO) & Sigma-Aldrich, St. Louis (USA) \\
\hline DMEM & $\begin{array}{l}\text { Thermo Fisher Scientific, Waltham, } \\
\text { Massachusetts (USA) }\end{array}$ \\
\hline Ethanol 99,9\% & Dr. Geyer, Renningen \\
\hline Foetal calf Serum (FCS) & Biochrom (Merck), Berlin \\
\hline Glutamin (L-Alanyl-L-Glutamin) & Biochrom (Merck), Berlin \\
\hline HEPES & Sigma-Aldrich, St. Louis (USA) \\
\hline Insulin & Sanofi, Paris (Frankreich) \\
\hline MEM-Earl w/o Phenolrot & Biochrom, Berlin \\
\hline Methanol & J. T. Baker, Griesheim \\
\hline NEA (Nicht essentielle Aminosäuren) & Biochrom (Merck), Berlin \\
\hline PeqGOLD Protein-Marker V & Peqlab \\
\hline Penicillin-Streptomycin $(10.000 \mathrm{U} / \mathrm{ml})$ & $\begin{array}{l}\text { Thermo Fisher Scientific, Waltham, } \\
\text { Massachusetts (USA) }\end{array}$ \\
\hline Phosphate Buffered Saline (PBS) & PAN Biotech, Aidenbach \\
\hline Phosphatase-Inhibitor & Sigma Aldrich, St. Louis (USA) \\
\hline Protease-Inhibitor & Sigma Aldrich, St. Louis (USA) \\
\hline Transferrin & Sigma Aldrich, St. Louis (USA) \\
\hline Trypan-Blau $(0,4 \%)$ & Sigma-Aldrich, St. Louis (USA) \\
\hline Trypsin-EDTA 0,05 \% & cc-Pro, Oberdorla \\
\hline
\end{tabular}

\subsubsection{Kits}

JC-1 Mitochondrial Membrane Potential Biotium, Köln

Detection Assay Kit 


\subsubsection{Proteine, Inhibitoren, Standards}

\begin{tabular}{|l|l|}
\hline Proteinaseinhibitorcocktail & Sigma, Deisenhofen \\
\hline Proteinstandard peqGold & peqlab, Erlangen \\
\hline Rinderserum-Albumin (BSA, 100x) & New England Biolabs, Ipswich (USA) \\
\hline
\end{tabular}

\subsubsection{Antikörper}

\subsubsection{Primärantikörper}

Im Western-Blot wurde folgender Primärantikörper eingesetzt:

Tabelle 2: Primärantikörper

\begin{tabular}{llll}
\hline Antigen & Spezies & Verdünnung & Herkunft/Referenz \\
\hline c-Myc & Kaninchen & $1: 10000$ & Abcam, Cambridge (UK) \\
\hline
\end{tabular}

\subsubsection{Sekundärantikörper}

Im Western-Blot wurde folgender Sekundärantikörper eingesetzt:

Tabelle 3: Sekundärantikörper

\begin{tabular}{lll}
\hline Spezies & Verdünnung & Herkunft/Referenz \\
\hline Esel & $1: 20000$ & GE Healthcare, München \\
$\begin{array}{l}\text { Kaninchen IgG horseradish } \\
\text { Peroxydase-gekoppelt }\end{array}$ & (TBS-Tween) & \\
\hline
\end{tabular}

\subsubsection{Versuchssubstanzen und Konzentrationen}

\subsubsection{2-DG}

Tabelle 4: 2-Deoxy-D-Glucose

\begin{tabular}{llll}
\hline Substanz & Stammlösung & Gelöst in & Herkunft \\
\hline 2-Deoxy-D-Glucose & $0,625 \mathrm{M}$ (in PBS) & PBS & $\begin{array}{l}\text { Sigma-Aldrich } \\
\text { (Merck), München }\end{array}$ \\
\hline
\end{tabular}


Tabelle 5: Konzentrationen 2-Deoxy-D-Glucose

\begin{tabular}{ll}
\hline Konzentration & Verdünnung \\
\hline $\mathbf{0 , 6 2 5} \mathbf{~ m M}$ & $1: 1.000$ \\
$\mathbf{2 , 5} \mathbf{~ m M}$ & $1: 250$ \\
$\mathbf{5} \mathrm{mM}$ & $1: 125$ \\
\hline
\end{tabular}

\subsubsection{4-OH-Tamoxifen}

Tabelle 6: 4-OH-Tamoxifen

\begin{tabular}{llll}
\hline Substanz & Stammlösung & Gelöst in & Herkunft \\
\hline 4-OH-Tamoxifen & $10^{-3} \mathrm{M}$ & Methanol & $\begin{array}{l}\text { Sigma-Aldrich, } \\
\text { (Merck), München }\end{array}$ \\
\hline
\end{tabular}

Tabelle 7: Konzentrationen 4-OH-Tamoxifen

\begin{tabular}{ll}
\hline Konzentration & Verdünnung \\
\hline $\mathbf{1 0 0} \mathrm{nM}$ & $1: 10.000$ \\
$\mathbf{1} \boldsymbol{\mu M}$ & $1: 1.000$ \\
$\mathbf{5} \boldsymbol{\mu M}$ & $1: 200$ \\
\hline
\end{tabular}

\subsubsection{CB-839}

Tabelle 8: CB-839

\begin{tabular}{llll}
\hline Substanz & Stammlösung & Gelöst in & Herkunft \\
\hline CB-839 & $10^{-3} \mathrm{M}$ & DMSO & $\begin{array}{l}\text { Selleckchem, } \\
\text { München }\end{array}$ \\
\hline
\end{tabular}

Tabelle 9: Konzentrationen CB-839

\begin{tabular}{ll}
\hline Konzentration & Verdünnung \\
\hline $\mathbf{1} \boldsymbol{\mu M}$ & $1: 1.000$ \\
$\mathbf{5} \boldsymbol{\mu M}$ & $1: 200$ \\
$\mathbf{1 0} \boldsymbol{\mu M}$ & $1: 100$ \\
\hline
\end{tabular}

Die Versuchssubstanzen wurden in Form ihrer Stammlösungen zubereitet und bei $-30{ }^{\circ} \mathrm{C}$ gelagert. 30 min vor Versuchsbeginn wurden sie bei Raumtemperatur erwärmt. 


\subsubsection{Zelllinien und Kulturbedingungen}

Tabelle 10: Verwendete Zelllinien

\begin{tabular}{|c|c|c|c|c|}
\hline Zelllinie & Entität & Eigenschaften & Herkunft & Referenz \\
\hline MCF7 & $\begin{array}{l}\text { Mammakarzinom, } \\
\text { Adenokarzinom }\end{array}$ & $\begin{array}{l}\text { ER/PR + } \\
\text { Her2/neu - }\end{array}$ & Pleuraerguss & Soule et al., 1973 \\
\hline T47D & $\begin{array}{l}\text { Mammakarzinom, } \\
\text { duktales } \\
\text { Karzinom }\end{array}$ & $\begin{array}{l}\text { ER/PR + } \\
\text { Her2/neu - }\end{array}$ & Pleuraerguss & Freake et al., 2005 \\
\hline $\begin{array}{l}\text { MCF7-TR } \\
\text { (Tamoxifen- } \\
\text { resistent) }\end{array}$ & $\begin{array}{l}\text { Mammakarzinom, } \\
\text { Adenokarzinom }\end{array}$ & $\begin{array}{l}\text { ER/PR + } \\
\text { Her2/neu - }\end{array}$ & $\begin{array}{l}\text { 4-OHT- } \\
\text { resistente } \\
\text { Sublinie } \\
\text { von MCF7 }\end{array}$ & Gunthert et al., 2005 \\
\hline $\begin{array}{l}\text { T47D-TR } \\
\text { (Tamoxifen- } \\
\text { resistent) }\end{array}$ & $\begin{array}{l}\text { Mammakarzinom, } \\
\text { duktales } \\
\text { Karzinom }\end{array}$ & $\begin{array}{l}\text { ER/PR + } \\
\text { Her2/neu - }\end{array}$ & $\begin{array}{l}\text { 4-OHT- } \\
\text { resistente } \\
\text { Sublinie } \\
\text { von T47D }\end{array}$ & Gunthert et al., 2005 \\
\hline
\end{tabular}

Die verwendeten Zelllinien wurden von der American Type Culture Collection (ATCC, Manassas, USA) bezogen.

Etabliert wurde die MCF7 Zelllinie an der Michigan Cancer Foundation in Zusammenarbeit mit der US Gesundheitsbehörde National Institute of Health (NIH). Die Etablierung der Zelllinie wurde durch die Ethikkommission des NIH genehmigt. Die Patientin hat ihr Einverständnis gegeben.

Die T47D-Zelllinie wurde im Chaim Sheba Medical Center der Universität Tel Aviv, Israel etabliert. Die Etablierung dieser Zelllinie wurde durch die örtliche Ethikkommission genehmigt. Die Patientin hat ihr Einverständnis gegeben.

Die Tamoxifen-resistenten Zellreihen MCF7-TR und T47D-TR wurden durch wöchentliche Substitution von 125 nM Tamoxifen über ein Jahr lang kultiviert, bis eine vergleichbare Proliferationsrate erzielt wurde wie bei den parenteralen Zelllinien MCF7 und T47D (Günthert et al. 2005).

Damit stellen sie ein Modell der sekundären Antiöstrogenresistenz dar.

Die Zellen wurden bei wassergesättigter Atmosphäre, $37{ }^{\circ} \mathrm{C}$ und $5 \% \mathrm{CO}_{2}$ in Inkubation gehalten. Das Arbeiten mit den Zellkulturen erfolgte ausschließlich an einer Sterilwerkbank. 


\subsubsection{Kulturmedium}

Tabelle 11: Kulturmedium

\begin{tabular}{ll}
\hline Inhalt & Menge \\
\hline $\begin{array}{l}\text { MEM } \\
\text { (+Phenolrot) }\end{array}$ & $500 \mathrm{ml}$ \\
FCS & $10 \%$ \\
P/S & $1 \%$ \\
Insulin & $50 \mathrm{IU}$ \\
Transferrin & $500 \mu \mathrm{g} / \mathrm{ml}$ \\
\hline
\end{tabular}

\subsubsection{Medium für Kryokonservierung}

Tabelle 12: Medium für Kryokonservierung

\begin{tabular}{ll}
\hline Inhalt & Menge \\
\hline $\begin{array}{l}\text { MEM } \\
\text { (+Phenolrot) }\end{array}$ & $500 \mathrm{ml}$ \\
FCS & \\
DMSO & $20 \%$ \\
\hline
\end{tabular}

\subsubsection{Medium für das AlamarBlue-Proliferationsassay}

Tabelle 13: Medium für das AlamarBlue-Proliferationsassay

\begin{tabular}{ll}
\hline Inhalt & Menge \\
\hline $\begin{array}{l}\text { DMEM } \\
\text { (+D-Glucose, Pyruvat) }\end{array}$ & $500 \mathrm{ml}$ \\
FCS & $5 \%$ \\
P/S & $1 \%$ \\
Glutamin & $1 \%$ \\
HEPES & $1 \%$ \\
NEAS & $1 \%$ \\
Insulin & $50 \mathrm{IU}$ \\
Transferrin & $500 \mu \mathrm{g} / \mathrm{ml}$ \\
\hline
\end{tabular}




\subsection{Methoden}

\subsubsection{Zellkultur}

\subsubsection{Revitalisierung}

Die in flüssigem Stickstoff kryokonservierten Zellen wurden im Wasserbad bei $37^{\circ} \mathrm{C}$ erwärmt, in eine $75 \mathrm{~cm}^{2}$-große Kulturflasche überführt und anschließend mit ca. $9 \mathrm{ml}$ Kulturmedium aufgefüllt und vorsichtig geschwenkt. Nach 24 Stunden erfolgte ein kompletter Mediumwechsel aufgrund der zelltoxischen Wirkung des Gefrierschutzmittels DMSO.

\subsubsection{Mediumwechsel}

Dreimal wöchentlich erfolgte ein Wechsel des Mediums. Dafür wurde das alte Kulturmedium mit einer Pipette aus der Kulturflasche abgesaugt und $10 \mathrm{ml}$ des bei $37^{\circ} \mathrm{C}$ erwärmten frischen Kulturmediums hinzugegeben und geschwenkt.

\subsubsection{Passagieren/Splitten der Zellen}

Um eine Überpopulation der Zellen in den Kulturflaschen zu vermeiden, wurde je nach Zellwachstum bei einer 70-80 \%igen Konfluenz eine Splittung der Zellen vorgenommen. Frisches Kulturmedium und Trypsin/EDTA wurden anfangs in einem $37{ }^{\circ} \mathrm{C}$ warmen Wasserbad erwärmt. Das alte Medium aus der Kulturflasche wurde abgesaugt, der Zellrasen mit 5 ml PBS gewaschen und erneut abgesaugt. Um eine Zellablösung zu erreichen, wurde zu den Zellen $3 \mathrm{ml}$ Trypsin/EDTA gegeben und das Gemisch für $5 \mathrm{~min}$ bei $37{ }^{\circ} \mathrm{C}$ und $5 \% \mathrm{CO}_{2}$ inkubiert. Anschließend erfolgte zur Stoppung der Reaktion eine Resuspension mit $7 \mathrm{ml}$ frischem Medium und je nach Verdünnungswunsch eine gewünschte Minimierung des Gemischs (1:2 bis 1:10), welches anschließend auf $10 \mathrm{ml}$ aufgefüllt und abschließend zur Kultivierung in den Inkubator bei $37{ }^{\circ} \mathrm{C}$ und $5 \% \mathrm{CO}_{2}$ gegeben wurde. Der Überstand wurde entweder verworfen (reines Passagieren), oder in weiteren Schritten verarbeitet (Zellzahl ermitteln, Zellen aussäen). 


\subsubsection{Einfrieren/Kryokonservierung}

Nach oben beschriebener Zell-Splittung wurde die Zellkultur bei $1300 \mathrm{rpm} 5 \mathrm{~min}$ zentrifugiert und der Überstand anschließend abgesaugt. Das verbliebene Zellpellet wurde in Einfriermedium (siehe Tab. 12) suspendiert.

Jeweils $1 \mathrm{ml}$ der Suspension wurde in beschriftete Kryogefäße gegeben, bevor die Zellen dann bei $-80{ }^{\circ} \mathrm{C}$ gekühlt wurden. Nach 24 h erfolgte die Überführung der Gefäße in die Kühlung durch flüssigen Stickstoff bei $-150^{\circ} \mathrm{C}$.

\subsubsection{Zellzahl ermitteln}

Die Zellen wurden, wie oben beschrieben (siehe 2.2.1.3), gesplittet. Dabei wurde der Überstand, der aus der Kultur zur Verdünnung entnommen wurde, bei $130 \mathrm{rpm} 5 \mathrm{~min}$ zentrifugiert. Der Überstand wurde abgesaugt und das Zellpellet je nach Dicke mit 7 bis $10 \mathrm{ml}$ vorgewärmtem Medium zum Aussäen resuspendiert. $10 \mu \mathrm{l}$ dieser Suspension wurden mit $10 \mu \mathrm{l}$ Typan-Blau in ein 0,5 ml-Tube gegeben, geschüttelt und resuspendiert. Anschließend wurden $10 \mu \mathrm{l}$ dieser Suspension in eine mit einem Deckglas geschichtete NeubauerZählkammer gegeben und unter mikroskopischer Ansicht die Zellzahl ermittelt.

Trypan-Blau hilft bei der Zellzahlbestimmung viabler Zellen. Da der Farbstoff von gesunden Zellmembranen nicht aufgenommen wird, erscheinen diese Zellen im Mikroskop heller als die blau angefärbte Umgebung. Zellen mit einer defekten Membran nehmen den blauen Farbstoff auf und erscheinen dementsprechend blau. Dies lässt eine Differenzierung viabler Zellen im Vergleich zu aviablen Zellen zu.

Aufgrund der Gegebenheiten der Neubauer-Zählkammer (Volumen: $1 \mathrm{~mm}$ x $1 \mathrm{~mm}$ x 0,1 mm $=1 \mu \mathrm{l})$ kann mittels der hier bestimmten Zahl die Zellzahl der gesamten Suspension abgeleitet werden. Mithilfe eines Lichtmikroskops wurde die Gesamt-Zellzahl in vier großen Quadranten ausgezählt. Der daraus bestimmte Mittelwert wurde mit dem Faktor $10^{4}$ multipliziert. Daraus ergibt sich die Zellzahl pro ml. 


\subsubsection{Zellen aussäen}

Um eine objektive Versuchsreihe zu gewährleisten, wurde nach Etablierung die Zellzahl 12.500 pro Well bei einer 96-Well-Platte festgelegt, bzw. 350.000 pro Well bei einer 6-WellPlatte. Dafür wurde der Verdünnungsfaktor aus der ermittelten Zellzahl bestimmt, indem die ermittelte Zellzahl durch die festgelegte Well-Zellzahl geteilt wurde. Mithilfe des Verdünnungsfaktors konnte für die Verdünnungssuspension auf die Anteile des Zellgemischs und des vorgewärmten Mediums zum Aussäen geschlossen werden.

Die entsprechende Verdünnungssuspension mit 125.000 Zellen/ml bzw. 350.000 Zellen/ml wurde mit einer sterilen Pipette auf die 96- bzw. 6-Well-Platte verteilt. Eine BLANK-Reihe, nur aus Medium zum Aussäen bestehend, wurde ebenfalls ausgesät.

\subsubsection{Assays}

\subsubsection{AlamarBlue-Proliferationsassay}

Um die Proliferation beurteilen zu können, wurde das AlamarBlue-Proliferationsassay angewandt. Genau genommen beschreibt man durch das AlamarBlue-Proliferationsassay die Viabilität, also die Lebensfähigkeit von Zellen. Hauptbestandteil des AlamarBlues ist der blaufarbige, nichttoxische Redox- und pH-Indikator Resazurin, welcher die Zellmembran durchdringen kann. Resazurin wird durch Reduktionsprozesse bzw. Elektronenaufnahme in das pinkfluoreszierende Resofurin reduziert. Reduktionsprozesse, die dadurch dargestellt werden können, findet man vor allem im Rahmen der mitochondrialen Atmungskette bei Reduktionen von unter anderem NADH, NAHPH, FADH und Cytochromen. Ausgehend davon, dass die Reduktionsfunktionen der Atmungskette die Viabilität der Zelle bedingen, lässt sich so ein Urteil über den Lebenszustand im Vergleich zu einer Kontrolle fällen (Al-Nasiry et al. 2007).

Nach erfolgreichem Aussäen erfolgte eine 24-stündige Inkubation bei $37{ }^{\circ} \mathrm{C}$ und $5 \% \mathrm{CO}_{2}$. Daraufhin wurde ein Mediumswechsel mit vorgewärmtem Medium zum Aussäen vorgenommen. Die Versuchssubstanzen zur Therapie der Zellreihen wurden in diesem frischen Medium gelöst und so den Zellen zugeführt. Anschließend erfolgte eine erneute Inkubation von 24,48 oder 72 Stunden bei $37^{\circ} \mathrm{C}$ und $5 \% \mathrm{CO}_{2}$. 
Mithilfe einer Multipette wurde in jedes Well $20 \mu$ l AlamarBlue-Substanz hinzugegeben und nach 4-stündiger Inkubation bei $37^{\circ} \mathrm{C}$ und $5 \% \mathrm{CO}_{2}$ eine spektralphotometrische Messung im Multidetection Microplate Reader bei $\lambda=570 \mathrm{~nm}$ und $\lambda=630 \mathrm{~nm}$ vorgenommen.

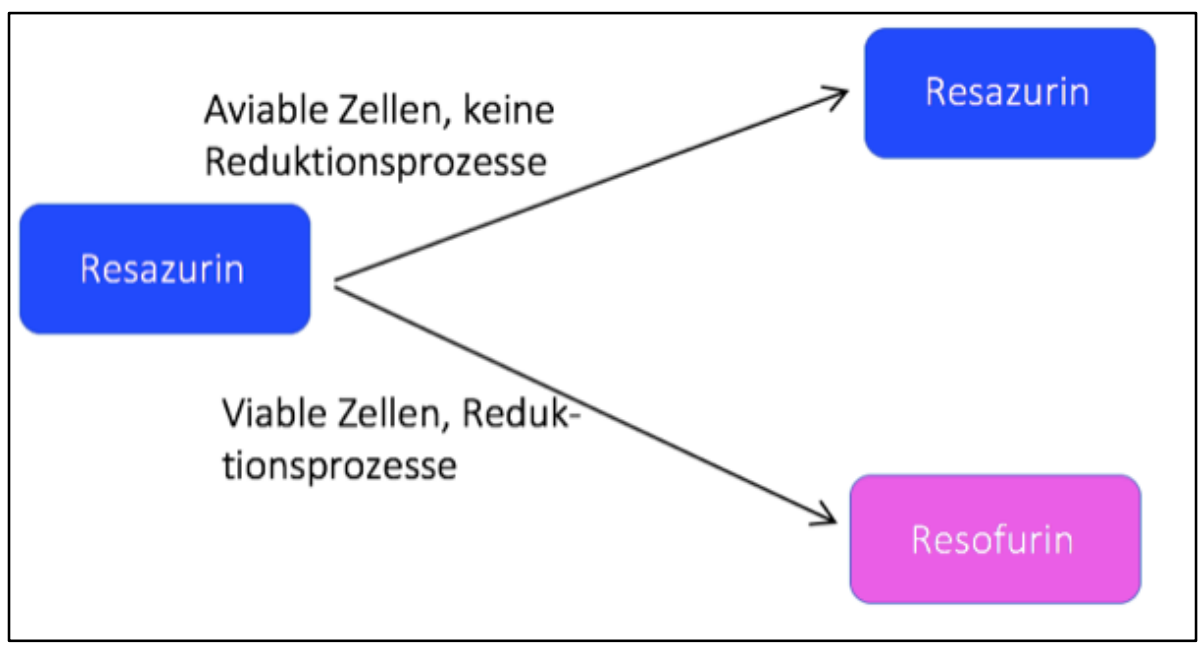

Abbildung 7: Schematische Darstellung der Reaktionen von AlamarBlue

Die Aussaatdichte für das AlamarBlue-Proliferationsassay ist in Tab. 14 dargestellt.

Tabelle 14: Aussaatdichte für das AlamarBlue-Proliferationsassay

\begin{tabular}{ll}
\hline Zelllinie & Zellen/ $\mathbf{m l}$ \\
\hline MCF7 & 125.000 \\
T47D & 125.000 \\
MCF7-TR & 125.000 \\
T47D-TR & 125.000 \\
\hline
\end{tabular}

\subsubsection{JC-1 Apoptose-Assay}

Tabelle 15: JC-1 Zusammensetzung

\begin{tabular}{ll}
\hline Komponente & Präparation \\
\hline 10x Assay Puffer & $1: 10$ mit destilliertem Wasser \\
\hline JC-1 Reagenz & $1: 100$ mit 10X Assay Puffer \\
\hline
\end{tabular}

Das JC-1-Apoptose-Assay wurde zur Darstellung der zytostatischen Apoptosewirkung der Substanzen auf die gewählten Zellreihen genutzt.

Die Mitochondrien vitaler Zellen besitzen zwei Membranen, eine äußere Membran und eine innere Membran. 
Dabei ist der Raum zwischen äußerer und innerer Membran positiv geladen, wobei der Raum innerhalb der inneren Membran negativ geladen ist (siehe Abb. 8). Durch diese Ladungsdifferenzen entsteht ein gewisses mitochondriales Membranpotential über die innere Mitochondrienmembran.

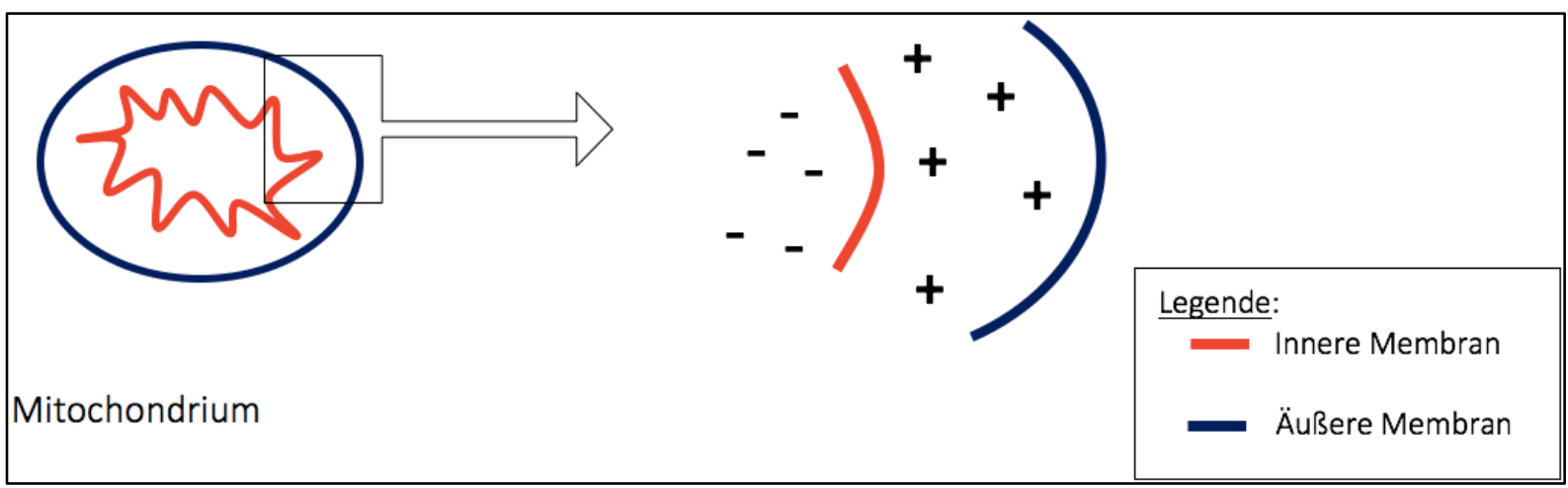

Abbildung 8: Mitochondriales Membranpotential

Eine der frühesten Phasen des Apoptose-Prozesses beschreibt eine Porenbildung der mitochondrialen Membran. Das hat zur Folge, dass das mitochondriale Membranpotential zusammenbricht. Apoptotische Zellen weisen also aufgrund der Porenbildung in der mitochondrialen Membran im Vergleich zu vitalen Zellen ein niedrigeres mitochondriales Membranpotential auf. Das JC-1-Reagenz ist ein lipophiler und kationischer Fluoreszenzfarbstoff, für den sowohl die Zell- als auch die Mitochondrienmembran permeabel ist. Diese Eigenschaft sorgt dafür, dass sich das JC-1-Reagenz bei gesunden Zellen in das innere negativ geladene Areal innerhalb der inneren mitochondrialen Membran der Mitochondrien anreichert und dort rotfluoreszierende Aggregate bildet. In apoptotischen Zellen findet aufgrund des geringeren mitochondrialen Membranpotentials keine Aggregatbildung an der inneren Membran statt, stattdessen liegt das JC-1-Reagenz als grün fluoreszierendes Monomer im Zytoplasma der Zelle vor (Smiley et al. 1991). Diese Fluoreszenzen können mittels Fluoreszenzdetektion gemessen werden.

Die Zellen wurden zunächst für 48 Stunden mit den Einzelsubstanzen sowie den Kombinationen inkubiert. Die Anwendung des JC-1-Assays erfolgte nach den Angaben des Herstellers. Die Fluoreszenzdetektion erfolgte im Multidetection Microplate Reader für die Rot-Fluoreszenz bei ex550 nm/em600 nm und für die Grün-Fluoreszenz bei ex485 nm/em535 nm. Die Division der beiden Fluoreszenzen ergab das Verhältnis gesunder und apoptotischer Zellen. 


\subsubsection{Proteinbiochemische Methoden}

\subsubsection{Proteinisolation}

Zur Proteinisolation wurden die Zellen in einer 6-Well-Platte für die gewünschte Zeit angezüchtet. Anschließend wurde das Medium abgesaugt und die Zellen mit $2 \mathrm{ml}$ 2- \%-iger PBS-EDTA-Lösung zum Lösen der Zellen für 10 min inkubiert. Nach dieser Zeit wurden die Zellen mittels Zellscrabber vom Boden der Well-Platte gelöst und die Zellen mit $3 \mathrm{ml}$ PBS gespült. Die entstandene Zellsuspension wurde im Anschluss daran für 5 min bei 1300 rpm zentrifugiert. Das daraus resultierte Zellpellet wurde mit $30 \mu \mathrm{l}$ Lysepuffer lysiert und abschließend bei $-20^{\circ} \mathrm{C}$ weggefroren.

Tabelle 16: Lysat-Zusammensetzungen

\begin{tabular}{ll}
\hline Lysat & Inhalt \\
\hline PBS-EDTA (0,2 \%) & $200 \mathrm{mg}$ Tetrasulfonium \\
& $100 \mathrm{ml} \mathrm{PBS}$ \\
Zell-Lysis-Puffer & $10 \mathrm{ml}$ Cell Lytic M \\
& $100 \mu$ l Phosphat-Inhibitor \\
& $100 \mu$ l Protease-Inhibitor \\
\hline
\end{tabular}

\subsubsection{Proteinbestimmung nach Bradford (Bradford 1976)}

Mittels der Methode nach Bradford wurde der Proteingehalt der Lysate quantitativ bestimmt. Mittels einer BSA-Lösung $(1 \mathrm{mg} / \mathrm{ml})$ und Aqua bidest. wurde die Eichgerade pipettiert.

Dazu wurde zunächst eine BSA-Stammlösung mit c=10 mg/ ml angesetzt.

Tabelle 17: Eichgerade

\begin{tabular}{lll}
\hline $\begin{array}{l}\text { Eichgerade } \\
\{\mathrm{mg} / \mathrm{ml}\}\end{array}$ & $\begin{array}{l}\text { BSA- } \\
\text { Stammlösung } \\
\{\boldsymbol{\mu l}\}\end{array}$ & PBS $\{\boldsymbol{\mu l}\}$ \\
\hline $\mathbf{1}$ & 100 & 900 \\
$(1: 10)$ & 75 & 925 \\
$\mathbf{0 , 7 5}$ & & \\
$(1: 13,33)$ & 50 & 950 \\
$\begin{array}{l}\mathbf{0 , 5} \\
(1: 20)\end{array}$ & & \\
$\mathbf{0 , 2 5}$ & 25 & 975 \\
$(1: 40)$ & 10 & 990 \\
$\begin{array}{l}\mathbf{0 , 1} \\
(1: 100)\end{array}$ & & \\
\hline
\end{tabular}


Die Proteinproben und die Standards wurden auf Eis aufgetaut und bei $1300 \mathrm{rpm}$ für 5 min zentrifugiert. Der Überstand wurde einerseits 1:2 mit dem Laemmli-Probenpuffer gemischt und bei $-20{ }^{\circ} \mathrm{C}$ weggefroren. Andererseits wurde der Überstand mit Aqua bidest. 1:10 verdünnt, was der Konzentrationsbestimmung diente. Hierfür wurden jeweils $10 \mu \mathrm{l}$ der Proteinverdünnung, die BSA-Stammlösungen, PBS (Konz. 0 mg/ ml) und Aqua bidest. auf eine unsterile 96-Well-Platte in Doppelbestimmung aufgetragen. In jedes Well wurde anschließend $200 \mu$ l Bradford-Lösung mittels Multipette hinzugegeben und für 5 min bei Raumtemperatur inkubiert. Abschließend erfolgte die Messung der Absorption bei $595 \mathrm{~nm}$ im Multidetection Reader. Der Farbstoff Coomassie Brilliant Blue bindet Proteinseitenketten und sorgt damit für eine absorptionsmaximale Verschiebung von $465 \mathrm{~nm}$ auf $595 \mathrm{~nm}$ mittels Farbumschlag. Dieser Umschlag ist repräsentativ für die Proteinkonzentration der Lysate und lässt sich spektralphotometrisch messen.

Tabelle 18: Substanzen zur Proteinbestimmung nach Bradford

\begin{tabular}{ll}
\hline Substanz & Inhalt \\
\hline Laemmli-Puffer & $5 \mathrm{ml}$ Ampuwa \\
& $5 \mathrm{ml}$ LDS Sample Buffer (4x) \\
& $1 \mathrm{ml}$ Sample Reducing Agent (10x) \\
Bradford-Lösung & $4 \mathrm{ml}$ Ampuwa \\
& $1 \mathrm{ml}$ BioRad-Lösung \\
\hline
\end{tabular}

\subsubsection{SDS-Polyacrylamid-Gelelektrophorese (SDS-PAGE)}

Um die Proteine ihrer Größe nach aufzutrennen, wurde die SDS-(sodium-dodecylsulfate-)Polyacrylamid-Gelelektrophorese (SDS-PAGE) genutzt. Hierbei wird die elektrophoretische Mobilität von Proteinen genutzt, wobei die Proteine durch das Detergens SDS gebunden werden und dabei eine negative Ladung erlangen. Dies führt dazu, dass diese gebundenen Proteine zur Anode wandern. Je nach Proteingröße verhält sich die negative Ladung proportional, sodass eine Auftrennung der SDS-Protein-Komplexe nach ihrer Molmasse innerhalb der Gelmatrix erfolgt.

Mittels der Methode nach Laemmli wurden die Lysate erst in einem Sammelgel mit 4,8 \% Polyacrylamid konzentriert und anschließend in einem Trenngel mit 7,5 \% Polyacrylamid aufgetrennt (Laemmli 1970). 
Die Zusammensetzung der Elektrophorese-Apparatur mit den Gelen und die Füllung mit dem Laufpuffer erfolgte nach Herstellerangaben.

Die mit dem Laemmli-Probenpuffer versetzten Lysate wurden bei RT aufgetaut, bei $95{ }^{\circ} \mathrm{C}$ für 5 min denaturiert, auf Eis abgekühlt und anschließend mittels Mikroliter-Pipette auf das Gel übertragen. Dabei wurde die erste Tasche in jedem Gel mit einem Proteinstandard $(7,5 \mu l)$ befüllt. Zur Proteinkonzentrierung wurde eine Spannung von 80 V für ca. 30 min. und zur Proteinauftrennung anschließend 150 V für eine Stunde angelegt.

Tabelle 19: Lösungszusammensetzungen

\begin{tabular}{lll}
\hline Bezeichnung & Name & Inhalt \\
\hline Lsg. I & $30 \%$ Acrylamid-Mix & $29,9 \mathrm{~g}$ Acrylamid \\
& & $0,8 \mathrm{~g}$ Bisacrylamid \\
& & $100 \mathrm{ml}$ Aqua bidest. \\
Lsg. II & $1,5 \mathrm{M}$ Tris pH 8,8 & $90,9 \mathrm{~g}$ Tris Pufferan \\
& & $400 \mathrm{ml}$ Aqua bidest. \\
& $+1,5 \mathrm{M} \mathrm{HCL}$ auf $\mathrm{pH} 8,8$ einstellen \\
& & $+500 \mathrm{ml}$ Aqua bidest. \\
Lsg. III & $10 \% \mathrm{~g} \mathrm{SDS}$ \\
& \multirow{2}{*}{$1,0 \mathrm{M}$ Tris pH 6,8 } & $90 \mathrm{ml}$ Aqua bidest. \\
Lsg. IV & & $30,3 \mathrm{~g}$ Tris Pufferan \\
& & $400 \mathrm{ml}$ Aqua bidest. \\
& $+1,5 \mathrm{M} \mathrm{HCL}$ auf pH 6,8 einstellen \\
& & $+500 \mathrm{ml}$ Aqua bidest. \\
\hline
\end{tabular}

Tabelle 20: Pufferzusammensetzung SDS-Page

\begin{tabular}{lll}
\hline Bezeichnung & Name & Inhalt \\
\hline Puffer I & 5x Elphopuffer, ohne SDS & $15,1 \mathrm{~g}$ Tris \\
& & $72 \mathrm{~g}$ Glycin \\
& & $1000 \mathrm{ml}$ Aqua bidest. \\
Gebrauchspuffer & Ca. pH 8,3-8,9 \\
& & $100 \mathrm{ml}$ Puffer I \\
& & $5 \mathrm{ml} 10 \%$-iges SDS \\
& & $500 \mathrm{ml}$ Aqua bidest. \\
\hline
\end{tabular}

Tabelle 21: Zusammensetzung von Sammel- und Trenngel

\begin{tabular}{lll}
\hline Material & Sammelgel (4,8 \%-ig) & Trenngel (7,5 \%-ig) \\
\hline Aqua bidest. & $2,7 \mathrm{ml}$ & $5,7 \mathrm{ml}$ \\
Lsg. I (30 \%-iger Acrylamid-Mix) & $670 \mu \mathrm{l}$ & $2,3 \mathrm{ml}$ \\
Lsg. II (1,5 M Tris pH 8,8) & - & $2,8 \mathrm{ml}$ \\
Lsg. III (10\% SDS) & $40 \mu \mathrm{l}$ & $110 \mu \mathrm{l}$ \\
Lsg. VI (1,0 M Tris pH 6,8) & $500 \mu \mathrm{l}$ & - \\
\hline 10\% APS & $40 \mu \mathrm{l}$ & $37 \mu \mathrm{l}$ \\
TEMED & $4 \mu \mathrm{l}$ & $20 \mu \mathrm{l}$ \\
\hline
\end{tabular}




\subsubsection{Western-Blot}

Beim Western-Blot transferiert man die Proteine, die durch die SDS-Page ihrer Größe nach innerhalb des Gels aufgetrennt wurden, auf eine Polyvinylidenfluorid- bzw. PVDF-TrägerMembran. Mittels spezifischer Antikörper lässt sich dadurch die gewünschte Immunodetection durchführen. Zunächst wurde die PVDF-Träger-Membran für $1 \mathrm{~min}$ in Methanol, anschließend für $5 \mathrm{~min}$ in Aqua bidest. und danach für $10 \mathrm{~min}$ in Transferpuffer geschwenkt. Dies diente der Aktivierung der Membran. Nachdem das Trenngel aus der Elektrophoreseapparatur für die SDS-Page entfernt und das Sammelgel verworfen wurde, wurde das Trenngel mit Aqua bidest. gespült und anschließend für 5 min in Transferpuffer geschwenkt. Die Halbtrockenzelle zur Durchführung des Western Blots erfolgte nach Angaben des Herstellers. Um die Proteine auf die PVDF-Membran zu übertragen, wurden acht Lagen Filterpapier mit konzentriertem Anodenpuffer getränkt, auf vier davon wurden luftblasenfrei sowohl das Gel, als auch die PVDF-Membran gegeben. Das Ganze wurde mit Transferpuffer übergossen und anschließend weitere vier Filterpapiere, welche vorher in Kathodenpuffer getränkt wurden, aufgelegt. Der Transfer erfolgte für eine Stunde bei $100 \mathrm{~V}$. Das Blotmodul wurde mit Transferpuffer gefüllt und in die Blotting-Apparatur eingespannt, wobei die PVDF-Membran zur Anode gerichtet war, und bei RT für $90 \mathrm{~min}$ bei $0,8 \mathrm{~mA} / \mathrm{m}^{3}$ transferiert.

Tabelle 22: Western-Blot Puffer

\begin{tabular}{|c|c|}
\hline Puffer & Inhalt \\
\hline Transferpuffer & $\begin{array}{l}\text { 1,515 g Tris Pufferan } \\
\text { 7,205 g Glycin } \\
100 \mathrm{ml} \text { Methanol } \\
500 \mathrm{ml} \text { Aqua bidest. }\end{array}$ \\
\hline Konz. Anodenpuffer pH 10,4 & $\begin{array}{l}\text { 18,2 g Tris Pufferan } \\
100 \mathrm{ml} \text { Methanol } 20 \% \\
500 \mathrm{ml} \text { Aqua bidest. }\end{array}$ \\
\hline Anodenpuffer pH 10,4 & $\begin{array}{l}\text { 1,82g Tris Pufferan } \\
100 \mathrm{ml} \text { Methanol } 20 \% \\
500 \mathrm{ml} \text { Aqua bidest. }\end{array}$ \\
\hline Kathodenpuffer pH 9,4 & $\begin{array}{l}\text { 2,62 g Amino-u-Carbonsäure } \\
1,51 \mathrm{~g} \text { Tris Pufferan } \\
100 \mathrm{ml} \text { Methanol } 20 \% \\
500 \mathrm{ml} \text { Aqua bidest }\end{array}$ \\
\hline Extraktionspuffer & $\begin{array}{l}3 \mathrm{~g} \mathrm{~K}_{2} \mathrm{HPO}_{4} \\
0,56 \mathrm{~g} \mathrm{EDTA} \\
0,2 \mathrm{~g} \mathrm{NaN} \\
115 \mathrm{ml} \text { Glycerin } 87 \% \\
1 \mathrm{~L} \text { Aqua bidest. }\end{array}$ \\
\hline
\end{tabular}




\subsubsection{Immundetektion}

Um die PVDF-Membran von den Rückständen zu befreien, wurde sie mit TBS-Tween gewaschen. Daraufhin erfolgte die Inkubation mit der Blocking-Lösung auf dem Wipptisch bei RT für eine Stunde. Der nächste Waschgang erfolgte mit TBS-Tween und dreifacher Wiederholung für jeweils 10 min. Anschließend wurde die Membran zur Inkubation über Nacht mit dem in TBS-Tween-verdünnten Primärantikörper auf den Schüttler bei $4{ }^{\circ} \mathrm{C}$ in eine luftdicht-verschlossene Plastikschale gegeben.

Nach der Inkubationszeit wurde der Primärantikörper durch einen Waschvorgang mit TBSTween und zweifacher Wiederholung für jeweils 10 min entfernt. Nun erfolgte die Inkubation der Membran mit dem in TBS-Tween-gelösten Sekundärantikörper (HRP-konjugiert) bei RT für eine Stunde auf dem Wipptisch. Der nächste Waschgang erfolgte nach der Inkubationszeit zur Entfernung des Sekundärantikörpers erneut mit TBS-Tween und dreifacher Wiederholung für jeweils $10 \mathrm{~min}$.

Die bildliche Darstellung der Immunodetection auf der PVDF-Membran erfolgte mittels LI-COR Osyssey Sa Imaging Systems.

Nach dem oben genannten Verfahren wurde außerdem GAPDH detektiert.

Tabelle 23: Bestandteile und Zusammensetzung für Immunodetektion

\begin{tabular}{lll}
\hline Bezeichnung & Name & Inhalt \\
\hline 10 x Waschlösung & $10 x \mathrm{TBS} \mathrm{pH} \mathrm{7,4}$ & $80 \mathrm{~g} \mathrm{NaCl}$ \\
& & $2 \mathrm{~g} \mathrm{KCl}$ \\
& & $30 \mathrm{~g} \mathrm{Tribase}$ \\
& & $900 \mathrm{ml}$ Aqua bidest. \\
Waschlösung & $+\mathrm{HCl}$ auf pH 7,4 einstellen \\
& TBS-Tween & $100 \mathrm{ml} \mathrm{10x} \mathrm{TBS}$ \\
Blocking-Lösung & & $10 \mathrm{ml}$ Tween20 $10 \%$ \\
& & $1 \mathrm{~L} \mathrm{Aqua} \mathrm{bidest.}$ \\
\hline
\end{tabular}




\subsubsection{Auswertung}

\subsubsection{Statistische Analysen}

Die statistischen Analysen wurden mit GraphPad Prism ${ }^{\circledR} 7.0$ für Windows (GraphPad Software, San Diego California USA, www.graphpad.com) durchgeführt. Unterschiede von $p<0,05$ wurden als signifikant gewertet.

\subsubsection{One-way ANOVA}

Die One-way ANOVA testet den Einfluss zweier variabler Faktoren auf die Messwerte eines Experimentes sowie deren Interaktion. Sie fand bei der statistischen Auswertung des alamarBlue ${ }^{\circledR}$ Proliferations-Assays und des JC-1 Mitochondrial Membrane Potential Detection Assays unter verschiedenen Konzentrationen im Vergleich untereinander und zur Kontrolle Anwendung.

Die Kontrolle wurde bei allen Versuchen bei 100 \% bzw. 1 festgelegt. 


\section{Ergebnisse}

\subsection{Analyse der antiproliferativen Wirkung}

4-OHT, 2-DG und CB-839 konnten in verschiedenen Studien einzeln bereits eine antiproliferative Wirkung auf Mammakarzinom-Zellen zeigen (Fisher et al. 2005, Wokoun et al. 2017, Gross et al. 2014). Allerdings ist noch nicht bekannt, inwiefern die Kombination der Wirkstoffe auf die Zelllinien MCF7 und T47D eine antiproliferative Wirkung haben und wie sich diese im Vergleich zu den entsprechenden Tamoxifen-resistenten Zelllinien MCF7-TR und T47D-TR verhält.

Daher wurde zunächst mittels AlamarBlue-Proliferationsassay genauer unter unterschiedlichen Konzentrationen und Wirkstoffkombinationen das Proliferationsverhalten der vier Zelllinen untersucht.

Dafür wurden die Zelllinien gleichermaßen in AlamarBlue-Medium (Vgl. Kapitel 2.1.9.3) ausgesät und nach $24 \mathrm{~h}$ durch ein mit den Versuchssubstanzen versetztem Medium therapiert. Dazu zählen die Substanzen 4-Hydroxy-Tamoxifen (100 nM, $1 \mu \mathrm{M}, 5 \mu \mathrm{M}), 2$,DG (0,625 mM, 2,5 mM, $5 \mathrm{mM})$ und CB-839 (1 $\mu \mathrm{M}, 5 \mu \mathrm{M}, 10 \mu \mathrm{M})$ (vgl. 2.1.8).

Als Kontrolle diente reines Medium. Die Zellviabilität wurde mittels AlamarBlueProliferationsassay nach $48 \mathrm{~h}$ Inkubation durch spektralphotometrische Messung im Multidetection Reader ermittelt (vgl. 2.2.2.1). Es erfolgten mindestens drei unabhängige Experimente mit mindestens drei verschiedenen Passagen. Signifikanzen wurden mittels One-way ANOVA im Turkey's multiple comparisons test ermittelt. Angegeben sind MW und $\pm \mathrm{SEM}$, mind. $\mathrm{N}=3$ biologische Replikate.

\subsubsection{Einzel-Therapie mit 4-OHT, 2-DG, CB-839}

Zunächst wurde die antiproliferative Wirkung der Wirkstoffe 4-OHT, 2-DG und CB-839 einzeln und in drei verschiedenen niedrig dosierten Konzentrationen in den Zelllinien MCF7, MCF7-TR, T47D und T47D-TR bestimmt. 


\subsubsection{MCF7 und MCF7-TR}

Die MCF7-Zelllinie zeigte unter der höchsten Tamoxifen-Konzentration (5 $\mu \mathrm{M}$ 4-OHT) eine signifikante Reduktion der Zellviabilität im Vergleich zur unbehandelten Kontrolle (MCF7, $5 \mu \mathrm{M}$ 4-OHT: 74,9 $\pm 4,609 \%, \mathrm{~N}=3, \mathrm{p}<0,05$ vs. Kontrolle), während bei der Tamoxifenresistenten Zelllinie kein Wirkungseffekt zu beobachten war.

Unter der Behandlung mit 2-DG reagierte die Tamoxifen-resistente Zelllinie bereits bei 2,5 mM 2-DG mit einer signifikanten Viabilitätsreduktion im Vergleich zur Kontrolle, den 4-OHTBehandlungen, der niedrigsten 2-DG-Behandlung $(0,625 \mathrm{mM})$ und den niedrigeren beiden Behandlungen mit CB-839 (MCF7-TR, 2,5 mM 2-DG: 68,88 $\pm 1,1 \%, N=3, p<0,0001$ vs.

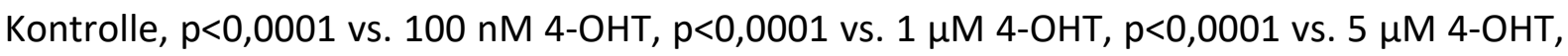
p<0,0001 vs. 0,625 mM 2-DG, p<0,0001 vs. $1 \mu \mathrm{M}$ CB-839, $\mathrm{p}<0,0001$ vs. $5 \mu \mathrm{M}$ CB-839). Die MCF7-Zelllinie reagierte unter der höchsten Konzentration 2-DG (5 mM 2-DG) signifikant viabilitätshemmend verglichen mit der unbehandelten Kontrolle, der niegdrigsten 4-OHTKonzentration (100 $\mathrm{nM})$, der niegdrigsten 2-DG-Konzentration $(0,625 \mathrm{mM})$ und den niedrigeren beiden CB-839-Konzentrationen (1 $\mu \mathrm{M}, 5 \mu \mathrm{M})$ (MCF7, $5 \mathrm{mM}$ 2-DG: 60,73 \pm $0,253 \%, N=3, p<0,001$ vs. Kontrolle, $p<0,05$ vs. $100 \mathrm{nM} \mathrm{4-OHT,} p<0,01$ vs. 0,625 mM 2-DG, $\mathrm{p}<0,001$ vs. $1 \mu \mathrm{M}$ CB-839, $\mathrm{p}<0,01$ vs. $5 \mu \mathrm{M}$ CB-839). Die dazugehörige TR-Zelllinie zeigte im Vergleich zur Kontrolle, allen 4-OHT-Behandlungen, der niedrigsten 2-DG-Behandlung $(0,625 \mathrm{mM})$ und den niedrigeren beiden CB-839-Behandlungen $(1 \mu \mathrm{M}, 5 \mu \mathrm{M})$ ebenfalls eine signifikante Reduktion der Viabilität (MCF7-TR, 5 mM 2-DG: 65,46 1,746 \%, N=3,p<0,0001

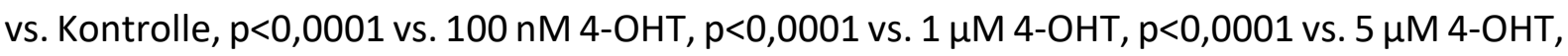
p<0,0001 vs. 0,625 mM 2-DG, p<0,0001 vs. $1 \mu \mathrm{M}$ CB-839, p<0,0001 vs. $5 \mu \mathrm{M}$ CB-839).

Bei der Therapie mit dem Glutaminase-Inhibitor CB-839 ließ sich feststellen, dass die MCF7TR-Zellen auf die höchste Konzentration (10 $\mu \mathrm{M}$ CB-839) signifikant viabilitätsmindernd im Vergleich zu der Kontrolle, allen 4-OHT-Behandlungen, der niegdrigsten 2-DG-Behandlung sowie den beiden niedrigeren CB-839-Behandlungen wirkte (MCF7-TR, $10 \mu \mathrm{M}$ CB-839: 65,07 $\pm 2,833 \%, N=3, p<0,0001$ vs. Kontrolle, $p<0,0001$ vs. 100 nM 4-OHT, $p<0,0001$ vs. $1 \mu M$ 4-OHT, $p<0,0001$ vs. $5 \mu \mathrm{M}$ 4-OHT, $p<0,0001$ vs. 0,625 mM 2-DG, $p<0,0001$ vs. $1 \mu \mathrm{M}$ CB-839, $p<0,0001$ vs. $5 \mu \mathrm{M}$ CB-839). Die MCF7-Zelllinie zeigte unter keiner der Behandlungen mit CB-839 eine signifikante Viabilitätshemmung. 
M C F 7

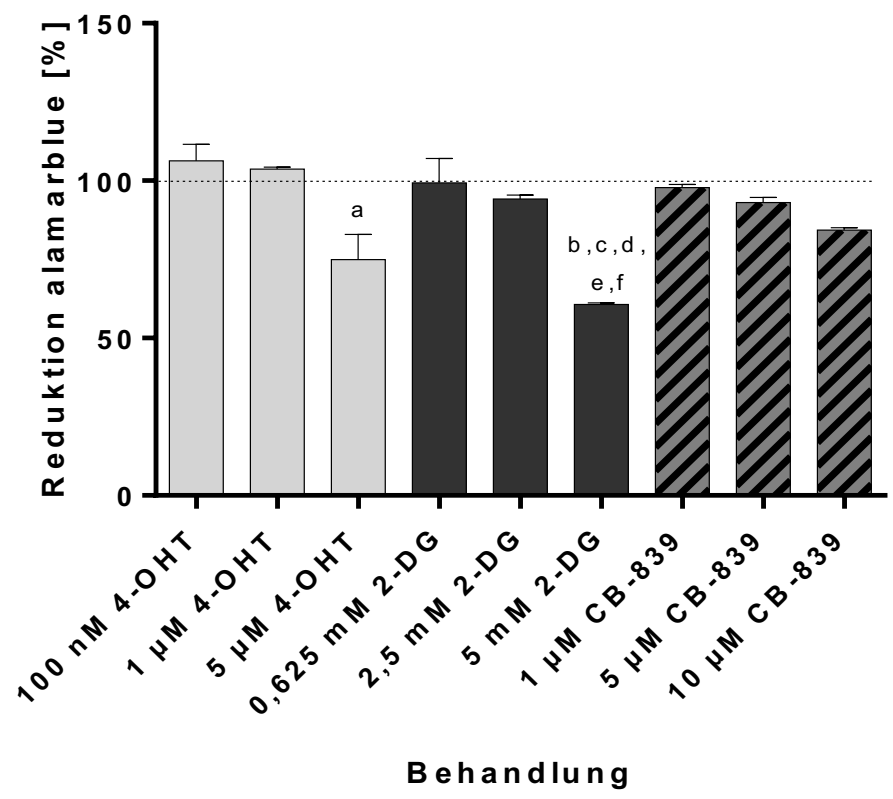

Abbildung 9: Viabilitätsinhibition der Mammakarzinomzelllinie MCF7

Behandelt wurde über $48 \mathrm{~h}$ mit unterschiedlichen Konzentrationen an 4-OHT, 2-DG und CB-839 (Kontrolle: unbehandelt). Die antiproliferative Wirkung wurde mittels alamarBlue Assay im Multidetection Reader ermittelt. Signifikanzen wurden mittels One-way ANOVA im Turkey's multiple comparisons test ermittelt.

$a, p<0,05$ vs. Kontrolle; $b, p<0,001$ vs. Kontrolle; $c, p<0,05$ vs. 100 nM 4-OHT; d, $p<0,01$ vs. 0,625 mM 2-DG; e, $p<0,001$ vs. $1 \mu \mathrm{M} C B-839 ; f, p<0,01$ vs. $5 \mu M$ CB-839.

\section{C F 7 -T R}



Abbildung 10: Viabilitätsinhibition der Tamoxifen-resistenten Mammakarzinomzelllinie MCF7-TR Behandelt wurde über $48 \mathrm{~h}$ mit unterschiedlichen Konzentrationen an 4-OHT, 2-DG und CB-839 (Kontrolle: unbehandelt). Die antiproliferative Wirkung wurde mittels alamarBlue Assay im Multidetection Reader ermittelt. Signifikanzen wurden mittels One-way ANOVA im Turkey's multiple comparisons test ermittelt.

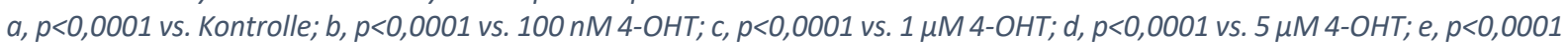
vs. 0,625 mM 2-DG; $f, p<0,0001$ vs. $1 \mu M C B-839 ; g, p<0,0001$ vs. $5 \mu M C B-839$. 


\subsubsection{T47D und T47D-TR}

Unter der Tamoxifen-Therapie zeigte sich bei den T47D-Zelllinien ein signifikanter viabilitätshemmender Effekt bei der höchsten Konzentration (5 $\mu \mathrm{M} 4-\mathrm{OHT})$ verglichen mit der Kontrolle und den Behandlungen mit den beiden niedrigeren 4-OHT-Therapien, den beiden niedrigeren 2-DG-Therapien und den CB-839-Therapien (T47D, $5 \mu \mathrm{M}$ 4-OHT: 61,45 \pm 1,855 \%, $\mathrm{N}=3, p<0,0001$ vs. Kontrolle; $\mathrm{p}<0,0001$ vs. $100 \mathrm{nM} 4-\mathrm{OHT}$; e, $\mathrm{p}<0,0001$ vs. $1 \mu \mathrm{M}$ 4-OHT; p<0,0001 vs. $0,625 \mathrm{mM} 2-\mathrm{DG} ; \mathrm{p}<0,0001$ vs. $2,5 \mathrm{mM} 2-\mathrm{DG} ; \mathrm{p}<0,0001$ vs. $1 \mu \mathrm{M}$ CB-839; p<0,0001 vs. $5 \mu \mathrm{M}$ CB-839; , $\mathrm{p}<0,01$ vs. $10 \mu \mathrm{M}$ CB-839), auch bei der TR-Zelllinie war ein signifikanter viabilitätshemmender Effekt im Vergleich zur unbehandelten Kontrolle feststellbar (T47D-TR, 5 MM 4-OHT: 89,15 \pm 0,51 \%, N=3, p<0,05 vs. Kontrolle). Bei der 2-DGTherapie zeigte die T47D-TR-Zelllinie eine signifikante Antiproliferation bei 2,5 mM 2-DG im Vergleich zu der unbehandelten Kontrolle, den beiden niedrigeren Konzentrationen an 4-OHT, der niedrigsten Konzentration an 2-DG und der niedrigsten Konzentration an CB-839 (T47D-TR, 2,5 mM 2-DG: 80,35 \pm 1,641 \%, N=3, p<0,0001 vs. Kontrolle; $p<0,001$ vs. 100 nM 4-OHT; $p<0,001$ vs. $1 \mu \mathrm{M}$ 4-OHT; $p<0,05$ vs. 0,625 mM 2-DG; $p<0,01$ vs. $1 \mu \mathrm{M}$ CB-839) bzw. bei 5 mM 2-DG im Verglich zu der unbehandelten Kontrolle, allen 4-OHT-Behandlungen, der niedrigsten 2-DG-Behandlung und den beiden niedrigeren CB-839-Behandlungen (T47D-TR, $5 \mathrm{mM}$ 2-DG: 75,05 $\pm 1,845 \%, \mathrm{~N}=3, \mathrm{p}<0,0001$ vs. Kontrolle; $p<0,0001$ vs. $100 \mathrm{nM}$ 4-OHT;


$1 \mu \mathrm{M}$ CB-839; $\mathrm{p}<0,01$ vs. $5 \mu \mathrm{M}$ CB-839). Bei der parenteralen Zelllinie wirkte die höchste Konzentration (5 mM 2-DG) signifikant inhibierend auf die Zellviabilität verglichen mit der Kontrolle, den niedrigeren beiden 4-OHT-Behandlungen, den niedrigeren beiden 2-DGBehandlungen und den CB-839-Behandlungen (T47D, 5 mM 2-DG: 51,53 $\pm 2,59 \%, N=3$, $p<0,0001$ vs. Kontrolle; $p<0,0001$ vs. 100 nM 4-OHT; e, $p<0,0001$ vs. $1 \mu \mathrm{M} 4-\mathrm{OHT} ; \mathrm{p}<0,0001$ vs. $0,625 \mathrm{mM} 2-D G ; p<0,0001$ vs. $2,5 \mathrm{mM} 2-\mathrm{DG}$; $p<0,0001$ vs. $1 \mu \mathrm{M}$ CB-839; $p<0,0001$ vs. $5 \mu \mathrm{M}$ CB-839; $\mathrm{p}<0,0001$ vs. $10 \mu \mathrm{M}$ CB-839).

Die Behandlung sowohl mit $5 \mu \mathrm{M}$ CB-839, als auch auch mit $10 \mu \mathrm{M}$ CB-839 zeigte bei der T47D-Zelllinie signifikante Reduktionen gegenüber der niedrigsten 2-DG-Behandlung (T47D, $5 \mu \mathrm{M}$ CB-839: 91,9 \pm 0,5995 \%, N=3, p<0,05 vs. 0,625 mM 2-DG; T47D, $10 \mu \mathrm{M}$ CB-839: 80,93 \pm $0,8768 \%, p<0,01$ vs. Kontrolle; $p<0,05$ vs. 100 nM 4-OHT; $p<0,01$ vs. $1 \mu \mathrm{M} 4-\mathrm{OHT} ; \mathrm{p}<0,0001$ vs. 0,625 mM 2-DG; $p<0,01$ vs. 2,5 mM 2-DG; $p<0,01$ vs. $1 \mu \mathrm{M}$ CB-839). 
Bei der T47D-TR-Zelllinie ließ sich eine signifikante Viabilitätshemmung unter der Behandlung mit $5 \mu \mathrm{M}$ CB-839 im Vergleich zu der unbehandelten Kontrolle beobachten (T47D-TR, $5 \mu \mathrm{M}$ CB-839: 88,83 $\pm 0,3667 \%, N=3, p<0,05$ vs. Kontrolle). Auch die Behandlung mit $10 \mu \mathrm{M} C B-839$ erbrachte eine signifikante Viabilitätsinhibition verglichen mit der Kontrolle, den niedrigeren beiden 4-OHT-Behandlungen und der jeweils niedrigsten Behandlung mit 2-DG bzw. CB-839 (T47D-TR, $10 \mu$ M CB-839: 80,93 \pm 0,6064 \%, $p<0,0001$ vs. Kontrolle; $p<0,001$ vs. 100 nM 4-OHT; p<0,001 vs. $1 \mu \mathrm{M}$ 4-OHT; $p<0,05$ vs. 0,625 mM 2-DG; $p<0,01$ vs. $1 \mu \mathrm{M}$ CB-839).

T 47 D

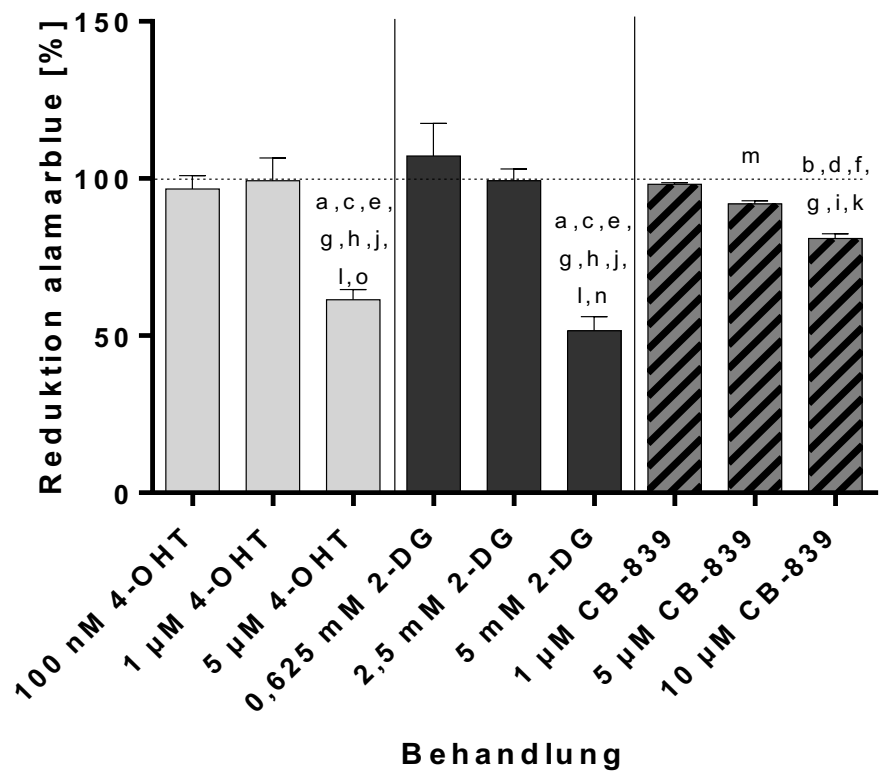

Abbildung 11: Viabilitätsinhibition der Mammakarzinomzelllinie T47D

Behandelt wurde über $48 \mathrm{~h}$ mit unterschiedlichen Konzentrationen an 4-OHT, 2-DG und CB-839 (Kontrolle: unbehandelt). Die antiproliferative Wirkung wurde mittels alamarBlue Assay im Multidetection Reader ermittelt. Signifikanzen wurden mittels One-way ANOVA im Turkey's multiple comparisons test ermittelt.

$a, p<0,0001$ vs. Kontrolle; $b, p<0,01$ vs. Kontrolle; c, $p<0,0001$ vs. 100 nM 4-OHT; $d, p<0,05$ vs. 100 nM 4-OHT; e, p<0,0001 vs. 1 MM 4-OHT; f, $p<0,01$ vs. 1 MM 4-OHT; $g, p<0,0001$ vs. 0,625 mM 2-DG; $h, p<0,0001$ vs. 2,5 mM 2-DG; $i, p<0,01$ vs. 2,5 mM

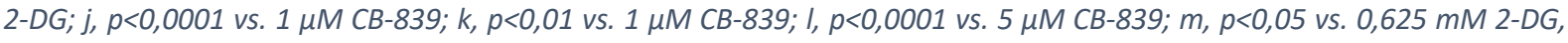
$n, p<0,0001$ vs. $10 \mu M C B-839 ; 0, p<0,01$ vs. $10 \mu M C B-839$. 
T 47 D - T R



Abbildung 12: Viabilitätsinhibition der tamoxifen-resistenen Mammakarzinomzelllinie T47D-TR

Behandelt wurde über $48 \mathrm{~h}$ mit unterschiedlichen Konzentrationen an 4-OHT, 2-DG und CB-839 (Kontrolle: unbehandelt). Die antiproliferative Wirkung wurde mittels alamarBlue Assay im Multidetection Reader ermittelt. Signifikanzen wurden mittels One-way ANOVA im Turkey's multiple comparisons test ermittelt.

$a, p<0,05$ vs. Kontrolle; $b, p<0,0001$ vs. Kontrolle; c, $p<0,001$ vs. 100 nM 4-OHT; $d, p<0,0001$ vs. 100 nM 4-OHT; e, $p<0,001$ vs.

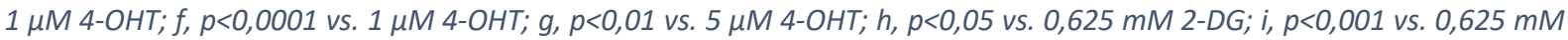

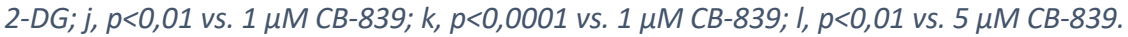


Tabelle 24: Statistische Auswertung des Viabilitäts-Assays unter Einzelbehandlungen

\begin{tabular}{|c|c|c|c|c|}
\hline $\begin{array}{l}\text { One-way-ANOVA mit } \\
\text { Turkey's multiple test }\end{array}$ & MCF7 & MCF7-TR & T47D & T47D-TR \\
\hline \multicolumn{5}{|l|}{ Kontolle } \\
\hline vs. $100 \mathrm{nM} 4-\mathrm{OHT}$ & $p>0,05$ & $p>0,05$ & $p>0,05$ & $p>0,05$ \\
\hline vs. $1 \mu \mathrm{M}$ 4-OHT & $p>0,05$ & $p>0,05$ & $p>0,05$ & $p>0,05$ \\
\hline vs. $5 \mu \mathrm{M}$ 4-OHT & $p<0,05$ & $p>0,05$ & $p<0,0001$ & $p<0,05$ \\
\hline vs. 0,635 mM 2-DG & $p>0,05$ & $p>0,05$ & $p>0,05$ & $p>0,05$ \\
\hline vs. $2,5 \mathrm{mM}$ 2-DG & $p>0,05$ & $p<0,0001$ & $p>0,05$ & $p>0,05$ \\
\hline vs. $5 \mathrm{mM}$ 2-DG & $p<0,001$ & $p<0,0001$ & $p<0,0001$ & $p<0,001$ \\
\hline vs. $1 \mu \mathrm{M}$ CB-839 & $p>0,05$ & $p>0,05$ & $p>0,05$ & $p>0,05$ \\
\hline vs. $5 \mu \mathrm{M}$ CB-839 & $p>0,05$ & $p>0,05$ & $p>0,05$ & $p>0,05$ \\
\hline vs. $10 \mu \mathrm{M}$ CB-839 & $p>0,05$ & $p<0,0001$ & $p<0,01$ & $p>0,05$ \\
\hline \multicolumn{5}{|l|}{100 nM 4-OHT } \\
\hline vs. $1 \mu \mathrm{M}$ 4-OHT & $p>0,05$ & $p>0,05$ & $p>0,05$ & $p>0,05$ \\
\hline vs. $5 \mu \mathrm{M}$ 4-OHT & $p>0,05$ & $p>0,05$ & $p<0,0001$ & $p>0,05$ \\
\hline vs. 0,635 mM 2-DG & $p>0,05$ & $p>0,05$ & $p>0,05$ & $p>0,05$ \\
\hline vs. $2,5 \mathrm{mM} 2-\mathrm{DG}$ & $p>0,05$ & $p<0,0001$ & $p>0,05$ & $p>0,05$ \\
\hline vs. 5 mM 2-DG & $p<0,05$ & $p<0,0001$ & $p<0,0001$ & $p<0,05$ \\
\hline vs. $1 \mu \mathrm{M}$ CB-839 & $p>0,05$ & $p>0,05$ & $p>0,05$ & $p>0,05$ \\
\hline vs. $5 \mu \mathrm{M}$ CB-839 & $p>0,05$ & $p>0,05$ & $p>0,05$ & $p>0,05$ \\
\hline vs. $10 \mu \mathrm{M}$ CB-839 & $p>0,05$ & $p<0,0001$ & $p<0,05$ & $p>0,05$ \\
\hline \multicolumn{5}{|l|}{$1 \mu \mathrm{M}$ 4-OHT } \\
\hline vs. $5 \mu \mathrm{M}$ 4-OHT & $p>0,05$ & $p>0,05$ & $p<0,0001$ & $p>0,05$ \\
\hline vs. 0,635 mM 2-DG & $p>0,05$ & $p>0,05$ & $p>0,05$ & $p>0,05$ \\
\hline vs. $2,5 \mathrm{mM}$ 2-DG & $p>0,05$ & $p<0,0001$ & $p>0,05$ & $p>0,05$ \\
\hline vs. 5 mM 2-DG & $p>0,05$ & $p<0,0001$ & $p<0,0001$ & $p>0,05$ \\
\hline vs. $1 \mu \mathrm{M}$ CB-839 & $p>0,05$ & $p>0,05$ & $p>0,05$ & $p>0,05$ \\
\hline vs. $5 \mu \mathrm{M}$ CB-839 & $p>0,05$ & $p>0,05$ & $p>0,05$ & $p>0,05$ \\
\hline vs. $10 \mu \mathrm{M}$ CB-839 & $p>0,05$ & $p<0,0001$ & $p<0,01$ & $p>0,05$ \\
\hline \multicolumn{5}{|l|}{ 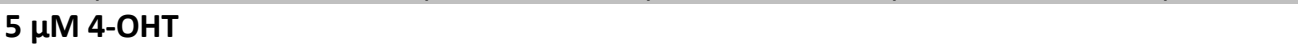 } \\
\hline vs. 0,635 mM 2-DG & $p>0,05$ & $p>0,05$ & $p<0,0001$ & $p>0,05$ \\
\hline vs. $2,5 \mathrm{mM} 2-\mathrm{DG}$ & $p>0,05$ & $p<0,0001$ & $p<0,0001$ & $p>0,05$ \\
\hline vs. 5 mM 2-DG & $p>0,05$ & $p<0,0001$ & $p>0,05$ & $p>0,05$ \\
\hline vs. $1 \mu \mathrm{M}$ CB-839 & $p>0,05$ & $p>0,05$ & $p<0,0001$ & $p>0,05$ \\
\hline vs. $5 \mu \mathrm{M}$ CB-839 & $p>0,05$ & $p>0,05$ & $p<0,0001$ & $p>0,05$ \\
\hline vs. $10 \mu \mathrm{M}$ CB-839 & $p>0,05$ & $p<0,0001$ & $p<0,01$ & $p>0,05$ \\
\hline \multicolumn{5}{|l|}{ 0,635 mM 2-DG } \\
\hline vs. $2,5 \mathrm{mM}$ 2-DG & $p>0,05$ & $p<0,0001$ & $p>0,05$ & $p>0,05$ \\
\hline vs. $5 \mathrm{mM}$ 2-DG & $p<0,01$ & $p<0,0001$ & $p<0,0001$ & $p<0,01$ \\
\hline vs. $1 \mu \mathrm{M}$ CB-839 & $p>0,05$ & $p>0,05$ & $p>0,05$ & $p>0,05$ \\
\hline vs. $5 \mu \mathrm{M}$ CB-839 & $p>0,05$ & $p>0,05$ & $p<0,05$ & $p>0,05$ \\
\hline vs. $10 \mu \mathrm{M}$ CB-839 & $p>0,05$ & $p<0,0001$ & $p<0,0001$ & $p>0,05$ \\
\hline \multicolumn{5}{|l|}{ 2,5 mM 2-DG } \\
\hline vs. 5 mM 2-DG & $p>0,05$ & $p>0,05$ & $p<0,0001$ & $p>0,05$ \\
\hline vs. $1 \mu \mathrm{M}$ CB-839 & $p>0,05$ & $p<0,0001$ & $p>0,05$ & $p>0,05$ \\
\hline vs. $5 \mu \mathrm{M}$ CB-839 & $p>0,05$ & $p<0,0001$ & $p>0,05$ & $p>0,05$ \\
\hline vs. $10 \mu \mathrm{M}$ CB-839 & $p>0,05$ & $p>0,05$ & $p<0,01$ & $p>0,05$ \\
\hline \multicolumn{5}{|l|}{5 mM 2-DG } \\
\hline vs. $1 \mu \mathrm{M}$ CB-839 & $P<0,001$ & $p<0,0001$ & $p<0,0001$ & $p<0,001$ \\
\hline vs. $5 \mu \mathrm{M}$ CB-839 & $P<0,01$ & $p<0,0001$ & $p<0,0001$ & $p<0,01$ \\
\hline vs. $10 \mu \mathrm{M}$ CB-839 & $p>0,05$ & $p>0,05$ & $p<0,0001$ & $p>0,05$ \\
\hline \multicolumn{5}{|l|}{$1 \mu \mathrm{M}$ СВ-839 } \\
\hline vs. $5 \mu \mathrm{M}$ CB-839 & $p>0,05$ & $p>0,05$ & $p>0,05$ & $p>0,05$ \\
\hline vs. $10 \mu \mathrm{M}$ CB-839 & $p>0,05$ & $p<0,0001$ & $p<0,01$ & $p>0,05$ \\
\hline \multicolumn{5}{|l|}{$5 \mu \mathrm{M}$ CB-839 } \\
\hline vs. $10 \mu \mathrm{M}$ CB-839 & $p>0,05$ & $p<0,0001$ & $p>0,05$ & $p>0,05$ \\
\hline
\end{tabular}




\subsubsection{Kombinationstherapie aus 4-OHT, 2-DG, CB-839}

\subsubsection{MCF7}

Die Kombination aus 4-OHT und 2-DG erbrachte bei der MCF7-Zelllinie eine signifikante Reduktion der Viabilität im Vergleich zur Kontrolle und zur 4-OHT-Therapie (MCF7, $1 \mu \mathrm{M}$ 4-OHT + 2,5 mM 2-DG: 90,36 \pm 1,335 \%, N=3, p<0,05 vs. Kontrolle; $p<0,001$ vs. $1 \mu \mathrm{M}$ 4-OHT), genauso wie bei der Kombination aus 4-OHT und CB-839 (MCF7, $1 \mu \mathrm{M}$ 4-OHT + $5 \mu \mathrm{M}$ CB-839: $87,31 \pm 1,589 \%, N=3, p<0,01$ vs. Kontrolle; $p<0,0001$ vs. $1 \mu \mathrm{M} 4-\mathrm{OHT})$.

Die Kombinationsbehandlung mit 2-DG und CB-839 sowie die Kombination aus allen drei Wirkstoffen 4-OHT, 2-DG und CB-839 zeigten eine Reduktion der Viabilität im Vergleich zu der Kontrolle, der alleinigen 4-OHT-, 2-DG-, CB-839-Therapie, der Kombination aus 4-OHT/2-DG und der aus 4-OHT/CB-839 (MCF7, 2,5 mM 2-DG+ $5 \mu \mathrm{M}$ CB-839: 76,74 \pm 1,517 \%, N=3, $p<0,0001$ vs. Kontrolle; $p<0,0001$ vs. $1 \mu \mathrm{M} 4-\mathrm{OHT} ; \mathrm{p}<0,0001$ vs. 2,5 mM 2-DG; $p<0,001$ vs. $5 \mu \mathrm{M}$ CB-839; $\mathrm{p}<0,001$ vs. $1 \mu \mathrm{M}$ 4-OHT + 2,5 mM 2-DG; p<0,01 vs. $1 \mu \mathrm{M}$ 4-OHT + $5 \mu \mathrm{M}$ CB-839. MCF7, $1 \mu \mathrm{M}$ 4-OHT + 2,5 mM 2-DG+ $5 \mu \mathrm{M}$ CB-839: 70,36 \pm 3,898 \%, N=3, $\mathrm{p}<0,0001$ vs. Kontrolle; $p<0,0001$ vs. $1 \mu \mathrm{M}$ 4-OHT; $p<0,0001$ vs. 2,5 mM 2-DG; $p<0,0001$ vs. 5 M CB-839; p<0,0001 vs. $1 \mu \mathrm{M}$ 4-OHT + 2,5 mM 2-DG; p<0,0001 vs. $1 \mu \mathrm{M}$ 4-OHT + $5 \mu \mathrm{M}$ CB-839). 


\section{C F 7}
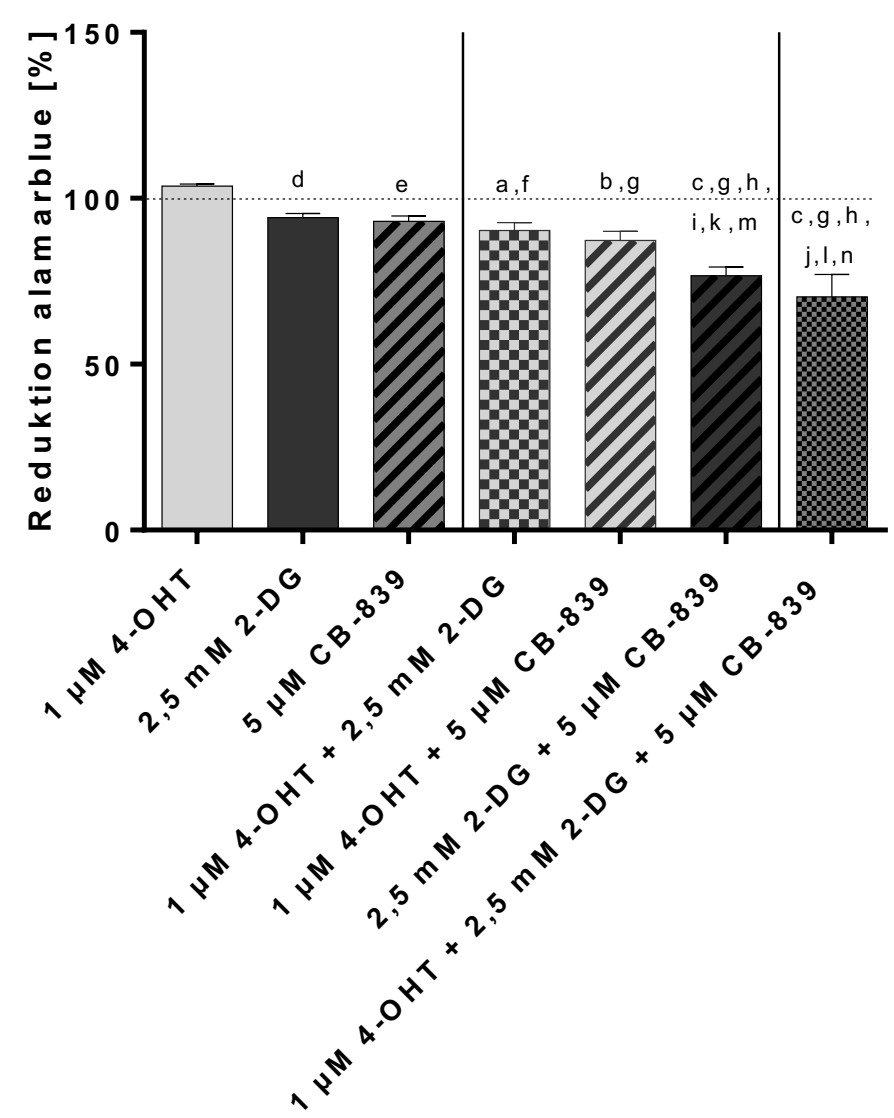

Behandlung

\section{Abbildung 13: Viabilitätsinhibition der Mammakarzinomzelllinie MCF7}

Behandelt wurde über $48 \mathrm{~h}$ mit unterschiedlichen Konzentrationen an 4-OHT, 2-DG und CB-839 (Kontrolle: unbehandelt). Die antiproliferative Wirkung wurde mittels alamarBlue Assay im Multidetection Reader ermittelt. Signifikanzen wurden mittels One-way ANOVA im Turkey's multiple comparisons test ermittelt.

$a, p<0,05$ vs. Kontrolle; $b, p<0,01$ vs. Kontrolle; c, $p<0,0001$ vs. Kontrolle; $d, p<0,01$ vs. 1 MM 4-OHT; e, $p<0,01$ vs. $1 \mu M$ 4-OHT;

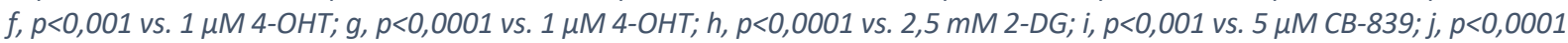
vs. $5 \mu M$ CB-839; $k, p<0,001$ vs. $1 \mu M$ 4-OHT + 2,5 mM 2-DG; l, p<0,0001 vs. $1 \mu M$ 4-OHT + 2,5 mM 2-DG; m, p<0,01 vs. $1 \mu M$ 4-OHT + $5 \mu M C B-839 ; n, p<0,0001$ vs. $1 \mu M$ 4-OHT + $5 \mu M C B-839$. 


\subsubsection{MCF7-TR}

Die MCF7-TR-Zelllinie erbachte eine signifikante Viabilitätsreduktion unter der alleinigen Behandlung mit 2-DG sowie unter der Kombinationsbehandlung aus 4-OHT und 2-DG, die sich signifikant stärker verhielten im Verleich zu der unbehandelten Kontrolle, der Behandlung mit 4-OHT und CB-839 alleine, sowie der Kombinationsbehandlung aus 4-OHT/CB-839 (MCF7-TR, 2,5 mM 2-DG: 69,88 $\pm 1,1 \%, N=3, p<0,0001$ vs. Kontrolle; $p<0,0001$ vs. $1 \mu \mathrm{M} 4-\mathrm{OHT} ; \mathrm{p}<0,0001$ vs. $5 \mu \mathrm{M}$ CB-839; $\mathrm{p}<0,01$ vs. $1 \mu \mathrm{M}$ 4-OHT + $5 \mu \mathrm{M}$ CB-839. MCF7-TR, $1 \mu \mathrm{M} 4-\mathrm{OHT}+$ 2,5 mM 2-DG: 72,2 $\pm 3,427 \%, N=3, p<0,0001$ vs. Kontrolle; $p<0,0001$ vs. $1 \mu \mathrm{M} 4-\mathrm{OHT}$; p<0,0001 vs. $5 \mu \mathrm{M}$ CB-839; $\mathrm{p}<0,05$ vs. $1 \mu \mathrm{M}$ 4-OHT + $5 \mu \mathrm{M}$ CB-839).

Die Kombinationsbehandlung aus 4-OHT und CB-839 zeigte eine signifikant stärkere Inhibition auf die Zellviabilität im Vergleich zur Kontrolle und der alleinigen 4-OHT- sowie CB-839Behandlung (MCF7-TR, $1 \mu \mathrm{M}$ 4-OHT $+5 \mu \mathrm{M}$ CB-839: 80,8 $\pm 0,6871 \%, N=3, p<0,0001$ vs. Kontrolle; $p<0,0001$ vs. $1 \mu \mathrm{M}$ 4-OHT; $p<0,001$ vs. $5 \mu \mathrm{M}$ CB-839).

Unter der Behandlung mit der Kombination aus 2-DG und CB-839 ergab sich eine signifikant särkere viabilitätsinhibitorische Wirkung im Vergleich zu den Behandlungen mit 4-OHT, CB-839, 4-OHT/2-DG und 4-OHT/CB-839 (MCF7-TR, 5 mM 2-DG + $5 \mu \mathrm{M}$ CB-839: 63,53 \pm

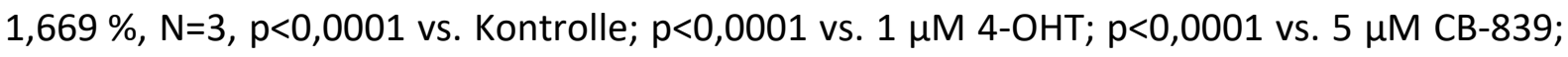
p<0,05 vs. $1 \mu \mathrm{M}$ 4-OHT + 2,5 mM 2-DG; p<0,0001 vs. $1 \mu \mathrm{M}$ 4-OHT + $5 \mu \mathrm{M}$ CB-839). Ähnlich zeigte auch die Kombination aus allen drei Wirkstoffen eine signifikant stärkere Viabilitätshemmung im Vergleich zu den Behandlungen mit 4-OHT, CB-839, 4-OHT/2-DG und

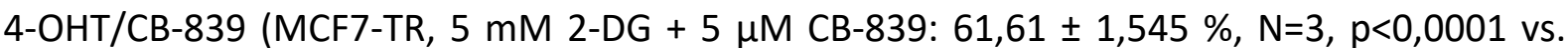
Kontrolle; $p<0,0001$ vs. $1 \mu \mathrm{M}$ 4-OHT; $p<0,0001$ vs. $5 \mu \mathrm{M}$ CB-839; $\mathrm{p}<0,001$ vs. $1 \mu \mathrm{M}$ 4-OHT + 2,5 mM 2-DG; $p<0,0001$ vs. $1 \mu \mathrm{M}$ 4-OHT + $5 \mu \mathrm{M}$ CB-839). 


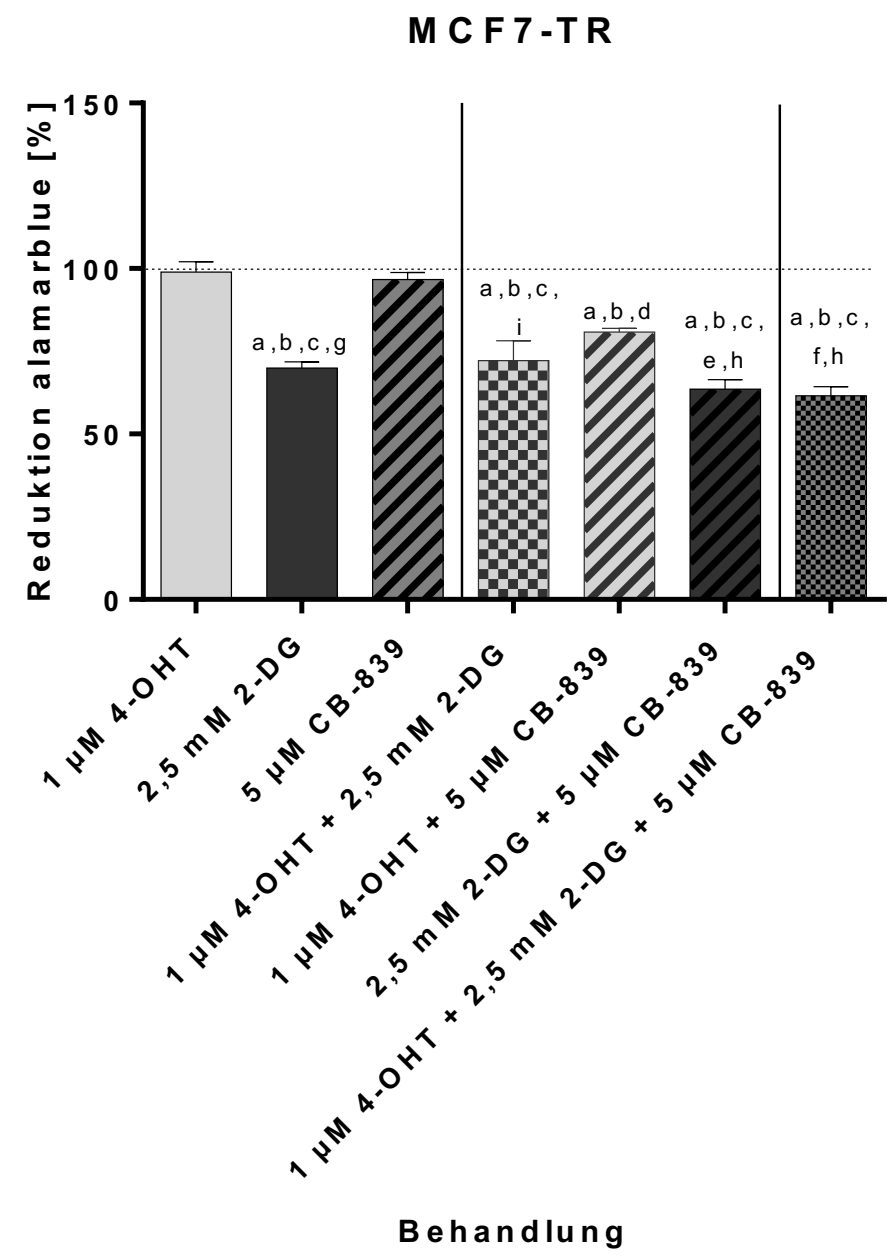

Abbildung 14: Viabilitätsinhibition der Mammakarzinomzelllinie MCF7

Behandelt wurde über $48 \mathrm{~h}$ mit unterschiedlichen Konzentrationen an 4-OHT, 2-DG und CB-839 (Kontrolle: unbehandelt). Die antiproliferative Wirkung wurde mittels alamarBlue Assay im Multidetection Reader ermittelt. Signifikanzen wurden mittels One-way ANOVA im Turkey's multiple comparisons test ermittelt.

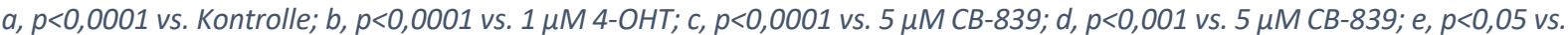
$1 \mu M$ 4-OHT + 2,5 mM 2-DG; f, p<0,001 vs. $1 \mu M$ 4-OHT + 2,5 mM 2-DG; $g, p<0,01$ vs. $1 \mu M$ 4-OHT + $5 \mu M C B-839 ; h, p<0,0001$ vs. $1 \mu M$ 4-OHT + $5 \mu M C B-839 ; i, p<0,05$ vs. $1 \mu M$ 4-OHT + $5 \mu M$ CB-839.

\subsubsection{T47D}

Die Einzelbehandlungen mit 2-DG und CB-839 sowie die Kombinationsbehandlungen mit 4-OHT/2-DG und 4-OHT/CB-839 zeigten eine signifikante Reduktion der Viabilität im Vergleich zur unbehandelten Kontrolle und der alleinigen 4-OHT-Therapie (T47D, 2,5 mM 2-DG: 88,24 \pm 0,7267 \%, N=3, p<0,001 vs. Kontrolle; p<0,01 vs. $1 \mu \mathrm{M}$ 4-OHT. T47D, $5 \mu \mathrm{M}$ CB-839: 91,14 \pm 0,7267 \%, p<0,01 vs. Kontrolle; p<0,05 vs. $1 \mu \mathrm{M}$ 4-OHT. T47D, $1 \mu \mathrm{M}$ 4-OHT + 2,5 mM 2-DG: 91,19 $\pm 2,478 \%, \mathrm{~N}=3, \mathrm{p}<0,05$ vs. $1 \mu \mathrm{M}$ 4-OHT. T47D, $1 \mu \mathrm{M}$ 4-OHT $+5 \mu \mathrm{M}$ CB-839: 88,55 \pm $0,6949 \%, N=3, p<0,001$ vs. Kontrolle; $p<0,01$ vs. $1 \mu \mathrm{M} 4-\mathrm{OHT})$. 
Die Kombination aus den beiden Metabolismus-Inhibitoren 2-DG und CB-839 und die Dreifach-Kobination aus allen drei Wirkstoffen erbrachten eine signifikant stärkere viabilitätsinhibitorische Wirkung im Vergleich zu allen Einzelbehandlungen sowie den beiden Kombinationen 4-OHT/2-DG und 4-OHT/CB-839 (T47D, 2,5 mM 2-DG: 75,99 \pm 1,797 \%, N=3, $p<0,0001$ vs. Kontrolle; $p<0,0001$ vs. $1 \mu \mathrm{M} 4-\mathrm{OHT} ; \mathrm{p}<0,001$ vs. 2,5 mM 2-DG; $p<0,0001$ vs. $5 \mu \mathrm{M}$ CB-839; $\mathrm{p}<0,0001$ vs. $1 \mu \mathrm{M}$ 4-OHT $+2,5$ mM 2-DG; $\mathrm{p}<0,001$ vs. $1 \mu \mathrm{M} 4-\mathrm{OHT}+5 \mu \mathrm{M}$ CB-839. T47D, 2,5 mM 2-DG: 73,18 $\pm 1,797 \%, N=3, p<0,0001$ vs. Kontrolle; $p<0,0001$ vs. $1 \mu M$ 4-OHT; $p<0,0001$ vs. 2,5 mM 2-DG; $p<0,0001$ vs. $5 \mu \mathrm{M}$ CB-839; $p<0,0001$ vs. $1 \mu \mathrm{M}$ 4-OHT + 2,5 mM 2-DG; $p<0,0001$ vs. $1 \mu \mathrm{M} 4-\mathrm{OHT}+5 \mu \mathrm{M}$ CB-839).

\section{T $47 \mathrm{D}$}

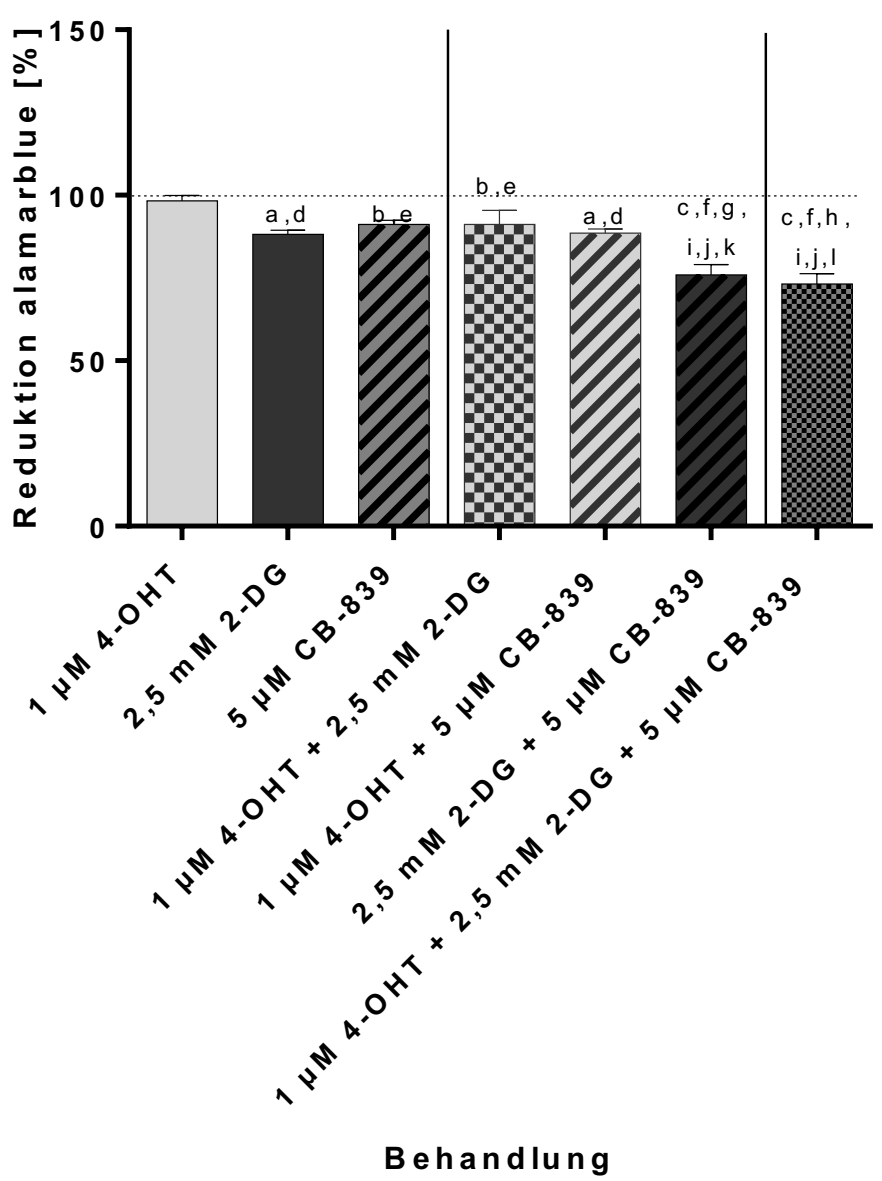

Abbildung 15: Viabilitätsinhibition der Mammakarzinomzelllinie T47D

Behandelt wurde über $48 \mathrm{~h}$ mit unterschiedlichen Konzentrationen an 4-OHT, 2-DG und CB-839 (Kontrolle: unbehandelt). Die antiproliferative Wirkung wurde mittels alamarBlue Assay im Multidetection Reader ermittelt. Signifikanzen wurden mittels One-way ANOVA im Turkey's multiple comparisons test ermittelt.

$a, p<0,001$ vs. Kontrolle; $b, p<0,01$ vs. Kontrolle; $c, p<0,0001$ vs. Kontrolle; $d, p<0,01$ vs. 1 MM 4-OHT; e, $p<0,05$ vs. 1 MM 4-OHT; $f, p<0,0001$ vs. $1 \mu M$ 4-OHT; $g, p<0,001$ vs. 2,5 mM 2-DG; $h, p<0,0001$ vs. 2,5 mM 2-DG; i, $p<0,0001$ vs. $5 \mu M$ CB-839; j, $p<0,0001$ vs. $1 \mu M$ 4-OHT + 2,5 mM 2-DG; k, p<0,001 vs. $1 \mu M$ 4-OHT + $5 \mu M C B-839 ; l, p<0,0001$ vs. $1 \mu M$ 4-OHT + $5 \mu M$ CB-839. 


\subsubsection{T47D-TR}

Unter der alleinigen Therapie mit 2-DG und der Kombinationstherapie aus 4-OHT/CB-839 ergab sich eine viabilitätsinhibitorische Wirkung verglichen mit der unbehandelten Kontrolle und der Therapie mit 4-OHT alleine (T47D-TR, 2,5 mM 2-DG: 80,35 $\pm 1,641$ \%, N=3, p<0,01 vs. Kontrolle; p<0,01 vs. $1 \mu \mathrm{M}$ 4-OHT. T47D-TR, $1 \mu \mathrm{M}$ 4-OHT + $5 \mu \mathrm{M}$ CB-839: 84,08 \pm 2,697 \%, N=3, $p<0,05$ vs. Kontrolle; $p<0,05$ vs. 1 MM 4-OHT). Die Kombination aus den beiden MetabolismusInhibitoren präsentierte bei den Zellen eine signifikant stärkere Hemmung im Vergleich zu allen drei Einzelbehandlungen und den beiden anderen Zweifach-Kombinationen 4-OHT/2-DG

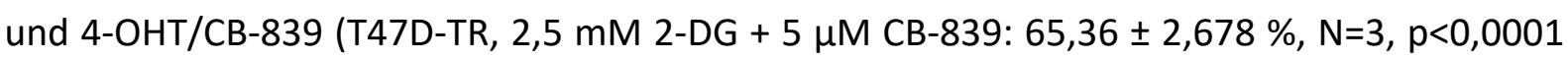
vs. Kontrolle; $p<0,0001$ vs. $1 \mu \mathrm{M}$ 4-OHT; $p<0,05$ vs. 2,5 mM 2-DG; $p<0,001$ vs. $5 \mu \mathrm{M}$ CB-839; p<0,001 vs. $1 \mu \mathrm{M}$ 4-OHT + 2,5 mM 2-DG; p<0,01 vs. $1 \mu \mathrm{M}$ 4-OHT + $5 \mu \mathrm{M}$ CB-839).

Die Dreifach-Behandlung war verglichen zu allen Einzel- und Zweifachbehandlungen

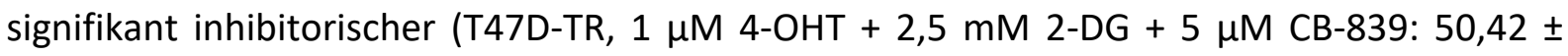
$3,687 \%, N=3, p<0,0001$ vs. Kontrolle; $p<0,0001$ vs. $1 \mu \mathrm{M}$ 4-OHT; $p<0,0001$ vs. 2,5 mM 2-DG;

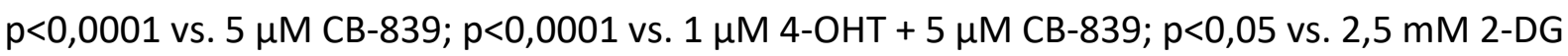

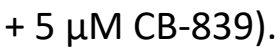




\section{T 47 D - T R}

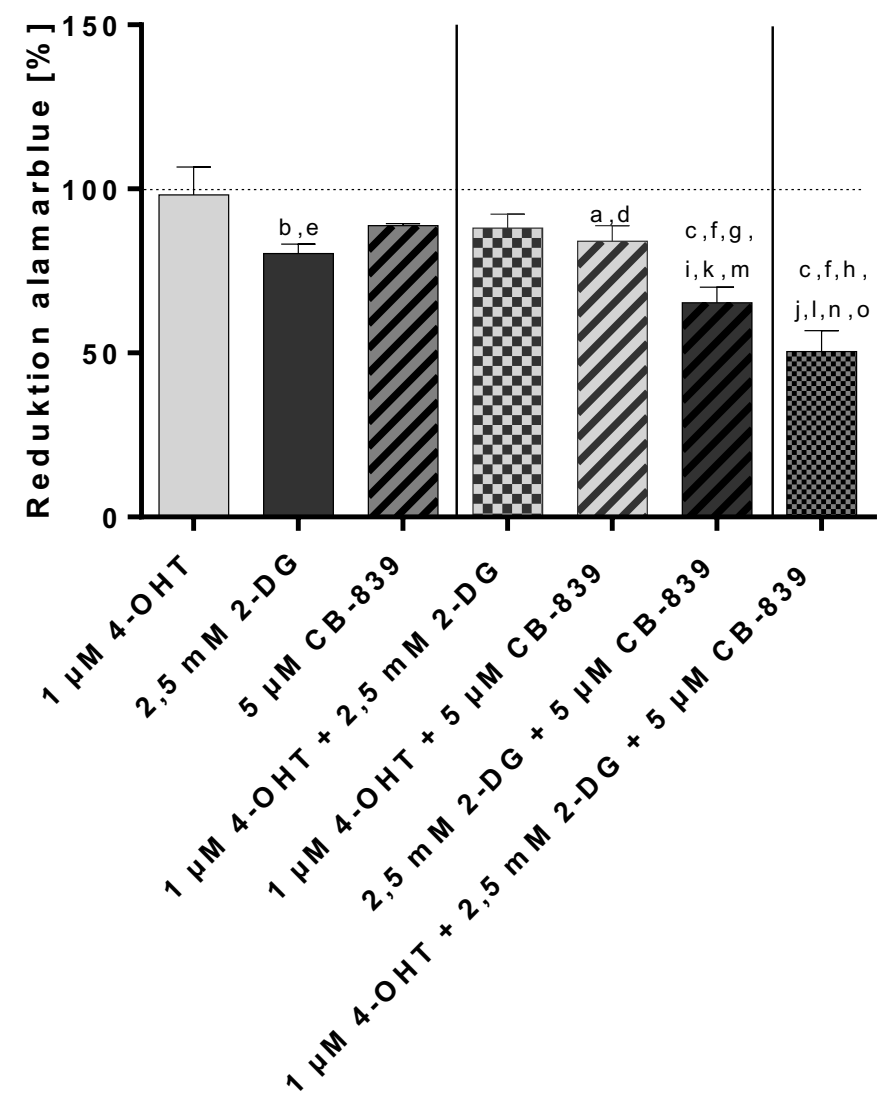

Behandlung

Abbildung 16: Viabilitätsinhibition der Mammakarzinomzelllinie T47D-TR

Behandelt wurde über $48 \mathrm{~h}$ mit unterschiedlichen Konzentrationen an 4-OHT, 2-DG und CB-839 (Kontrolle: unbehandelt). Die antiproliferative Wirkung wurde mittels alamarBlue Assay im Multidetection Reader ermittelt. Signifikanzen wurden mittels One-way ANOVA im Turkey's multiple comparisons test ermittelt.

$a, p<0,05$ vs. Kontrolle; $b, p<0,01$ vs. Kontrolle; c, $p<0,0001$ vs. Kontrolle; $d, p<0,05$ vs. $1 \mu M$ 4-OHT; e, $p<0,01$ vs. $1 \mu M$ 4-OHT;

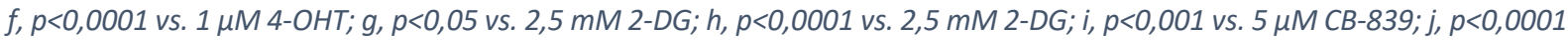
vs. 5 MM CB-839; $k, p<0,001$ vs. $1 \mu M$ 4-OHT + 2,5 mM 2-DG; l, p<0,0001 vs. $1 \mu M$ 4-OHT + 2,5 mM 2-DG; m, p<0,01 vs. $1 \mu M$ 4-OHT + $5 \mu M C B-839 ; n, p<0,0001$ vs. $1 \mu M$ 4-OHT + $5 \mu M C B-839 ; 0, p<0,05$ vs. 2,5 mM 2-DG + $5 \mu M C B-839$. 
Tabelle 25: Statistische Auswertung des Viabilitäts-Assays unter Kombinationsbehandlungen

\begin{tabular}{|c|c|c|c|c|}
\hline $\begin{array}{l}\text { One-way-ANOVA mit } \\
\text { Turkey's multiple test }\end{array}$ & MCF7 & MCF7-TR & T47D & T47D-TR \\
\hline \multicolumn{5}{|l|}{ Kontrolle } \\
\hline vs. $1 \mu \mathrm{M}$ 4-OHT & $p>0,05$ & $p>0,05$ & $p>0,05$ & $p>0,05$ \\
\hline vs. $2,5 \mathrm{mM}$ 2-DG & $p>0,05$ & $p<0,0001$ & $p<0,001$ & $p<0,01$ \\
\hline vs. 5 HM CB-839 & $p>0,05$ & $p>0,05$ & $p<0,01$ & $p>0,05$ \\
\hline vs. $1 \mu \mathrm{M}$ 4-OHT + 2,5 mM 2-DG & $p<0,05$ & $p<0,0001$ & $p<0,01$ & $p>0,05$ \\
\hline vs. $1 \mu \mathrm{M}$ 4-OHT + $5 \mu \mathrm{M}$ CB-839 & $p<0,01$ & $p<0,0001$ & $p<0,001$ & $p<0,05$ \\
\hline vs. $2,5 \mathrm{mM} 2-\mathrm{DG}+5 \mu \mathrm{M}$ CB-839 & $p<0,0001$ & $p<0,0001$ & $p<0,0001$ & $p<0,0001$ \\
\hline vs. $1 \mu \mathrm{M} 4-\mathrm{OHT}+2,5 \mathrm{mM} 2-\mathrm{DG}+5 \mu \mathrm{M}$ CB-839 & $p<0,0001$ & $p<0,0001$ & $p<0,0001$ & $p<0,0001$ \\
\hline \multicolumn{5}{|l|}{$1 \mu \mathrm{M}$ 4-OHT } \\
\hline vs. $2,5 \mathrm{mM} 2-\mathrm{DG}$ & $p<0,05$ & $\mathrm{p}<0,0001$ & $p<0,01$ & $p<0,01$ \\
\hline vs. $5 \mu \mathrm{M}$ CB-839 & $p<0,01$ & $p>0,05$ & $p<0,05$ & $p>0,05$ \\
\hline vs. $1 \mu \mathrm{M}$ 4-OHT + 2,5 mM 2-DG & $p<0,001$ & $p<0,0001$ & $p<0,05$ & $p>0,05$ \\
\hline vs. $1 \mu \mathrm{M}$ 4-OHT + $5 \mu \mathrm{M}$ CB-839 & $p<0,0001$ & $p<0,0001$ & $p<0,01$ & $p<0,05$ \\
\hline vs. $2,5 \mathrm{mM} 2-\mathrm{DG}+5 \mu \mathrm{M}$ CB-839 & $p<0,0001$ & $p<0,0001$ & $p<0,0001$ & $p<0,0001$ \\
\hline vs. $1 \mu \mathrm{M} 4-\mathrm{OHT}+2,5 \mathrm{mM}$ 2-DG + $5 \mu \mathrm{M}$ CB-839 & $p<0,0001$ & $p<0,0001$ & $p<0,0001$ & $p<0,0001$ \\
\hline \multicolumn{5}{|l|}{ 2,5 mM 2-DG } \\
\hline vs. $5 \mu \mathrm{M}$ CB-839 & $p>0,05$ & $p<0,0001$ & $p>0,05$ & $p>0,05$ \\
\hline vs. $1 \mu \mathrm{M}$ 4-OHT + 2,5 mM 2-DG & $p>0,05$ & $p>0,05$ & $p>0,05$ & $p>0,05$ \\
\hline vs. $1 \mu \mathrm{M}$ 4-OHT + $5 \mu \mathrm{M}$ CB-839 & $p>0,05$ & $p<0,01$ & $p>0,05$ & $p>0,05$ \\
\hline vs. $2,5 \mathrm{mM} 2-\mathrm{DG}+5 \mu \mathrm{M}$ CB-839 & $p<0,0001$ & $p>0,05$ & $p<0,001$ & $p<0,05$ \\
\hline vs. $1 \mu \mathrm{M} 4-\mathrm{OHT}+2,5 \mathrm{mM} 2-\mathrm{DG}+5 \mu \mathrm{M}$ CB-839 & $p<0,0001$ & $p>0,05$ & $p<0,0001$ & $p<0,0001$ \\
\hline \multicolumn{5}{|l|}{$5 \mu \mathrm{M}$ CB-839 } \\
\hline vs. $1 \mu \mathrm{M}$ 4-OHT + 2,5 mM 2-DG & $p>0,05$ & $\mathrm{p}<0,0001$ & $p>0,05$ & $p>0,05$ \\
\hline vs. $1 \mu \mathrm{M}$ 4-OHT + $5 \mu \mathrm{M}$ CB-839 & $p>0,05$ & $\mathrm{p}<0,001$ & $p>0,05$ & $p>0,05$ \\
\hline vs. $2,5 \mathrm{mM} 2-\mathrm{DG}+5 \mu \mathrm{M}$ CB-839 & $p<0,001$ & $p<0,0001$ & $p<0,0001$ & $\mathrm{p}<0,001$ \\
\hline vs. $1 \mu \mathrm{M}$ 4-OHT + 2,5 mM 2-DG + $5 \mu \mathrm{M}$ CB-839 & $p<0,0001$ & $p<0,0001$ & $p<0,0001$ & $p<0,0001$ \\
\hline \multicolumn{5}{|l|}{$1 \mu \mathrm{M}$ 4-OHT + 2,5 mM 2-DG } \\
\hline vs. $1 \mu \mathrm{M}$ 4-OHT + $5 \mu \mathrm{M}$ CB-839 & $p>0,05$ & $p<0,05$ & $p>0,05$ & $p>0,05$ \\
\hline vs. $2,5 \mathrm{mM} 2-\mathrm{DG}+5 \mu \mathrm{M}$ CB-839 & $p<0,001$ & $p<0,05$ & $p<0,0001$ & $p<0,001$ \\
\hline vs. $1 \mu \mathrm{M}$ 4-OHT + 2,5 mM 2-DG + $5 \mu \mathrm{M}$ CB-839 & $p<0,0001$ & $p<0,01$ & $p<0,0001$ & $p<0,0001$ \\
\hline \multicolumn{5}{|l|}{$1 \mu \mathrm{M}$ 4-ОНТ + $5 \mu \mathrm{M}$ CB-839 } \\
\hline vs. $2,5 \mathrm{mM} 2-\mathrm{DG}+5 \mu \mathrm{M}$ CB-839 & $\mathrm{p}<0,01$ & $p<0,0001$ & $p<0,001$ & $\mathrm{p}<0,01$ \\
\hline vs. $1 \mu \mathrm{M} 4-\mathrm{OHT}+2,5 \mathrm{mM}$ 2-DG + $5 \mu \mathrm{M}$ CB-839 & $p<0,0001$ & $p<0,0001$ & $p<0,0001$ & $p<0,0001$ \\
\hline \multicolumn{5}{|l|}{ 2,5 mM 2-DG + $5 \mu \mathrm{M}$ CB-839 } \\
\hline vs. $1 \mu \mathrm{M}$ 4-OHT + 2,5 mM 2-DG + $5 \mu \mathrm{M}$ CB-839 & $p>0,05$ & $p>0,05$ & $p>0,05$ & $p<0,05$ \\
\hline
\end{tabular}




\subsection{Untersuchung der Apoptoseinduktion}

Im nächsten Schritt sollte untersucht werden, auf welchem Mechanismus die Viabilitätsminderungen der vier Zelllinien unter den verschiedenen Behandlungen beruhten. Dies erfolgte mit Hilfe des JC-1 Mitochondrial Membrane Potential Detection Assay, mit dessen Hilfe sich das Zusammenbrechen des mitochondrialen Membranpotentials, eines der ersten Schritte der Apoptose, darstellen lassen.

Die Zelllinien wurden gleichermaßen in JC-1-Medium ausgesät und nach $24 \mathrm{~h}$ durch ein mit den Versuchssubstanzen versetztem Medium therapiert (Vgl. 2.2.2.2). Dazu zählten die Substanzen 4-OHT (1 $\mu \mathrm{M}), 2$-DG $(2,5 \mathrm{mM})$ und CB-839 (5 $\mu \mathrm{M})$ (Vgl. 2.1.8). Nach $48 \mathrm{~h}$ Inkubation erfolgte die spektralphotometrische Messung im Multidetection Reader. Als Kontrolle diente reines Medium. Es erfolgten mindestens drei unabhängige Experimente mit drei verschiedenen Passagen. Signifikanzen wurden mittels One-way ANOVA im Turkey's multiple comparisons test ermittelt. Angegeben sind $\mathrm{MW}$ und $\pm \mathrm{SEM}, \mathrm{N}=5$ biologische Replikate.

\subsubsection{MCF7}

Die Kombinationstherapie aus 4-OHT und 2-DG zeigte eine signifikante Herunterregulierung des mitochondrialen Membranpotentials im Vergleich zur Kontrolle und der Einzelbehandlung mit 4-OHT (MCF7, 5 M 4-OHT + 2,5 mM 2-DG: 0,5673 $\pm 0,0547, \mathrm{~N}=5, \mathrm{p}<0,001$ vs. Kontrolle; $\mathrm{p}<0,05$ vs. $1 \mu \mathrm{M}$ 4-OHT). Unter der Kombinationsbehandlung, bestehend aus den beiden Metabolismus-Inhibitoren 2-DG und CB-839, zeigte sich eine signifikant stärkere Hemmung des mitochondrialen Membranpotentials im Vergleich zur unbehandelten Kontrolle (MCF7, 2,5 mM 2-DG + $5 \mu \mathrm{M}$ CB-839: 0,624 $\pm 0,05897, \quad \mathrm{~N}=5, \mathrm{p}<0,01$ vs. Kontrolle). Die Kombinationsbehandlung aus allen drei Wirkstoffen präsentierte eine signifikant stärkere Hemmung auf das mitochondriale Membranpotential verglichen mit der unbehandelten Kontrolle und der alleinigen 4-OHT-Therapie (MCF7, $5 \mu \mathrm{M}$ 4-OHT + 2,5 mM 2-DG + $5 \mu \mathrm{M}$ CB-839: 0,5299 $\pm 0,05818, N=5, p<0,001$ vs. Kontrolle; $p<0,01$ vs. $1 \mu M$ 4-OHT). 


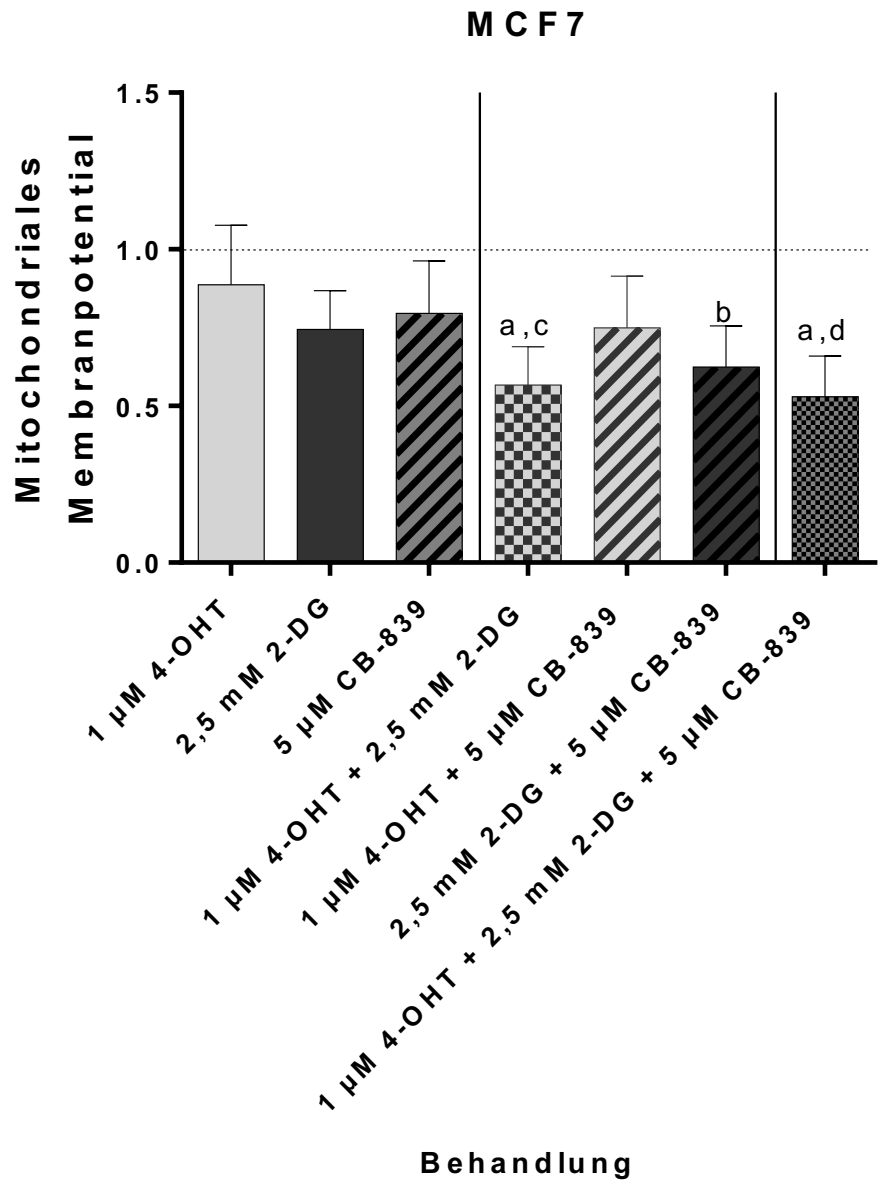

Abbildung 17: Apoptoseinduktion der Mammakarzinomzelllinie MCF7

Behandelt wurde über $48 \mathrm{~h}$ mit unterschiedlichen Konzentrationen an 4-OHT, 2-DG und CB-839 (Kontrolle: unbehandelt). Die apoptoseinduzierende Wirkung wurde mittels JC-1-Assay im Multidetection Reader ermittelt. Signifikanzen wurden mittels One-way ANOVA im Turkey's multiple comparisons test ermittelt.

$a, p<0,001$ vs. Kontrolle; $b, p<0,01$ vs. Kontrolle; c, $p<0,05$ vs. 1 MM 4-OHT; d, p<0,01 vs. 1 MM 4-OHT.

\subsubsection{MCF7-TR}

Bei der MCF7-TR-Zelllinie zeigte sich eine signifikante hemmende Wirkung auf das mitochondriale Membranpotential unter den viabilitätshemmenden Therapien aus der Kombinationsbehandlung 4-OHT und 2-DG, und den beiden Metabolismus-Inhibitoren (2-DG und CB-839) im Vergleich zur unbehandelten Kontrolle (MCF7-TR, 1 MM 4-OHT + 2,5 mM 2-DG: 0,6551 \pm 0,05207, N=5, p<0,05 vs. Kontrolle. MCF7-TR, 2,5 mM 2-DG + $5 \mu$ M CB-839: 0,5587 \pm $0,1049, N=5, p<0,01$ vs. Kontrolle).

Die Dreifach-Kombination, bestehend aus 4-OHT, 2-DG und CB-839 bewirkte eine signifikante Hemmung des mitochondrialen Membranpotentials im Vergleich zur unbehandelten Kontrolle und der alleinigen 2-DG-Therapie (MCF7-TR, $1 \mu \mathrm{M}$ 4-OHT + 2,5 mM 2-DG + $5 \mu \mathrm{M}$ CB-839: 0,5058 $\pm 0,1022, N=5, p<0,01$ vs. Kontrolle; $p<0,05$ vs. 2,5 mM 2-DG). 


\section{C F 7-TR}

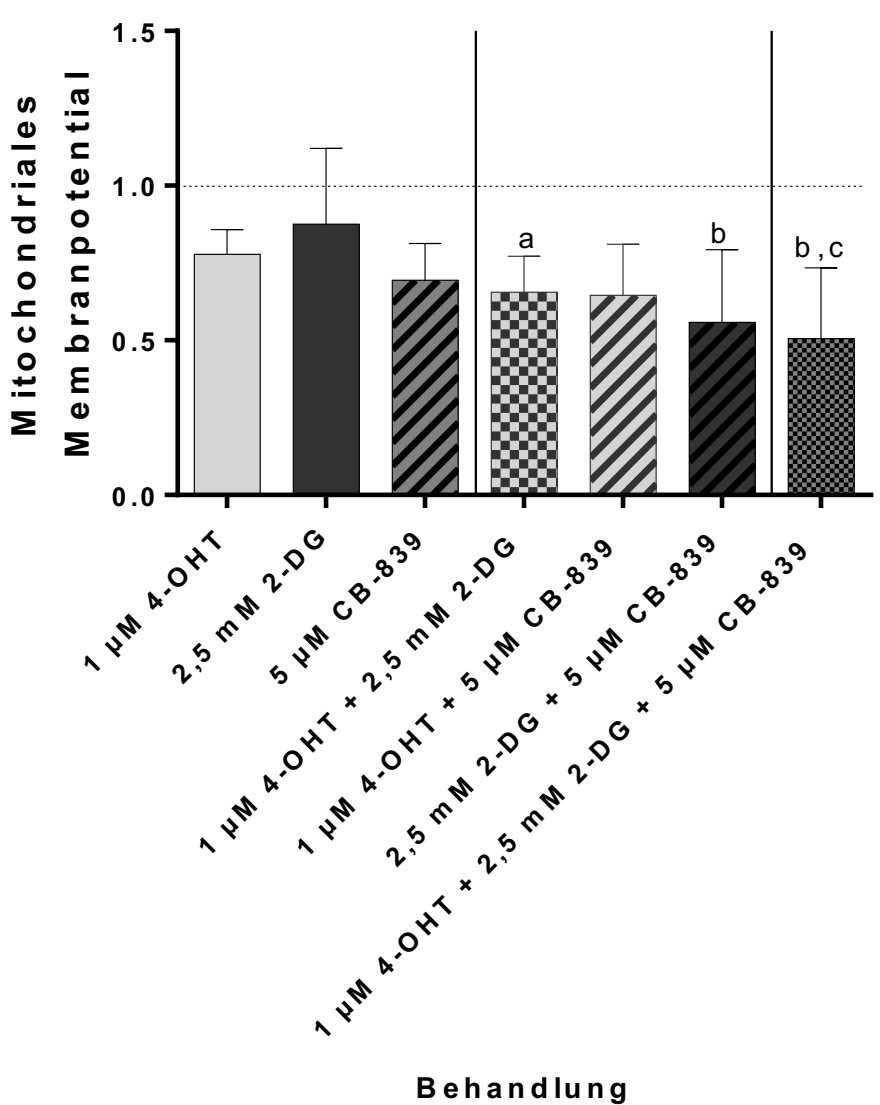

Abbildung 18: Apoptoseinduktion der Mammakarzinomzelllinie MCF7-TR

Behandelt wurde über $48 \mathrm{~h}$ mit unterschiedlichen Konzentrationen an 4-OHT, 2-DG und CB-839 (Kontrolle: unbehandelt). Die apoptoseinduzierende wurde mittels JC-1-Assay im Multidetection Reader ermittelt. Signifikanzen wurden mittels One-way ANOVA im Turkey's multiple comparisons test ermittelt.

$a, p<0,05$ vs. Kontrolle; $b, p<0,01$ vs. Kontrolle; $c, p<0,05$ vs. 5 mM 2-DG.

\subsubsection{T47D}

Es zeigte sich bei der T47D-Zelllinie, dass das mitochondriale Membranpotential bei den Behandlungen mit 4-OHT alleine und bei den Kombinationsbehandlungen 2-DG/CB-839 und 4-OHT/2-DG/CB-839 signifikant niedriger war im Vergleich zur unbehandelten Kontrolle

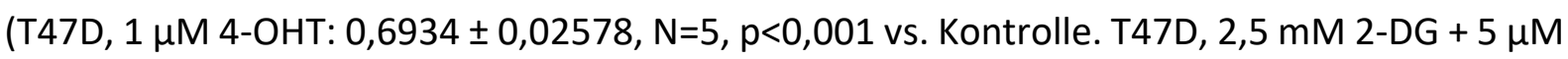
CB-839: 0,6853 \pm 0,06021, $\mathrm{N}=5, \mathrm{p}<0,001$ vs. Kontrolle. T47D, $1 \mu \mathrm{M}$ 4-OHT + 2,5 mM 2-DG + $5 \mu \mathrm{M}$ CB-839: 0,6511 $\pm 0,06221, N=5, p<0,001$ vs. Kontrolle). Die Kombinationsbehandlung 4-OHT/2-DG ergab eine signifikante Inhibition des mitochondrialen Membranpotentials verglichen zur Kontrolle, zur alleinigen 2-DG-Therapie und zur Kombinationsbehandlung 4-OHT/CB-839 (T47D, $1 \mu \mathrm{M}$ 4-OHT + 2,5 mM 2-DG: 0,5627 $\pm 0,02448, N=5, p<0,0001$ vs. Kontrolle; $p<0,001$ vs. 2,5 mM 2-DG; $p<0,05$ vs. $1 \mu \mathrm{M}$ 4-OHT+5 $\mu \mathrm{M}$ CB-839). 
T 47 D

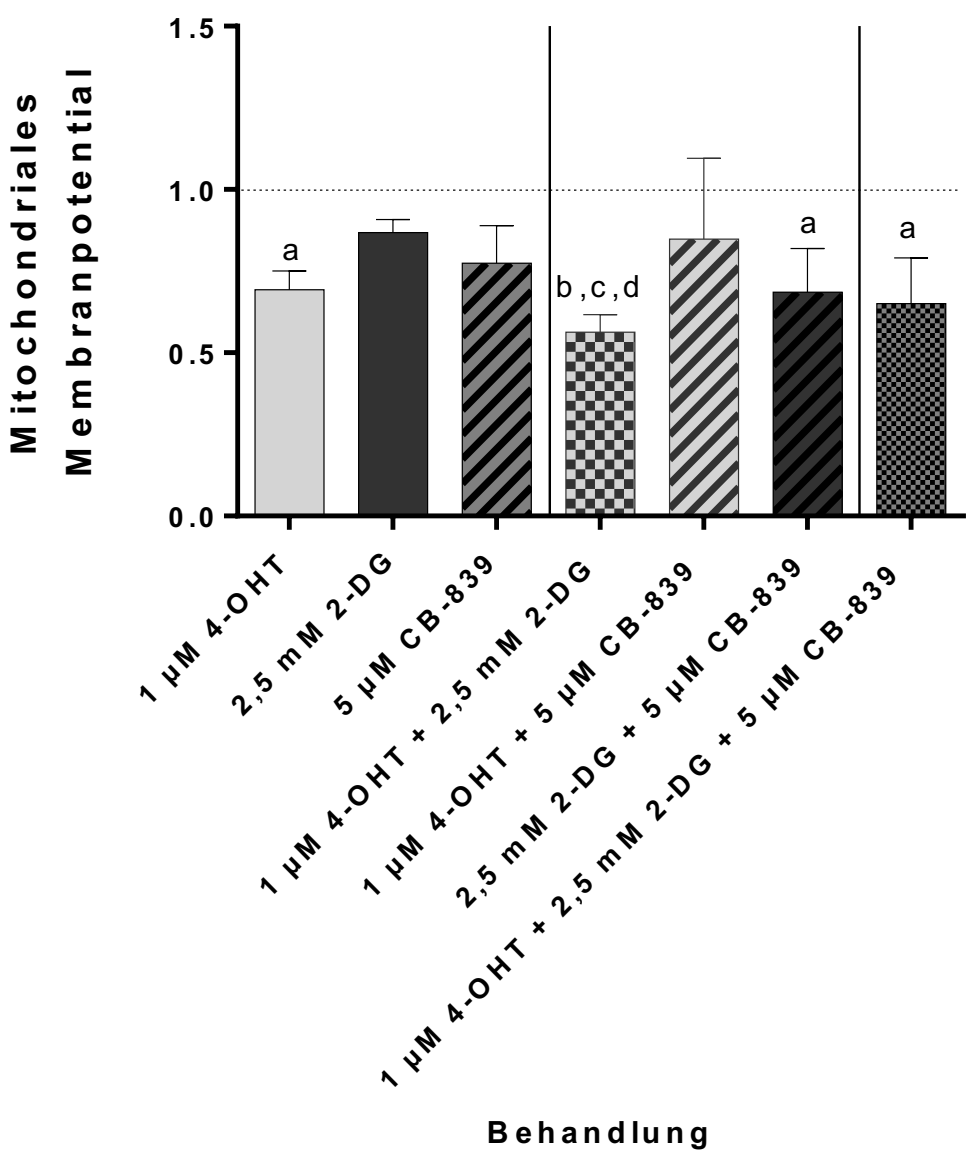

Abbildung 19: Apoptoseinduktion der Mammakarzinomzellinie T47D

Behandelt wurde über $48 \mathrm{~h}$ mit unterschiedlichen Konzentrationen an 4-OHT, 2-DG und CB-839 (Kontrolle: unbehandelt). Die apoptoseinduzierende Wirkung wurde mittels JC-1-Assay im Multidetection Reader ermittelt. Signifikanzen wurden mittels One-way ANOVA im Turkey's multiple comparisons test ermittelt.

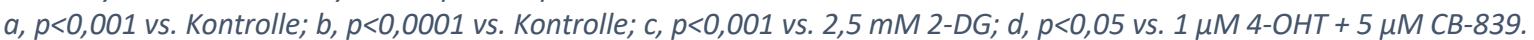

\subsubsection{T47D-TR}

Bei der T47D-TR-Zelllinie zeigte sich eine signifikante Reduktion des mitochondrialen Membranpotentials unter der alleinigen 4-OHT-Therapie im Vergleich zur unbehandelten Kontrolle (T47D-TR, $1 \mu \mathrm{M}$ 4-OHT: 0,7344 $\pm 0,02138, \mathrm{~N}=5, \mathrm{p}<0,01$ vs. Kontrolle). Unter der alleinigen 2-DG-Therapie zeigte sich eine signifikante Reduktion verglichen zur unbehandelten Kontrolle und zur alleinigen CB-839-Therapie (T47D-TR, 2,5 mM 2-DG: 0,6977 \pm 0,04008, N=5, $p<0,01$ vs. Kontrolle; $p<0,05$ vs. $5 \mu \mathrm{M}$ CB-839). Die Kombinationsbehandlung 4-OHT/2-DG führte zu einer signifikanten Inhibition des mitochondrialen Membranpotentials im Vergleich zur Kontrolle, zu der Einzelbehandlung mit 4-OHT bzw. mit CB-839 sowie zu der Kombinationsbehandlung mit 4-OHT/CB-839 (T47D-TR, $1 \mu \mathrm{M}$ 4-OHT + 2,5 mM 2-DG: 
$0,4975 \pm 0,01446, N=5, p<0,0001$ vs. Kontrolle; $p<0,05$ vs. $1 \mu \mathrm{M} 4-\mathrm{OHT} ; \mathrm{p}<0,0001$ vs. $5 \mu \mathrm{M}$ CB-839; $p<0,0001$ vs. $1 \mu \mathrm{M}$ 4-OHT + $5 \mu \mathrm{M}$ CB-839). Eine signifikante Reduktion verglichen mit der Kontrolle, der CB-839-Therapie und der 4-OHT/CB-839-Therapie bewirkte die Kombinationsbehandlung bestehend aus den beiden Metabolismus-Inhibitoren 2-DG und CB-839 (T47D-TR, 2,5 mM 2-DG + $5 \mu$ M CB-839: 0,6533 \pm 0,03355, N=5, $p<0,001$ vs. Kontrolle; p<0,01 vs. $5 \mu \mathrm{M}$ CB-839; $\mathrm{p}<0,05$ vs. $1 \mu \mathrm{M}$ 4-OHT $+5 \mu \mathrm{M}$ CB-839). Die Kombination aus allen drei Wirkstoffen 4-OHT, 2-DG und CB-839 führte zu einer Reduktion des mitochondrialen Membranpotentials im Vergleich zur Kontrolle, der CB-839-Therapie und der 4-OHT/CB-839-Therapie (T47D-TR, $1 \mu \mathrm{M}$ 4-OHT + 2,5 mM 2-DG + $5 \mu \mathrm{M}$ CB-839: 0,6533 \pm 0,03355, $N=5, p<0,0001$ vs. Kontrolle; $p<0,001$ vs. $5 \mu \mathrm{M}$ CB-839; $\mathrm{p}<0,01$ vs. $1 \mu \mathrm{M} 4-\mathrm{OHT}+5 \mu \mathrm{M}$ CB-839).

\section{T 47 D - T R}

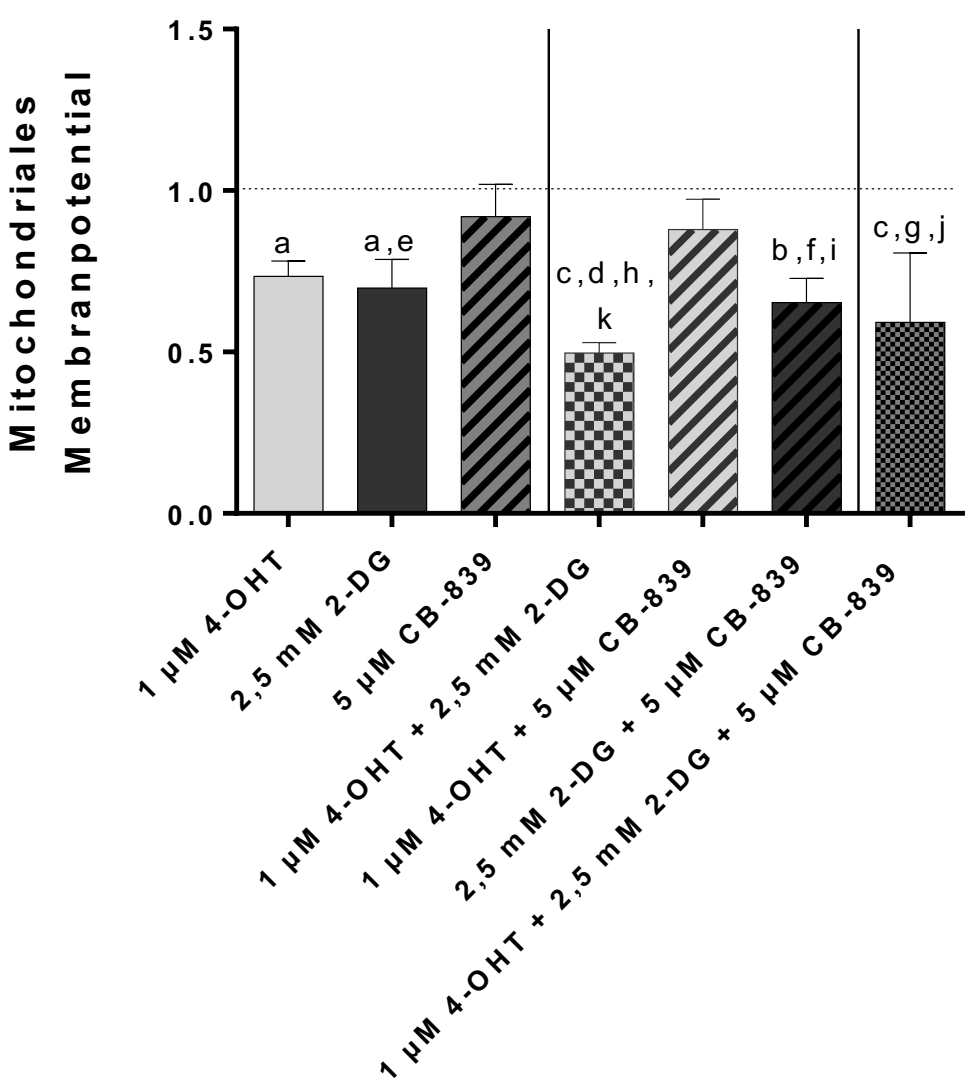

Behandlung

\section{Abbildung 20: Apoptoseinduktion der Mammakarzinomzelllinie T47D-TR}

Behandelt wurde über $48 \mathrm{~h}$ mit unterschiedlichen Konzentrationen an 4-OHT, 2-DG und CB-839 (Kontrolle: unbehandelt). Die apoptoseinduzierende Wirkung wurde mittels JC-1-Assay im Multidetection Reader ermittelt. Signifikanzen wurden mittels One-way ANOVA im Turkey's multiple comparisons test ermittelt. Angegeben sind MW und \pm SEM, N=5 biologische Replikate.

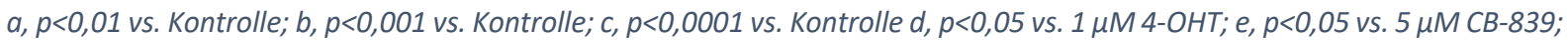

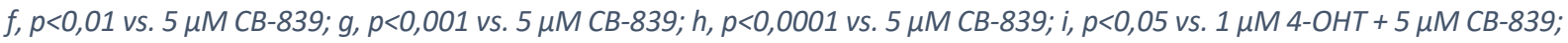
j, $p<0,01$ vs. $1 \mu M$ 4-OHT + $5 \mu M C B-839 ; k, p<0,0001$ vs. $1 \mu M$ 4-OHT + $5 \mu M$ CB-839. 
Tabelle 26: Statistische Auswertung des JC-1-Assays unter Kombinationsbehandlungen

\begin{tabular}{|c|c|c|c|c|}
\hline $\begin{array}{l}\text { One-way-ANOVA mit } \\
\text { Turkey's multiple test }\end{array}$ & MCF7 & MCF7-TR & T47D & T47D-TR \\
\hline \multicolumn{5}{|l|}{ Kontrolle } \\
\hline vs. $1 \mu \mathrm{M} 4-\mathrm{OHT}$ & $p>0,05$ & $p>0,05$ & $p<0,01$ & $p<0,01$ \\
\hline vs. $2,5 \mathrm{mM}$ 2-DG & $p>0,05$ & $p>0,05$ & $p>0,05$ & $p<0,01$ \\
\hline vs. $5 \mu \mathrm{M}$ CB-839 & $p>0,05$ & $p>0,05$ & $p>0,05$ & $p>0,05$ \\
\hline vs. $1 \mu \mathrm{M}$ 4-OHT + 2,5 mM 2-DG & $p<0,001$ & $p>0,05$ & $p<0,0001$ & $p<0,0001$ \\
\hline vs. $1 \mu \mathrm{M} 4-\mathrm{OHT}+5 \mu \mathrm{M}$ CB-839 & $p>0,05$ & $p<0,05$ & $p>0,05$ & $p>0,05$ \\
\hline vs. $2,5 \mathrm{mM} 2-\mathrm{DG}+5 \mu \mathrm{M}$ CB-839 & $p<0,01$ & $p<0,01$ & $p<0,01$ & $p<0,001$ \\
\hline vs. $1 \mu \mathrm{M}$ 4-OHT + 2,5 mM 2-DG + $5 \mu \mathrm{M}$ CB-839 & $p<0,001$ & $p<0,01$ & $p<0,01$ & $p<0,0001$ \\
\hline \multicolumn{5}{|l|}{$1 \mu \mathrm{M}$ 4-OHТ } \\
\hline vs. $2,5 \mathrm{mM} 2-\mathrm{DG}$ & $p>0,05$ & $p>0,05$ & $p>0,05$ & $p>0,05$ \\
\hline vs. 5 нM CB-839 & $p>0,05$ & $p>0,05$ & $p>0,05$ & $p>0,05$ \\
\hline vs. $1 \mu \mathrm{M}$ 4-OHT + 2,5 mM 2-DG & $p<0,05$ & $p>0,05$ & $p>0,05$ & $p<0,05$ \\
\hline vs. $1 \mu \mathrm{M}$ 4-OHT + $5 \mu \mathrm{M}$ CB-839 & $p>0,05$ & $p>0,05$ & $p>0,05$ & $p>0,05$ \\
\hline vs. $2,5 \mathrm{mM} 2-\mathrm{DG}+5 \mu \mathrm{M}$ CB-839 & $p>0,05$ & $p>0,05$ & $p>0,05$ & $p>0,05$ \\
\hline vs. $1 \mu \mathrm{M}$ 4-OHT + 2,5 mM 2-DG + $5 \mu \mathrm{M}$ CB-839 & $p<0,01$ & $p>0,05$ & $p>0,05$ & $p>0,05$ \\
\hline \multicolumn{5}{|l|}{ 2,5 mM 2-DG } \\
\hline vs. $5 \mu \mathrm{M}$ CB-839 & $p>0,05$ & $p>0,05$ & $p>0,05$ & $p<0,05$ \\
\hline vs. $1 \mu \mathrm{M}$ 4-OHT + 2,5 mM 2-DG & $p>0,05$ & $p>0,05$ & $p<0,01$ & $p>0,05$ \\
\hline vs. $1 \mu \mathrm{M}$ 4-OHT + $5 \mu \mathrm{M}$ CB-839 & $p>0,05$ & $p>0,05$ & $p>0,05$ & $p>0,05$ \\
\hline vs. 2,5 mM 2-DG + $5 \mu \mathrm{M}$ CB-839 & $p>0,05$ & $p>0,05$ & $p>0,05$ & $p>0,05$ \\
\hline  & $p>0,05$ & $p<0,05$ & $p<0,05$ & $p>0,05$ \\
\hline \multicolumn{5}{|l|}{5 нM CB-839 } \\
\hline vs. $1 \mu \mathrm{M}$ 4-OHT + 2,5 mM 2-DG & $p>0,05$ & $p>0,05$ & $p>0,05$ & $p<0,0001$ \\
\hline vs. $1 \mu \mathrm{M}$ 4-OHT + $5 \mu \mathrm{M}$ CB-839 & $p>0,05$ & $p>0,05$ & $p>0,05$ & $p>0,05$ \\
\hline vs. $2,5 \mathrm{mM}$ 2-DG + $5 \mu \mathrm{M}$ CB-839 & $p>0,05$ & $p>0,05$ & $p>0,05$ & $p<0,01$ \\
\hline vs. $1 \mu \mathrm{M}$ 4-OHT + 2,5 mM 2-DG + $5 \mu \mathrm{M}$ CB-839 & $p>0,05$ & $p>0,05$ & $p>0,05$ & $p<0,001$ \\
\hline \multicolumn{5}{|l|}{$1 \mu \mathrm{M}$ 4-OHT + 2,5 mM 2-DG } \\
\hline vs. $1 \mu \mathrm{M}$ 4-OHT + $5 \mu \mathrm{M}$ CB-839 & $p>0,05$ & $p>0,05$ & $p<0,05$ & $p<0,0001$ \\
\hline vs. $2,5 \mathrm{mM}$ 2-DG + $5 \mu \mathrm{M}$ CB-839 & $p>0,05$ & $p>0,05$ & $p>0,05$ & $p>0,05$ \\
\hline vs. $1 \mu \mathrm{M}$ 4-OHT + 2,5 mM 2-DG + 5 M CB-839 & $p>0,05$ & $p>0,05$ & $p>0,05$ & $p>0,05$ \\
\hline \multicolumn{5}{|l|}{$1 \mu \mathrm{M}$ 4-ОНТ + $5 \mu \mathrm{M}$ CB-839 } \\
\hline vs. 2,5 mM 2-DG + $5 \mu \mathrm{M}$ CB-839 & $p>0,05$ & $p>0,05$ & $p>0,05$ & $p<0,05$ \\
\hline 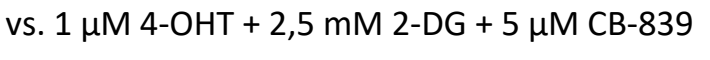 & $p>0,05$ & $p>0,05$ & $p>0,05$ & $p<0,01$ \\
\hline \multicolumn{5}{|l|}{ 2,5 mM 2-DG + $5 \mu \mathrm{M}$ CB-839 } \\
\hline vs. $1 \mu \mathrm{M}$ 4-OHT + 2,5 mM 2-DG + $5 \mu \mathrm{M}$ CB-839 & $p>0,05$ & $p>0,05$ & $p>0,05$ & $p>0,05$ \\
\hline
\end{tabular}




\section{3 Überprüfung der c-Myc Aktivität}

Um genauer zu untersuchen, wie sich das Proto-Onkogen c-Myc unter den unterschiedlichen Behandlungen verhält, wurde die c-Myc-Expression mittels Western-Blot ermittelt. Hierfür wurden die vier Zelllinien MCF7, MCF7-TR, T47D und T47D-TR $24 \mathrm{~h}$ nach dem Aussäen für $48 \mathrm{~h}$ mit den Wirkstoffen 4-OHT (1 $\mu \mathrm{M})$, 2-DG $(5 \mathrm{mM})$ und $\mathrm{CB}-839(10 \mu \mathrm{M})$ bzw. mit der Kombination aus den jeweiligen Wirkstoffen behandelt.

Als Proteinkontrolle diente GAPDH.

Signifikanzen wurden mittels One-way ANOVA im Turkey's multiple comparisons test ermittelt. Angegeben sind MW und $\pm \mathrm{SEM}, \mathrm{N}=3$ biologische Replikate.

\subsection{1 c-Myc-Expression im Vergleich}

Zunächst wurde überprüft, inwiefern c-Myc von den vier unbehandelten Zelllinien MCF7, MCF7-TR, T47D und T47D-TR im Vergleich zueinander exprimiert wurde.

Die TR-Zelllinien zeigten im Vergleich zu ihren parenteralen Zelllinien eine stärkere c-Myc-Expression, wobei diese bei der MCF7-TR-Zelllinie im Vergleich zur parenteralen MCF7-Zelllinie nicht signifikant war. Allerdings zeigte sich eine signifikant stärkere c-Myc-Expression bei der T47D-TR-Zelllinie im Vergleich zu der parenteralen T47D-Zelllinie (T47D-TR, 411,6 $\pm 77,82, p<0,05$ vs. T47D). 
A

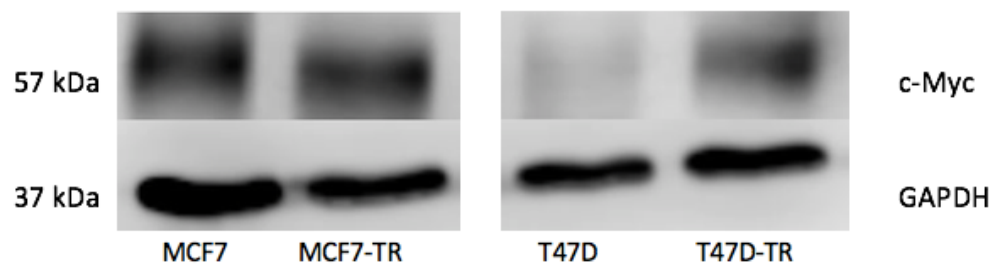

B

Vergleich MCF 7/MCF 7-TR



Vergleich T47D/T 47D-TR

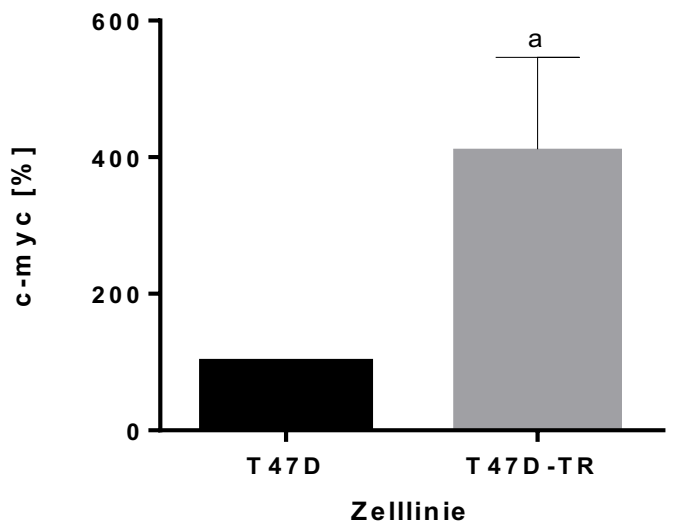

Abbildung 21:

A: Western-Blot-Analyse von c-Myc bei den Mammakarzinomzelllinien MCF7, MCF7-TR, T47D und T47D-TR. Die Zelllinien waren alle unbehandelt, verglichen wurde die c-Myc-Expression im Vergleich zwischen parenteraler (als Kontrolle) und Tamoxifen-resistenter Zelllinie. Die Detektion erfolgte mittels Western-Blot.

B: Quantitative Analyse der c-Myc-Expression

a, $p<0,01$ vs. T47D. $N=3$ 


\subsubsection{MCF7}

Eine signifikante Herunterregulierung des c-Mycs bei der MCF7-Zelllinie konnte unter allen verschiedenen Behandlungen im Vergleich zur Kontrolle nachgewiesen werden (MCF7, $1 \mu \mathrm{M}$ 4-OHT: $15,3 \pm 3,991, N=4, p<0,0001$ vs. Kontrolle. MCF7, 2,5 mM 2-DG: 44,76 $\pm 17,06, N=4$, p<0,01 vs. Kontrolle. MCF7, 5 MM CB-839: 21,42 $\pm 2,657, N=4, p<0,001$ vs. Kontrolle. MCF7, $1 \mu \mathrm{M}$ 4-OHT + 2,5 mM 2-DG: 34,86 \pm 18,03, N=4, p<0,01 vs. Kontrolle. MCF7, $1 \mu \mathrm{M} 4-\mathrm{OHT}+$

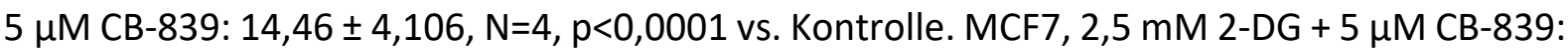


$7,541 \pm 3,268, N=4, p<0,0001$ vs. Kontrolle). 
A

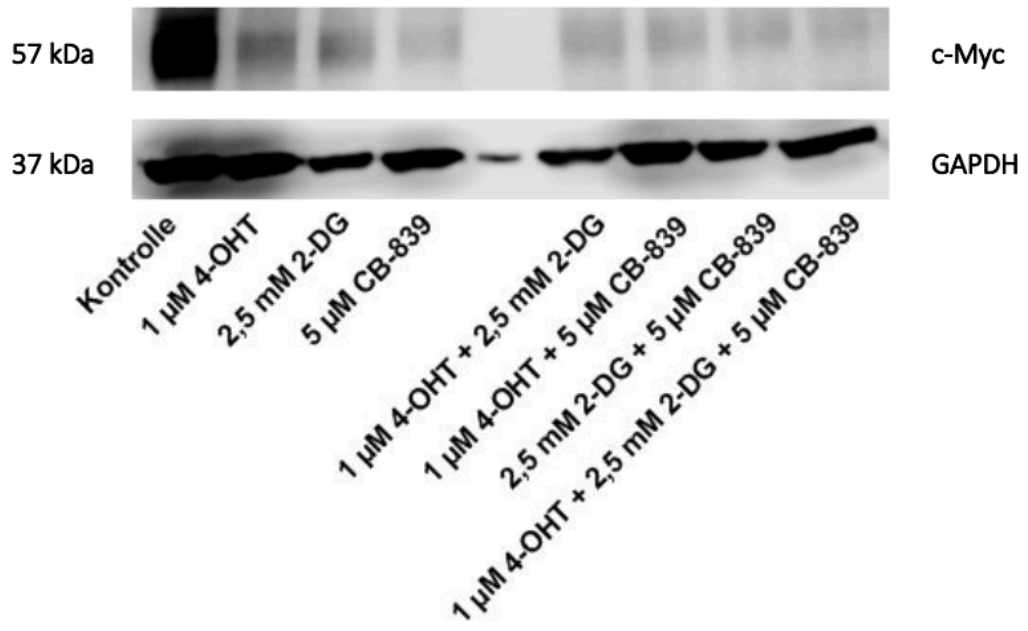

B

\section{C F 7}

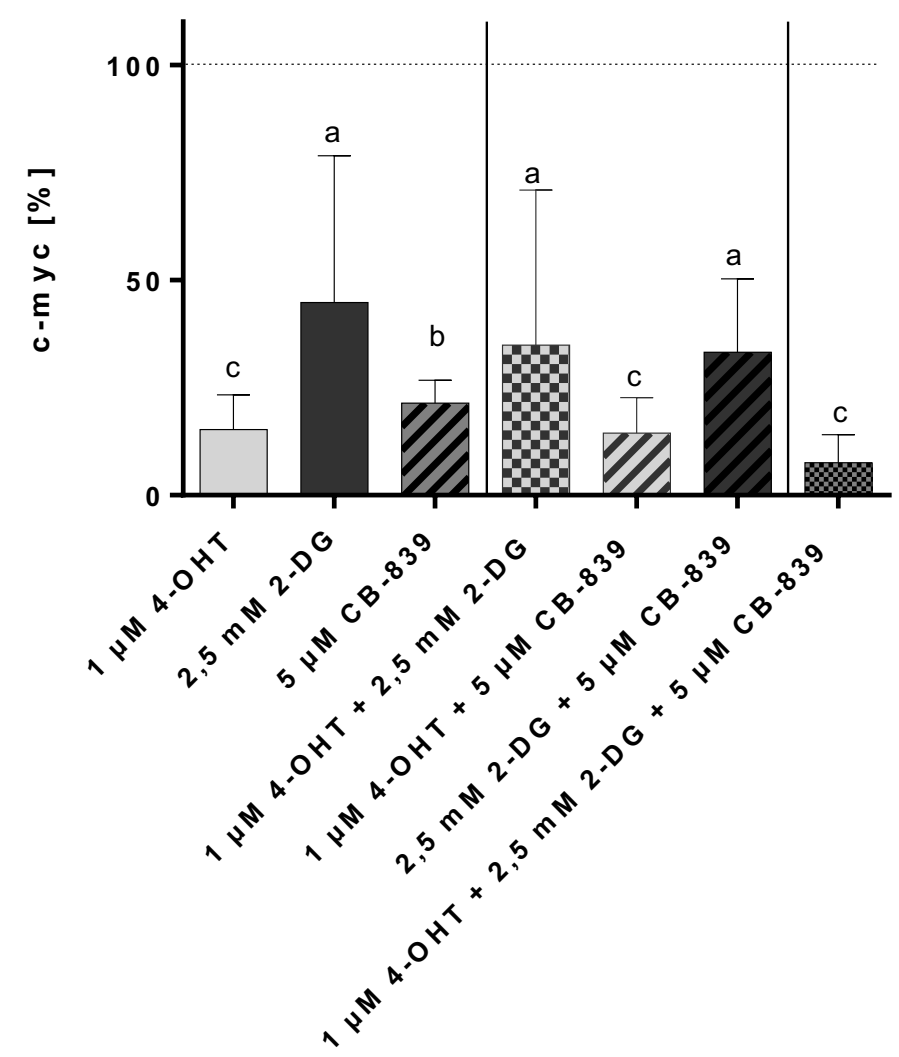

Behandlung

Abbildung 22:

A: Western-Blot-Analyse von c-Myc bei der Mammakarzinomzelllinie MCF7

Behandelt wurde über $48 \mathrm{~h}$ mit unterschiedlichen Konzentrationen an 4-OHT, 2-DG und CB-839 (Kontrolle: unbehandelt). Die anschließende Detektion erfolgte mittels Western-Blot.

B: Quantitative Analyse der Effekte der einzelnen Behandlungen auf c-Myc

$a, p<0,01$ vs. Kontrolle; $b, p<0,001$ vs. Kontrolle; $c, p<0,0001$ vs. Kontrolle. $N=3$ 


\subsubsection{MCF7-TR}

Eine signifikante Herunterregulierung des c-Mycs bei der MCF7-TR-Zelllinie konnte unter den Kombinationsbehandlungen im Vergleich zur Kontrolle und der alleinigen 4-OHT-Therapie gezeigt werden (MCF7-TR, $1 \mu \mathrm{M}$ 4-OHT + 2,5 mM 2-DG: 40,33 \pm 15,96, N=3, p<0,05 vs. Kontrolle; p<0,05 vs. $1 \mu \mathrm{M}$ 4-OHT. MCF7-TR, $1 \mu \mathrm{M}$ 4-OHT + $5 \mu \mathrm{M}$ CB-839: 27,67 \pm 5,548, N=3,

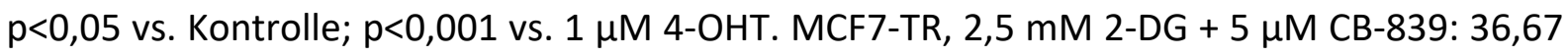
$\pm 13,2, N=3, p<0,05$ vs. Kontrolle; $p<0,001$ vs. $1 \mu \mathrm{M}$ 4-OHT. MCF7-TR, $1 \mu \mathrm{M} 4-\mathrm{OHT}+2,5 \mathrm{mM}$ 2-DG + $5 \mu$ M CB-839: 27,67 $\pm 13,17, N=3, p<0,05$ vs. Kontrolle; $p<0,001$ vs. $1 \mu M$ 4-OHT. 
A

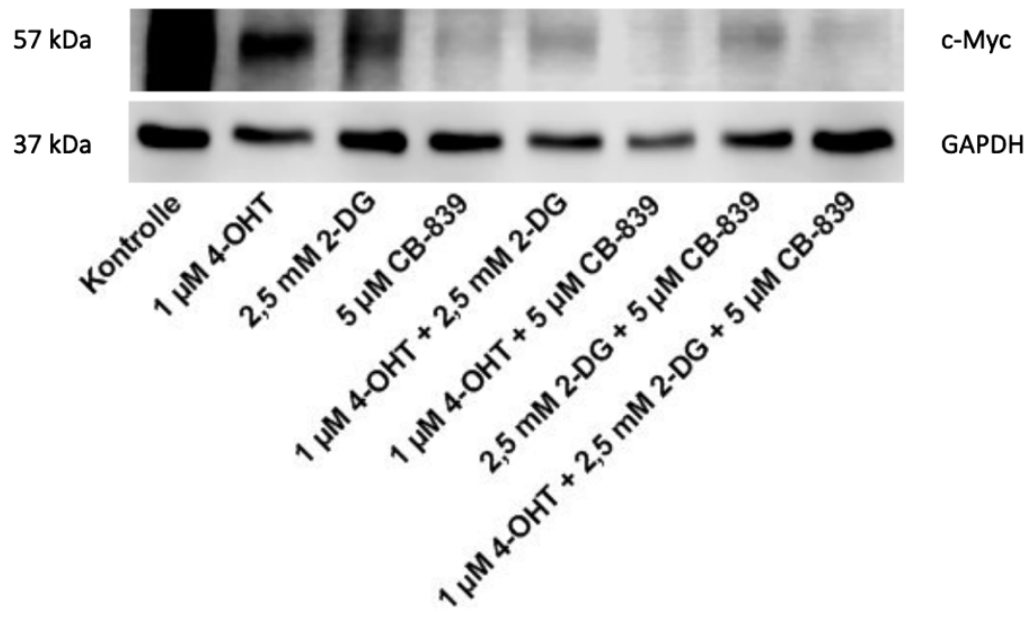

B

M C F 7-TR

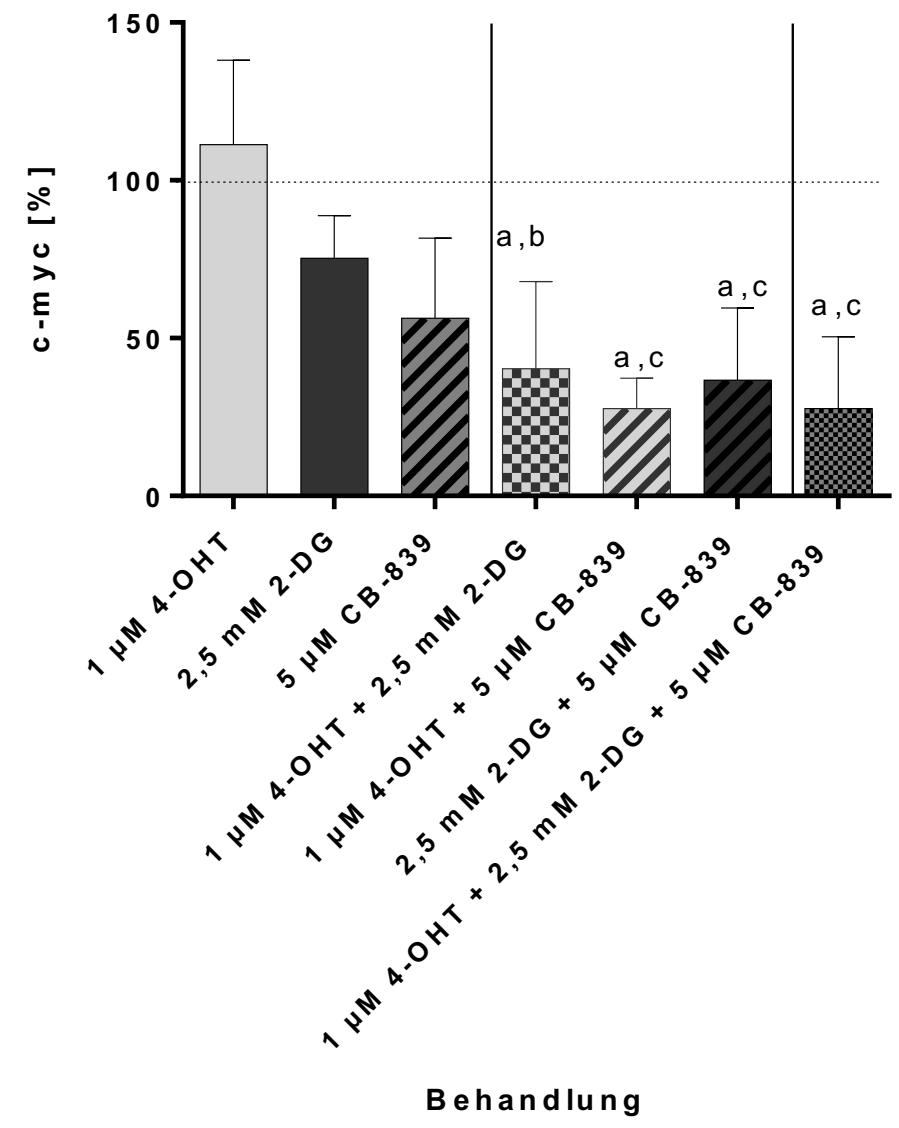

Abbildung 23:

A: Western-Blot-Analyse von c-Myc bei der Mammakarzinomzelllinie MCF7-TR

Behandelt wurde über $48 \mathrm{~h}$ mit unterschiedlichen Konzentrationen an 4-OHT, 2-DG und CB-839 (Kontrolle: unbehandelt). Die anschließende Detektion erfolgte mittels Western-Blot.

$B:$ Quantitative Analyse der Effekte der einzelnen Behandlungen auf c-Myc

$a, p<0,05$ vs. Kontrolle; $b, p<0,05$ vs. 1 MM 4-OHT; c, $p<0,001$ vs. $1 \mu \mathrm{M} 4-\mathrm{OHT}$. N=3 


\subsubsection{T47D}

Bei der T47D-Zelllinie konnte ebenfalls eine signifikante Herunterregulierung des c-Mycs im Vergleich zur unbehandelten Kontrolle beobachtet werden (T47D, $1 \mu \mathrm{M}$ 4-OHT + $5 \mu \mathrm{M}$ CB-839:

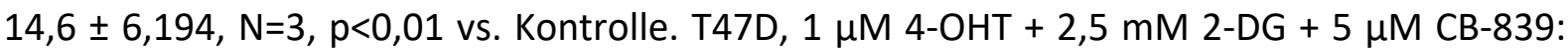
$22,6 \pm 3,669, N=3, p<0,01$ vs. Kontrolle). 
A



c-Myc

GAPDH

B

T 47 D

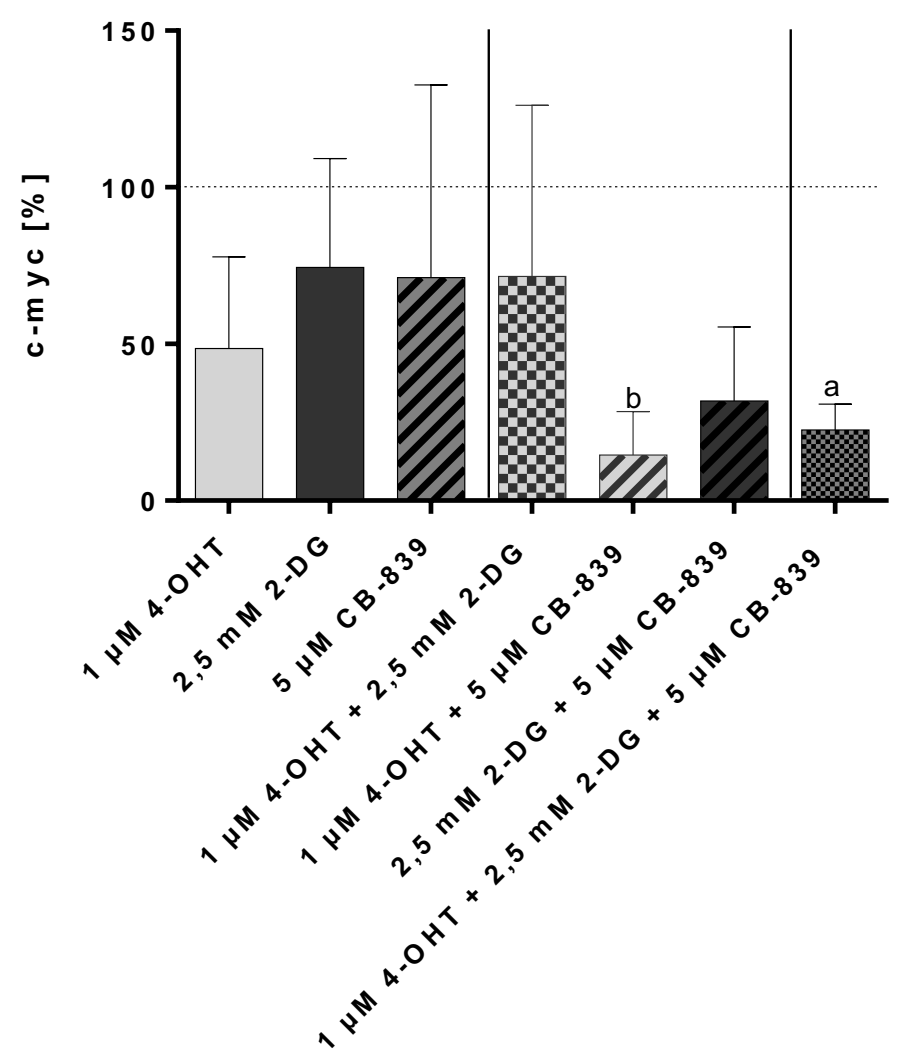

Behandlung

Abbildung 24:

A: Western-Blot-Analyse von c-Myc bei der Mammakarzinomzelllinie T47D

Behandelt wurde über $48 \mathrm{~h}$ mit unterschiedlichen Konzentrationen an 4-OHT, 2-DG und CB-839 (Kontrolle: unbehandelt). Die anschließende Detektion erfolgte mittels Western-Blot.

B: Quantitative Analyse der Effekte der einzelnen Behandlungen auf c-Myc

$a, p<0,05$ vs. Kontrolle; $b, p<0,01$ vs. Kontrolle. $N=3$ 


\subsubsection{T47D-TR}

Bei der T47D-TR-Zelllinie konnte festgestellt werden, dass es unter der Behandlung mit CB-839 alleine und der Kombinationsbehandlung 2-DG/CB-839 zu einer Herunterregulierung des c-Mycs im Vergleich zur Kontrolle und der alleinigen 4-OHT-Therapie kam (T47D-TR, $5 \mu \mathrm{M}$ CB-839: 11,93 $\pm 4,114, \mathrm{~N}=3, \mathrm{p}<0,05$ vs. Kontrolle; $\mathrm{p}<0,01$ vs. $1 \mu \mathrm{M}$ 4-OHT. T47D-TR, 2,5 mM 2-DG + 5 MM CB-839: 9,377 $\pm 5,885, N=3, p<0,05$ vs. Kontrolle; $p<0,01$ vs. $1 \mu M$ 4-OHT).

Die Kombinationsbehandlung, bestehend aus 4-OHT und CB-839 sowie die Kombinationsbehandlung, bestehend aus allen drei Wirkstoffen bewirkten eine signifikante Herunterregulierung des c-Mycs im Vergleich zur alleinigen 4-OHT-Therapie (T47D-TR,

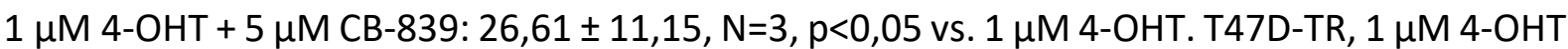
+ 2,5 mM 2-DG + $5 \mu \mathrm{M}$ CB-839: 21,98 \pm 16,99, N=3, p<0,05 vs. $1 \mu \mathrm{M}$ 4-OHT). 
A

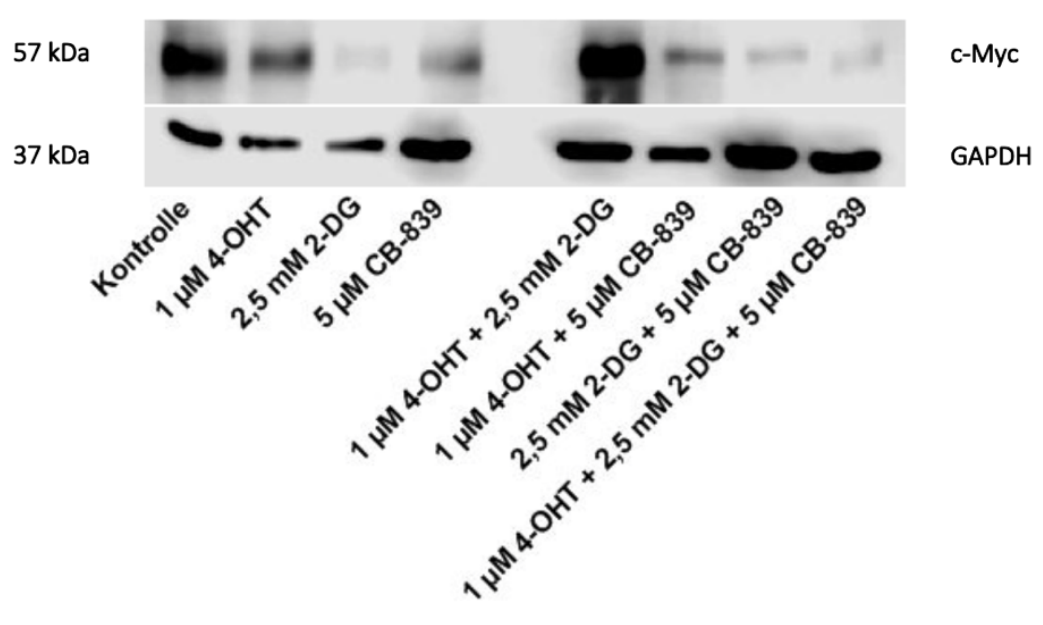

B

T 47 D - TR



Behandlung

Abbildung 25:

A: Western-Blot-Analyse von c-Myc bei der Mammakarzinomzellinie T47D-TR

Behandelt wurde über $48 \mathrm{~h}$ mit unterschiedlichen Konzentrationen an 4-OHT, 2-DG und CB-839 (Kontrolle: unbehandelt). Die anschließende Detektion erfolgte mittels Western-Blot.

$B:$ Quantitative Analyse der Effekte der einzelnen Behandlungen auf c-Myc




Tabelle 27: Statistische Auswertung des Proteinnachweises von c-Myc unter Kombinationsbehandlungen

\begin{tabular}{|c|c|c|c|c|}
\hline $\begin{array}{l}\text { One-way-ANOVA mit } \\
\text { Turkey's multiple test }\end{array}$ & MCF7 & MCF7-TR & T47D & T47D-TR \\
\hline \multicolumn{5}{|l|}{ Kontrolle } \\
\hline vs. $1 \mu \mathrm{M}$ 4-OHT & $p<0,0001$ & $p>0,05$ & $p>0,05$ & $p>0,05$ \\
\hline vs. $2,5 \mathrm{mM}$ 2-DG & $p<0,01$ & $p>0,05$ & $p>0,05$ & $p>0,05$ \\
\hline vs. 5 HM CB-839 & $p<0,001$ & $p>0,05$ & $p>0,05$ & $p<0,05$ \\
\hline vs. $1 \mu \mathrm{M}$ 4-OHT + 2,5 mM 2-DG & $p<0,01$ & $p<0,05$ & $p>0,05$ & $p>0,05$ \\
\hline vs. $1 \mu \mathrm{M}$ 4-OHT + $5 \mu \mathrm{M}$ CB-839 & $p<0,0001$ & $p<0,05$ & $p<0,01$ & $p>0,05$ \\
\hline vs. $2,5 \mathrm{mM} 2-\mathrm{DG}+5 \mu \mathrm{M}$ CB-839 & $p<0,01$ & $p<0,05$ & $p>0,05$ & $p<0,05$ \\
\hline vs. $1 \mu \mathrm{M} 4-\mathrm{OHT}+2,5 \mathrm{mM} 2-\mathrm{DG}+5 \mu \mathrm{M}$ CB-839 & $p<0,0001$ & $p<0,05$ & $p<0,05$ & $p>0,05$ \\
\hline \multicolumn{5}{|l|}{$1 \mu \mathrm{M}$ 4-OHT } \\
\hline vs. $2,5 \mathrm{mM} 2-\mathrm{DG}$ & $p>0,05$ & $p>0,05$ & $p>0,05$ & $p>0,05$ \\
\hline vs. $5 \mu \mathrm{M}$ CB-839 & $p>0,05$ & $p>0,05$ & $p>0,05$ & $p<0,05$ \\
\hline vs. $1 \mu \mathrm{M}$ 4-OHT + 2,5 mM 2-DG & $p>0,05$ & $p<0,05$ & $p>0,05$ & $p>0,05$ \\
\hline vs. $1 \mu \mathrm{M}$ 4-OHT + $5 \mu \mathrm{M}$ CB-839 & $p>0,05$ & $p<0,01$ & $p>0,05$ & $p<0,05$ \\
\hline vs. $2,5 \mathrm{mM} 2-\mathrm{DG}+5 \mu \mathrm{M}$ CB-839 & $p>0,05$ & $p<0,01$ & $p>0,05$ & $p<0,01$ \\
\hline vs. $1 \mu \mathrm{M} 4-\mathrm{OHT}+2,5 \mathrm{mM}$ 2-DG + $5 \mu \mathrm{M}$ CB-839 & $p>0,05$ & $p<0,01$ & $p>0,05$ & $p<0,05$ \\
\hline \multicolumn{5}{|l|}{ 2,5 mM 2-DG } \\
\hline vs. $5 \mu \mathrm{M}$ CB-839 & $p>0,05$ & $p>0,05$ & $p>0,05$ & $p>0,05$ \\
\hline vs. $1 \mu \mathrm{M}$ 4-OHT + 2,5 mM 2-DG & $p>0,05$ & $p>0,05$ & $p>0,05$ & $p>0,05$ \\
\hline vs. $1 \mu \mathrm{M}$ 4-OHT + $5 \mu \mathrm{M}$ CB-839 & $p>0,05$ & $p>0,05$ & $p>0,05$ & $p>0,05$ \\
\hline vs. $2,5 \mathrm{mM} 2-\mathrm{DG}+5 \mu \mathrm{M}$ CB-839 & $p>0,05$ & $p>0,05$ & $p>0,05$ & $p>0,05$ \\
\hline vs. $1 \mu \mathrm{M} 4-\mathrm{OHT}+2,5 \mathrm{mM} 2-\mathrm{DG}+5 \mu \mathrm{M}$ CB-839 & $p>0,05$ & $p>0,05$ & $p>0,05$ & $p>0,05$ \\
\hline \multicolumn{5}{|l|}{$5 \mu \mathrm{M}$ CB-839 } \\
\hline vs. $1 \mu \mathrm{M}$ 4-OHT + 2,5 mM 2-DG & $p>0,05$ & $p>0,05$ & $p>0,05$ & $p>0,05$ \\
\hline vs. $1 \mu \mathrm{M}$ 4-OHT + $5 \mu \mathrm{M}$ CB-839 & $p>0,05$ & $p>0,05$ & $p>0,05$ & $p>0,05$ \\
\hline vs. $2,5 \mathrm{mM} 2-\mathrm{DG}+5 \mu \mathrm{M}$ CB-839 & $p>0,05$ & $p>0,05$ & $p>0,05$ & $p>0,05$ \\
\hline vs. $1 \mu \mathrm{M}$ 4-OHT + 2,5 mM 2-DG + $5 \mu \mathrm{M}$ CB-839 & $p>0,05$ & $p>0,05$ & $p>0,05$ & $p>0,05$ \\
\hline \multicolumn{5}{|l|}{$1 \mu \mathrm{M}$ 4-OHT + 2,5 mM 2-DG } \\
\hline vs. $1 \mu \mathrm{M}$ 4-OHT + $5 \mu \mathrm{M}$ CB-839 & $p>0,05$ & $p>0,05$ & $p>0,05$ & $p>0,05$ \\
\hline vs. $2,5 \mathrm{mM} 2-\mathrm{DG}+5 \mu \mathrm{M}$ CB-839 & $p>0,05$ & $p>0,05$ & $p>0,05$ & $p>0,05$ \\
\hline vs. $1 \mu \mathrm{M}$ 4-OHT + 2,5 mM 2-DG + $5 \mu \mathrm{M}$ CB-839 & $p>0,05$ & $p>0,05$ & $p>0,05$ & $p>0,05$ \\
\hline \multicolumn{5}{|l|}{$1 \mu \mathrm{M}$ 4-ОНТ + $5 \mu \mathrm{M}$ CB-839 } \\
\hline vs. $2,5 \mathrm{mM} 2-\mathrm{DG}+5 \mu \mathrm{M}$ CB-839 & $p>0,05$ & $p>0,05$ & $p>0,05$ & $p>0,05$ \\
\hline vs. $1 \mu \mathrm{M} 4-\mathrm{OHT}+2,5 \mathrm{mM} 2-\mathrm{DG}+5 \mu \mathrm{M}$ CB-839 & $p>0,05$ & $p>0,05$ & $p>0,05$ & $p>0,05$ \\
\hline \multicolumn{5}{|l|}{ 2,5 mM 2-DG + $5 \mu \mathrm{M}$ CB-839 } \\
\hline vs. $1 \mu \mathrm{M}$ 4-OHT + 2,5 mM 2-DG + $5 \mu \mathrm{M}$ CB-839 & $p>0,05$ & $p>0,05$ & $p>0,05$ & $p>0,05$ \\
\hline
\end{tabular}




\section{Diskussion}

Die wesentliche Fragestellung dieser Arbeit war, ob sich die Therapie mit dem niedrig dosierten 4-OHT durch eine Anti-Metabolismus-Therapie mittels 2-DG und/oder CB-839 optimieren lässt und inwiefern dabei Unterschiede zu den TR-Zelllinien zu beobachten sind. Neben dem Viabilitätsverhalten sollte außerdem überprüft werden, ob sich die verschiedenen Behandlungen im Apoptose-Verhalten widerspiegeln und welche Auswirkungen diese proteinbiochemisch auf c-Myc haben.

Mittels Viabilitätssassay wurde nachgewiesen, dass die Substanzen dosisabhängig eine Hemmung der Zellproliferation bewirkten.

Es konnte gezeigt werden, dass es unter der Therapie mit 4-OHT dosisabhängig zu einer Proliferationsreduktion von ER-positiven Zellen kam. Gleichzeitig konnte gezeigt werden, dass bei Tamoxifen-resistenten Zelllinien diese Reduktion gar nicht bzw. geringfügiger ausgeprägt war. Dass die T47D-TR-Zelllinie unter der höchsten 4-OHT-Behandlung signifikant viabilitätshemmend wirkte, lässt die Vermutung zu, dass die sekundäre Anti-ER-Resistenz an dieser Stelle nicht vollständig ausgeprägt war.

2-DG führte ebenfalls sowohl bei den Tamoxifen-sensiblen, als auch bei den Tamoxifenresistenten Zelllinien zu einer dosisabhängigen Viabilitätsminderung. Vergleichend konnte hier beobachtet werden, dass die Tamoxifen-resistenten Zelllinien in beiden Fällen im Vergleich zu ihren parenteralen Zelllinien bei einer niedrigeren Konzentration (2,5 mM 2-DG) eine stärkere Viabilitätsinhibition zeigten. Bei höherer Konzentration (5 mM 2-DG) jedoch war der Wirkeffekt der parenteralen Zelllinien stärker verglichen mit den zugehörigen Tamoxifenresistenten Zelllinien.

Ein dosisabhängiges Wirkprofil konnte unter der Therapie mit CB-839 bei allen vier Zelllinien gezeigt werden. Allerdings zeigte die Tamoxifen-resistente Zelllinie MCF7-TR im Vergleich zu ihrer parenteralen Zelllinie MCF7 unter der höchsten CB-839-Konzentration (10 $\mu$ M CB-839) eine stärkere Viabilitätshemmung. Die beiden Zelllinien T47D und T47D-TR verhielten sich bezüglich des Wirkprofils ähnlich.

Bei der MCF7-Zelllinie konnten die stärksten Effekte im Rahmen der Behandlung mit der höchsten Konzentration 4-OHT bzw. 2-DG erzielt werden. Verglichen dazu zeigte die dazugehörige Tamoxifen-resistente Zelllinie den stärksten Effekt unter der jeweils höchsten Konzentration der Metabolismus-Inhibitoren 2-DG bzw. CB-839. 
Die T47D-Zelllinie präsentierte die stärksten hemmenden Effekte auf die Zellviabilität unter der Behandlung mit der höchsten Konzentration an 4-OHT und 2-DG, wohingegen die dazugehörige Tamoxifen-resistente Zelllinie die stärkste viabilitätshemmende Wirkung unter den jeweils höchsten Konzentrationen der Metabolismus-Inhibitoren 2-DG und CB-839 aufwies. Daraus ergab sich zunächst die Beobachtung, dass bei den parenteralen Zelllinien MCF7 und T47D im Vergleich zu den anderen Behandlungen die stärkste Wirkung unter der 4-OHT- bzw. 2-DG-Therapie erzielt werden konnte. Hingegen präsentierten die beiden Tamoxifen-resistenten Zelllinien MCF7-TR und T47D-TR starke Viabilitätshemmungen unter der Behandlung mit den Metabolismus-Inhibitoren 2-DG und CB-839. 2-DG konnte also zusammenfassend bei allen Zelllinien als wirksam evaluiert werden. 4-OHT zeigte keine bzw. eine schlechte Wirksamkeit bei den Tamoxifen-resistenten Zelllinien, hier konnte sich CB-839 als wirksam erweisen.

Betrachtet man hinsichtlich dessen genauer die Literatur, so haben Gross et al. (2014) zeigen können, dass CB-839 zwar auf Mammakarzinom-Zellen aus verschiedenen Subtypen einen proliferativ-inhibierenden Effekt habe, allerdings nicht auf die Zelllinie T47D in niedrigen Konzentrationen bis $1 \mu \mathrm{M}$. Dies konnte in dieser Arbeit in geringeren Konzentrationen an CB-839 $(1 \mu \mathrm{M}$ und $5 \mu \mathrm{M})$ übereinstimmend gezeigt werden, allerdings konnte in höherer CB-839-Konzentration (10 $\mu \mathrm{M})$ ein Wirkeffekt nachgewiesen werden, was eine dosisabhängige Viabilitätsminderung vermuten lässt. Aft et al. (2002) zeigten in Brustkrebszellen eine Hemmung des Zellwachstums unter einer Therapie mit 2-DG ab einer Konzentration von 4 mM. Damit überschneiden sich diese Ergebnisse mit denen dieser Arbeit. Leung et al. (2014) stellten fest, dass es unter den Tamoxifen-resistenten Zelllinien zu einer gesteigerten Glykolyse käme und zu einer verminderten Sensitivität zytotoxischer Medikamente. Unter dieser Annahme kann man davon ausgehen, dass die Tamoxifenresistenten Zelllinien besser auf die Anti-Glucose-Therapie ansprechen müssten. In dieser Arbeit konnte diese These insoweit bestätigt werden, als dass die parenteralen, nichtresistenten Zelllinien MCF7 und T47D erst eine signifikante Viabilitätsminderung ab 5 mM 2-DG zeigten, die Tamoxifen-resistenten Zelllinien MCF7-TR und T47D-TR bereits unter einer Konzentration von 2,5 mM 2-DG. Allerdings zeigten bei beiden Zelllinien die TR-Zelllinien im Vergleich zu ihren parenteralen Linien eine schwächere Inhibition auf die höchste Konzentration (5 mM 2-DG). 
Anschließend wurde im Viabilitätsassay die Wirkungen der verschiedenen Behandlungen in Kombination miteinander näher betrachtet und verglichen.

Bei der MCF7-Zelllinie wies die Kombinationsbehandlung aus den beiden MetabolismusInhibitoren sowie die Dreifach-Kombination die stärkste Viabilitätsinhibition im Vergleich zu den anderen Behandlungen auf. Die dazugehörige Tamoxifen-resistente Zelllinie zeigte neben einer bereits starken Viabilitätsinhibition unter der alleinigen 2-DG-Therapie ebenfalls eine vergleichsweise starke Hemmung durch die kombinierten Metabolismus-Inhibitoren und durch die Dreifach-Kombination. Dabei präsentierte sich grundsätzlich die Hemmung bei der Tamoxifen-resistenten Zelllinie MCF7-TR stärker verglichen mit der parenteralen Zelllinie MCF7. Die T47D-Zelllinie reagierte unter der kombinierten Metabolismus-Inhibition sowie der Dreifach-Kombination am stärksten viabilitätshemmend im Vergleich zu den anderen Behandlungen. Verglichen dazu zeigte die T47D-TR-Zelllinie die stärkste viabilitätshemmende Wirkung unter der Dreifach-Kombination.

Insgesamt lässt sich zusammenfassen, dass die Kombinationstherapien bei allen Zelllinien eine bessere Wirksamkeit im Vergleich zu den Einzel-Therapien präsentierten. Im Viabilitätsassay zeigten dabei die TR-Zelllinien auf alle Kombinationsbehandlungen stärker viabilitätshemmende Effekte als die parenteralen Zelllinien.

Grundsätzlich ließ sich außerdem beobachten, dass die kombinierte Metabolismus-Inhibition der kombinierten Tamoxifen-Therapie bei allen Zelllinien überlegen war. Die Kombination aus den beiden Metabolismus-Inhibitoren 2-DG und CB-839 zeigte bei allen vier Zelllinien eine signifikant stärkere Hemmung auf die Zellviabilität im Vergleich zu den Einzelbehandlungen. Durch die Dreifach-Kombination konnte teilweise ein synergistisch-supportiv inhibitorischer Effekt erzeugt werden. Die Therapie mit niedrig dosiertem 4-OHT zeigte im Viabilitätsassay allein bei den TR-Zelllinien durch Kombination mit CB-839 eine signifikant bessere viabilitätshemmende Wirkung im Vergleich zu den jeweiligen Einzelbehandlungen. Die Kombination aus 4-OHT und 2-DG konnte bei keiner der vier Zelllinien eine signifikant stärkere Viabilitätsinhibition präsentieren. Die Forschungsgruppe um Daurio et al. (2016) untersuchte den Wirkmechanismus des Tamoxifens an verschiedenen Mammakarzinom-Zellen. Sie stellten fest, dass Tamoxifen einen hemmenden Effekt auf den mitochondrialen Komplex I habe, wodurch es zu einer Erhöhung des AMP/ATP-Verhältnisses käme, was über die Aktivierung der AMPK zu einer gesteigerten Glykolyse führe. 
Daraus schlossen sie, dass sich deswegen eine Kombination aus Tamoxifen und einem Glykolysehemmer anbiete. Dies konnte in dieser Arbeit anhand der Kombination aus 4-OHT und 2-DG nicht bestätigt werden, keine der vier untersuchten Zelllinien zeigte einen signifikant besseren Effekt auf die Viabilitätsinhibition unter der Kombinationstherapie im Vergleich zu den Einzelbehandlungen, allerdings muss an dieser Stelle angemerkt werden, dass in dieser Arbeit mit vergleichsweise niedrigen Konzentrationen gearbeitet wurde. Desweiteren fanden Ambrosio et al. (2017) heraus, dass Glucose die Tamoxifen-Sensitivität über den CTFG (engl. connective tissue growth factor) hemme. Attia et al. (2015) zeigten außerdem, dass sich die Tamoxifen-Zytotoxizität durch Kombination mit dem Glykolyse-Inhibitor 3-Brompyruvat in vitro bei MCF7- und T47D-Zelllinien steigern ließe. In dieser Arbeit konnte keine signifikante zytotoxische Optimierung unter der Kombinationsbehandlung aus Tamoxifen und dem Glykolyse-Inhibitor in den vergleichsweise niedrigen Konzentrationen gezeigt werden.

Die Arbeitsgruppe um Woo et al. (2015) wies anhand von MCF7-TR-Zellen nach, dass im Vergleich zu den nicht-TR-Zellen die Glykolyseaktivität, Akt/mTOR und HIF-1-alpha erhöht seien. Diesbezüglich empfahlen sie eine Glykolyseinhibition bei hormonresistenten Mammakarzinom-Zellen.

Im Viabilitätsassay zeigten in dieser Arbeit die TR-Zelllinien auf die Einzelbehandlung mit 2-DG zwar eine frühere, jedoch nicht so starke Wirkung im Vergleich zu den parenteralen Linien. Nichtsdestotrotz zeigten sie auf alle Kombinationsbehandlungen stärker viabilitätshemmende Effekte im Vergleich zu den parenteralen Zelllinien, wobei vor allem die Kombinationsbehandlungen mit dem Glykolyse-Hemmstoff CB-839 im Vergleich zu 2-DG bessere Effekte erzielten.

Um die Viabilitätshemmung hinsichtlich des genaueren Mechanismuses unter den verschiedenen Behandlungen besser einordnen $z u$ können, erfolgte neben dem Viabilitätsassay ein Apoptose-Assay mithilfe von JC-1. Hier konnte gezeigt werden, dass sich, korrelierend zu dem Viabilitätsassay, die Apoptose größtenteils entsprechend verhielt.

Bei der MCF7-Zelllinie ließ sich eine Hemmung auf das mitochondriale Membranpotential unter der Dreifachkombination, aber auch unter den Kombinationen aus 4-OHT und 2-DG sowie den Metabolismus-Inhibitoren beobachten. Ähnliches zeigte sich bei der dazugehörigen Tamoxifen-resistenten MCF7-TR-Zelllinie, sowie der T47D- und T47D-TR-Zelllinie. 
Es ließ sich beobachten, dass bei drei der vier Zelllinien (MCF7, T47D, T47D-TR) eine signifikant starke Hemmung auf das mitochondriale Membranpotential durch die Kombinationsbehandlung 4-OHT + 2-DG zum Zeitpunkt der Messung (vgl. 2.2.2.2) bewirkt wurde. Dieser Effekt der Apoptose-Induktion spiegelt sich nicht im Viabilitätsverhalten wider und ist am ehesten mit der Sensibilität der Methodik an sich zu begründen.

Um das Proliferations- und Apoptose-Verhalten der Zelllinien unter den verschiedenen Behandlungen daher noch näher zu betrachten, wurde c-Myc auf proteinbiochemischer Ebene mithilfe des Western-Blots untersucht.

Zur besseren Einordnung diese Ergebnisse sollen zunächst die Hintergründe von c-Myc näher beleuchtet werden.

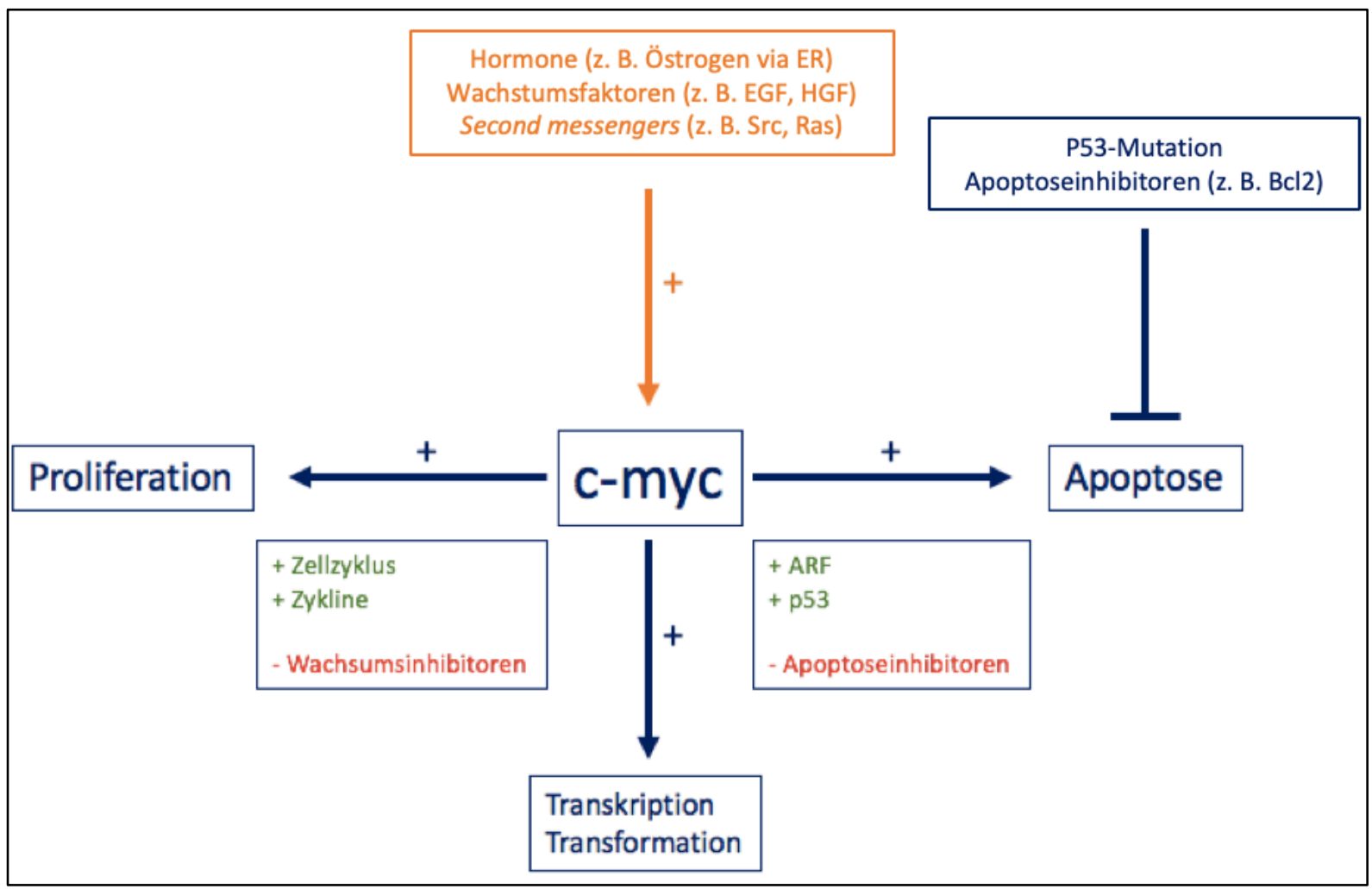

Abbildung 26: Wirkungsweise von c-Myc (nach Meyer und Penn 2008)

C-Myc gehört zur Myc-Familie und spielt als Transkriptionsfaktor eine zentrale Rolle in Bezug auf Transkription, Transformation, Proliferation und Apoptose (vgl. Abb. 26).

Dabei wurde mit dem Hintergrund dieser Arbeit die Rolle von c-Myc insbesondere bei der Proliferation und der Apoptose näher beleuchtet. C-Myc kann durch Hormone und die dazugehörigen Rezeptoren, wie Östrogen mit dem Östrogen-Rezeptor (ER) und durch Wachstumsfaktoren (engl. growth factors, GF) aktiviert werden (Dubik und Shiu 1992; Dong et al. 2018). 
Außerdem spielen weitere sekundäre Botenstoffe (engl. second messengers) wie das G-Protein Ras (engl. rat sarcoma) eine Rolle in der Aktivierung von Myc (Meyer und Penn 2008).

Ist Myc aktiviert, so führt dies durch Anregung des Zellzyklusses und durch Aktivierung von Zyklinen sowie durch Hemmung von Wachstumsinhibitoren auf der einen Seite zur ZellProliferation (Amati et al. 1998). Auf der anderen Seite fördert Myc die Apoptose durch Aktivierung von ARF (Adenosyl-Ribosylierungs-Faktor) und p53 sowie durch Hemmung von antiapoptotischen Proteinen (Klefstrom et al. 1997; Zindy et al. 1998). Dieses Gleichgewicht aus Proliferations- und Apoptose-Induktion stellt zunächst eine Barriere bei der Tumorentstehung dar. Kommt es jedoch durch verschiedene Prozesse wie bspw. eine p53-Mutation oder eine Proliferation von Bcl-2 als antiapoptotisches Protein zu einer Hemmung der Apoptose, so gerät das System aus dem Gleichgewicht und die Tumorentstehung ist gewährleistet (Gabay et al. 2014). Es ist bekannt, dass eine Großzahl an malignen Tumoren daher eine Hochregulierung von Myc beinhalten (Escot et al. 1986). Ein Knock-Down von Myc führte in malignen Tumoren, wo Myc zuvor hochreguliert war, zu einer Hemmung der Proliferation, allerdings auch zu einer Zunahme von Apoptose, was die Abhängigkeit von c-Myc in malignen Tumoren herleiten lässt (Cappellen et al. 2007). Hinsichtlich therapeutscher Angriffspunkte konnte bereits gezeigt werden, dass bei Zellen, die eine Hochregulierung von c-Myc präsentierten, ein Glucose- bzw. ein Glutamin-Entzug zu einer gesteigerten Apoptose führten, da nicht ausreichend Metabolite für die durch Myc induzierte gesteigerte Proliferation gewährleistet werden konnte (Shim et al. 1998; Yuneva et al. 2007).

Die eingesetzten Wirkstoffe stehen somit im Kontext mit c-Myc. 4-OHT als SERM reguliert die ERs und führt dadurch zur Inhibition von c-Myc und somit zur Proliferationsinhibition. 2-DG als Glykolyseinhibitor und CB-839 als Glutaminase-Inhibitor greifen in den Metabolismus ein und hemmen die durch c-Myc gesteigerte Proliferation, wodurch es zu einer verstärkten Apoptose kommt. 


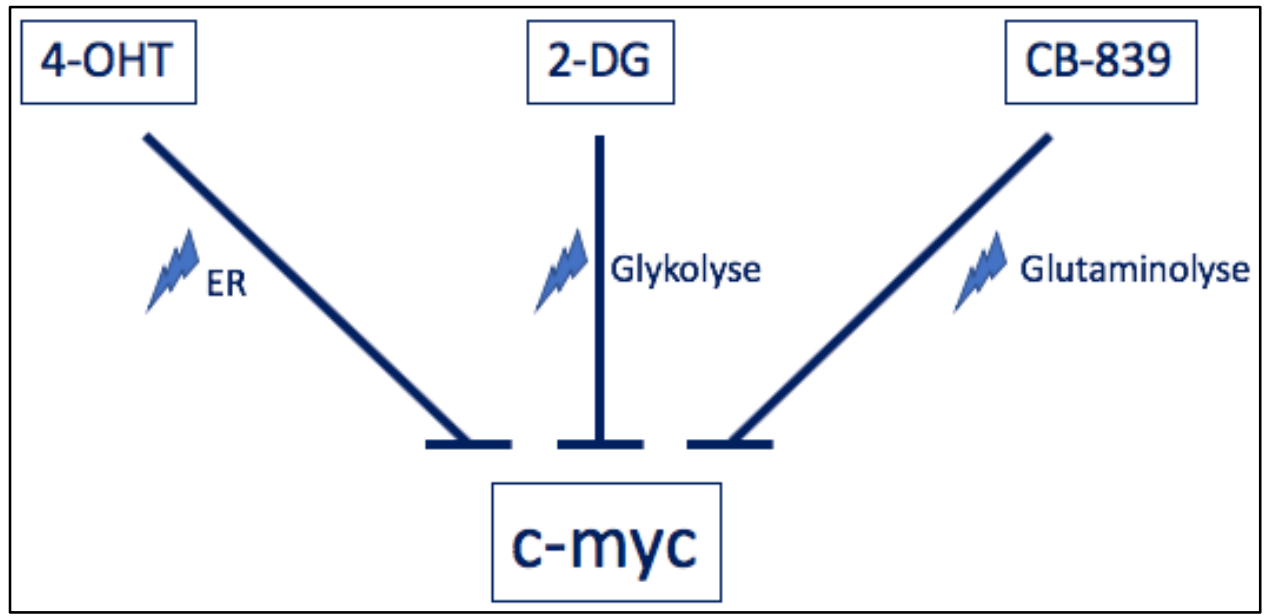

Abbildung 27: Wirkung von 4-OHT, $2 D G$ und $C B-839$ auf c-Myc

Watson et al. (1993) konnten bereits die c-Myc Amplifikation in MCF7- und T47D-Zelllinien nachweisen. In dieser Arbeit konnte ebenfalls der c-Myc-Proteinnachweis auf proteinbiochemischer Ebene in MCF7-, MCF7-TR-, T47D- und T47D-TR-Zelllinien hergestellt werden. Eine Arbeit von McNeal et al. (2006) zeigte, dass c-Myc eine zentrale Rolle in der endokrinen Resistenzentwicklung spiele. Dabei ist die Hochregulierung von c-Myc mit einer sekundären Resistenzentwicklung assoziiert (Miller et al. 2011). In der Literatur zeigte sich außerdem, dass Tamoxifen-resistente Zelllinien im Vergleich zu den nichtresistenten Zelllinien höhere c-Myc-Werte präsentierten, verbunden mit einem invasiveren und proliferativeren Wachstum sowie einer schlechteren Prognose (Yu et al. 2019). Außerdem zeigte sich in ER-resistenten Zelllinien eine mit c-Myc assoziierte Hochregulierung des GlucoseMetabolismuses (Green et al. 2016). Fallah et al. (2017) empfahlen sogar den Nachweis einer Hochregulierung von Myc als Prädiktor einer Antiöstrogentherapie-Resistenz.

In dieser Arbeit konnte übereinstimmend bestätigt werden: im Vergleich zu den parenteralen Zelllinien MCF7 und T47D war bei den Tamoxifen-resistenten Zelllinien MCF7-TR und T47D-TR eine stärkere Expressivität von c-Myc zu beobachten.

\begin{tabular}{|c|c|c|}
\hline $\begin{array}{l}\text { Parenterale } \\
\text { Zelllinien } \\
\text { MCF7, T47D }\end{array}$ & $\begin{array}{c}>1 \text { Jahr wöchentliche Gabe von } 125 \mathrm{nM} \text { 4-OHT, } \\
\text { Sekundäre Resistenzentwicklung }\end{array}$ & $\begin{array}{c}\text { Tamoxifen-resistente } \\
\text { Zelllinien } \\
\text { MCF7-TR, T47D-TR }\end{array}$ \\
\hline & 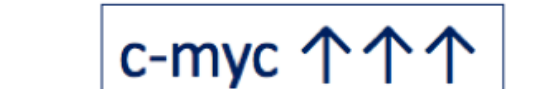 & \\
\hline
\end{tabular}

Abbildung 28: Sekundäre Resistenzentwicklung und c-Myc (nach Günthert et al. 2005) 
In dieser Arbeit konnte desweiteren gezeigt werden, dass es unter fast allen Behandlungen zu einer teilweise signifikanten c-Myc-Herunterregulierung kam, besonders unter den Kombinationsbehandlungen. Dadurch kann der Zusammenhang zwischen den eingesetzten Wirkstoffen und c-Myc bestätigt werden. Eine Ausnahme stellte die Behandlung mit 4-OHT alleine bei den TR-Zelllinien dar, hier kam es zu keiner Herunterregulierung des c-Mycs. Dies zeigt, dass die sekundäre Tamoxifen-Resistenz auch proteinbiochemisch Auswirkungen auf die c-Myc-Expressivität haben muss. 


\subsection{Ausblick}

Die Ergebnisse dieser Arbeit zeigen, dass die Kombinationsbehandlungen aus 4-OHT, 2-DG und CB-839 in vitro einen signifikant stärkeren inhibitorischen Effekt im Vergleich zu den Einzelbehandlungen mit 4-OHT, 2-DG oder CB-839 bewirkten. Allerdings zeigte sich bei keiner der Zelllinien eine Therapieoptimierung im Vergleich zu den Einzelbehandlungen bei der Kombination aus 4-OHT und 2-DG. Die viabilitätsinhibitorischen Effekte spiegelten sich größtenteils im Apoptoseverhalten wider. Außerdem konnte unter den Behandlungen eine Herunterregulierung des Proto-Onkogens c-Myc auf proteinbiochemischer Ebene beobachtet werden.

Die Zelllinien MCF7 und T47D stellen durch ihre Eigenschaften als ER- und PR-positive epitheliale, nicht invasive Zelllinien ein in vitro Modell von Mammakarzinomen des Subtyps luminal A und damit die häufigste Form dar. In der Praxis gilt Tamoxifen bei diesem Subtyp als etablierte Therapieempfehlung. Allerdings wird diese Therapie durch die toxischen Nebenwirkungen erschwert. In dieser Arbeit konnte gezeigt werden, dass die alleinige Therapie mit Tamoxifen bei den Zelllinien MCF7 und T47D am effektivsten durch eine Kombination mit dem Glutaminase-Inhibitor CB-839 optimiert werden konnte. In vivo würde sich hier anbieten diese Kombination zu evaluieren, besonders in Hinblick auf eine Konzentrationsreduktion der Einzelsubstanzen, um der möglichen Entwicklung von Nebenwirkungen entgegenzuwirken.

Die Entwicklung einer sekundären Tamoxifen-Resistenz stellt ein häufiges Problem in der Praxis dar. Mithilfe der Zelllinien MCF7-TR und T47D-TR konnte ein Modell der sekundären Antiöstrogen-Resistenz in vitro repräsentiert werden und mit den parenteralen Zelllinien unter den verschiedenen Behandlungen verglichen werden. Hierbei konnte in dieser Arbeit gezeigt werden, dass gerade die Tamoxifen-resistenten Zelllinien in vitro sensibler auf die kombinierte Metabolismus-Inhibition im Vergleich zu ihren parenteralen Zelllinien reagierten. Eine in vivo Evaluation dieser Kombination wäre hier sinnvoll. Bei der T47D-TR-Zelllinie konnte sogar unter der Dreifach-Kombinationsbehandlung ein im Vergleich zu allen anderen Behandlungen signifikant stärkerer Effekt beobachtet werden, sodass es an dieser Stelle interessant zu evaluieren wäre, ob hier die Tamoxifen-Resistenz durch die Kombination mit den beiden Metabolismus-Inhibitoren überwunden werden könnte. 


\section{Zusammenfassung}

Mammakarzinome exprimieren zu einem großen Anteil Hormonrezeptoren. Diese häufige und wichtige Eigenschaft der Hormonsensibilität wird sich therapeutisch als Target mittels Tamoxifen als selektiver ER-Modulator zu Nutzen gemacht, wobei diese Therapie durch Nebenwirkungen und Resistenzentwicklungen erschwert wird. Daher wurden weitere Targets zur Therapieoptimierung in vitro evaluiert. Hierzu zählten einerseits der Glykolyse-Inhibitor 2-DG, der in die Eigenschaft des Warburg-Effekts, also des erhöhten Glucosebedarfs von Tumoren eingreift, sowie der Glutaminase-Inhibitor CB-839, der auf die bei Tumoren gesteigerte Glutaminolyse hemmend einwirkt. Die Kombinationsbehandlungen zeigten mit Ausnahme der Kombination aus Tamoxifen (4-OHT) und 2-Deoxy-D-Glucose (2-DG) einen signifikant stärkeren inhibitorischen Effekt auf die Viabilität im Vergleich zu den Einzelbehandlungen. Hierbei konnte gezeigt werden, dass sich bei den Tamoxifen-resistenten Zelllinien im Vergleich zu den nicht resistenten Zelllinien ein stärkerer reduzierender Effekt auf die Zellviabilität unter den Kombinationsbehandlungen ergab. Additiv konnte mittels JC-1-Assay bestätigt werden, dass die Viabilitätsminderungen durch Apoptoseinduktion bewirkt wurden. Außerdem konnte auf proteinbiochemischer Ebene gezeigt werden, dass es unter den Behandlungen zu einer Herunterregulierung des Proto-Onkogens c-Myc kam. Dabei ergab sich bei den Tamoxifen-resistenten Zelllinien eine stärkere Exprimierung von c-Myc im Vergleich zu den parenteralen Zelllinien, welche jedoch behandlungsabhängig herunterreguliert werden konnte.

Es konnte also gezeigt werden, dass sich die Kombinationsbehandlungen je nach Zellentität und Resistenzstatus durchaus anbieten. Zur Therapieoptimierung des Mammakarzinoms gilt es dies in weiteren Untersuchungen sowohl in vitro, als auch in vivo zu evaluieren. 


\section{Literaturverzeichnis}

Aft RL, Zhang FW, Gius D (2002): Evaluation of 2-deoxy-D-glucose as a chemotherapeutic agent: mechanism of cell death. Br J Cancer $\underline{87}, 805-812$

Al-nasiry S, Geusens N, Hanssens M, Luyten C, Pijnenborg R (2007): The use of Alamar Blue assay for quantitative analysis of viability, migration and invasion of choriocarcinoma cells. Hum Rep 22, 1304-1309

Amant F, Moerman P, Neven P, Timmerman D, Van Limbergen E, Vergote I (2005):

Endometrial cancer. Lancet $\underline{366}, 491-505$

Amati B, Alevizopoulos K, Vlach J (1998): Myc and the cell cycle. Front Biosci J $\underline{3}$ d250-268

Ambrosio MR, D’Esposito V, Costa V, Liguoro D, Collina F, Cantile M, Prevete N, Passaro C, Mosca G, De Laurentiis M, et al. (2017): Glucose impairs Tamoxifen responsiveness modulating connective tissue growth factor in breast cancer cells. Oncotarget $\underline{8}, 109000-109017$

Anderson WF, Chatterjee N, Ershler WB, Brawley OW (2002): Estrogen receptor breast cancer phenotypes in the Surveillance, Epidemiology, and End Results database.

Breast Cancer Res Treat 76, 27-36

Attia YM, EL-Abhar HS, Al Marzabani MM, Shouman SA (2015): Targeting glycolysis by 3-bromopyruvate improves Tamoxifen cytotoxicity of breast cancer cell lines. BMC Cancer $\underline{15}, 838$

Barkhem T, Carlsson B, Nilsson Y, Enmark E, Gustafsson J, Nilsson S (1998): Differential response of estrogen receptor alpha and estrogen receptor beta to partial estrogen agonists/antagonists. Mol Pharmacol 54, 105-112

Cappellen D, Schlange T, Bauer M, Maurer F, Hynes NE (2007): Novel c-MYC target genes mediate differential effects on cell proliferation and migration. EMBO Rep $\underline{8}$, 70-76

Carey LA, Perou CM, Livasy CA, Dressler LG, Cowan D, Conway K, Karaca G, Troester MA, Tse CK, Edmiston S, et al. (2006): Race, breast cancer subtypes, and survival in the Carolina Breast Cancer Study. JAMA 295, 2492-2502

Cronin-Fenton DP, Damkier P, Lash TL (2014): Metabolism and transport of Tamoxifen in relation to its effectiveness: new perspectives on an ongoing controversy. Future Oncol $\underline{10}$, 107-122 
Damaghi M, Tafreshi NK, Lloyd MC, Sprung R, Estrella V, Wojtkowiak JW, Morse DL, Koomen JM, Bui MM, Gatenby RA et al. (2015): Chronic acidosis in the tumour microenvironment selects for overexpression of LAMP2 in the plasma membrane. Nat Commun $\underline{6}, 8752$

Daurio NA, Tuttle SW, Worth AJ, Song EY, Davis JM, Snyder NW, Blair IA, Koumenis C (2016): AMPK activation and metabolic reprogramming by Tamoxifen through estrogen receptorindependent mechanisms suggests new uses for this therapeutic modality in cancer treatment. Cancer Res $\underline{76}$, 3295-3306

DeBerardinis RJ, Cheng T (2010): Q's next: the diverse functions of glutamine in metabolism, cell biology and cancer. Oncogene 29, 313-324

Deming SL, Nass SJ, Dickson RB, Trock BJ (2000): C-myc amplification in breast cancer: A meta-analysis of its occurrence and prognostic relevance. $\mathrm{Br} J$ Cancer $\underline{83}, 1688-1695$

DKG, DGGG (2018): Interdisziplinäre S3-Leitlinie für die Früherkennung, Diagnose, Therapie und Nachsorge des Mammakarzinoms. Leitlinienprogramm Onkologie Version 4.1. Abgerufen von https://www.awmf.org/uploads/tx_szleitlinien/032-045OLI_S3_Mammakarzinom_2018-09.pdf; abgerufen am 15.08.2019

Dong N, Xu B, Xu J (2018): EGF-mediated overexpression of Myc attenuates miR-26b by recruiting HDAC3 to induce epithelial-mesenchymal transition of lens epithelial cells. BioMed Res Int 2018, 7148023-7148023

Dubik D, Shiu RP (1992): Mechanism of estrogen activation of c-myc oncogene expression. Oncogene $\underline{7}, 1587-1594$

EBCTCG (Early Breast Cancer Trialists' Collaborative Group) (2005): Effects of chemotherapy and hormonal therapy for early breast cancer on recurrence and 15-year survival: an overview of the randomised trials. Lancet $\underline{365}, 1687-1717$

EBCTCG (Early Breast Cancer Trialists' Collaborative Group) (2011): Relevance of breast cancer hormone receptors and other factors to the efficacy of adjuvant Tamoxifen: patient-level meta-analysis of randomised trials. Lancet $\underline{378}, 771-784$

Escot C, Theillet C, Lidereau R, Spyratos F, Champeme MH, Gest J, Callahan R (1986): Genetic alteration of the c-myc protooncogene (MYC) in human primary breast carcinomas. Proc Natl Acad Sci U S A 83, 4834-4838

Estrella V, Chen T, Lloyd M, Wojtkowiak J, Cornnell HH, Ibrahim-Hashim A, Bailey K, Balagurunathan Y, Rothberg JM, Sloane BF, et al. (2013): Acidity generated by the tumor microenvironment drives local invasion. Cancer Res $\underline{73}, 1524-1535$ 
Fallah Y, Brundage J, Allegakoen P, Shajahan-Haq AN (2017): MYC-Driven pathways in breast cancer subtypes. Biomolecules $\underline{7}, 53$

Fisher B, Costantino JP, Wickerham DL, Cecchini RS, Cronin WM, Robidoux A, Bevers TB, Kavanah MT, Atkins JN, Margolese RG, et al. (2005): Tamoxifen for the prevention of breast cancer: current status of the National Surgical Adjuvant Breast and Bowel Project P-1 study. J Natl Cancer Inst 97, 1652-1662

Gabay M, Li Y, Felsher DW (2014): MYC activation is a hallmark of cancer initiation and maintenance. Cold Spring Harb Perspect Med $\underline{4}$, a014241

GEKID, ZfKD: Krebs in Deutschland für 2013/2014. 11. Ausgabe; Robert Koch-Institut, Berlin 2017

GEKID, ZfKD: Krebs in Deutschland für 2015/2016. 12. Ausgabe; Robert Koch-Institut, Berlin 2019

Green AR, Aleskandarany MA, Agarwal D, Elsheikh S, Nolan CC, Diez-Rodriguez M, Macmillan RD, Ball GR, Caldas C, Madhusudan S, et al. (2016): MYC functions are specific in biological subtypes of breast cancer and confers resistance to endocrine therapy in luminal tumours. Br J Cancer 114, 917-928

Gross MI, Demo SD, Dennison JB, Chen L, Chernov-Rogan T, Goyal B, Janes JR, Laidig GJ, Lewis ER, Li J, et al. (2014): Antitumor activity of the glutaminase inhibitor CB-839 in triple-negative breast cancer. Mol Cancer Ther $\underline{13}$, 890-901

Günthert AR, Gründker C, Olota A, Läsche J, Eicke N, Emons G (2005): Analogs of GnRH-I and $\mathrm{GnRH}-\mathrm{Il}$ inhibit epidermal growth factor-induced signal transduction and resensitize resistant human breast cancer cells to $4 \mathrm{OH}-T a m o x i f e n$. Eur J Endocrinol $\underline{153}$, 613-625

Hensley CT, Wasti AT, DeBerardinis RJ (2013): Glutamine and cancer: cell biology, physiology, and clinical opportunities. J Clin Invest $\underline{123}$, 3678-3684

Jansen-Dürr P, Meichle A, Steiner P, Pagano M, Finke K, Botz J, Wessbecher J, Draetta G, Eilers M (1993): Differential modulation of cyclin gene expression by MYC.

Proc Natl Acad Sci U S A 90, 3685-3689

Klefstrom J, Arighi E, Littlewood T, Jäättelä M, Saksela E, Evan GI, Alitalo K (1997): Induction of TNF-sensitive cellular phenotype by c-Myc involves p53 and impaired NF-kappaB activation. EMBO J $\underline{16}, 7382-7392$ 
Koppenol WH, Bounds PL, Dang CV (2011): Otto Warburg's contributions to current concepts of cancer metabolism. Nat Rev Cancer 11, 325-337

Krebs in Deutschland 2017, siehe GEKID, ZfKD 2017

Laemmli UK (1970): Cleavage of structural proteins during the assembly of the head of bacteriophage T4. Nature $\underline{227}, 680-685$

Laszlo J, Humphreys SR, Goldin A (1960): Effects of glucose analogues (2-deoxy-d-glucose, 2-deoxy-d-galactose) on experimental tumors. J Natl Cancer Inst 24, 267-281

Leitlinie Mammakarzinom 2018, siehe DKG, DGGG (2018)

Leung EY, Kim JE, Askarian-Amiri M, Joseph WR, McKeage MJ, Baguley BC (2014): Hormone resistance in two MCF-7 breast cancer cell lines is associated with reduced mTOR signaling, decreased glycolysis, and increased sensitivity to cytotoxic drugs. Front Oncol 4, 221

Locasale JW, Cantley LC (2011): Metabolic flux and the regulation of mammalian cell growth. Cell Metab 14, 443-451

Maher JC, Krishan A, Lampidis TJ (2004): Greater cell cycle inhibition and cytotoxicity induced by 2-deoxy-D-glucose in tumor cells treated under hypoxic vs aerobic conditions. Cancer Chemother Pharmacol $\underline{53}$, 116-122

McNeil CM, Sergio CM, Anderson LR, Inman CK, Eggleton SA, Murphy NC, Millar EKA, Crea P, Kench JG, Alles MC, et al. (2006): C-Myc overexpression and endocrine resistance in breast cancer. J Steroid Biochem Mol Biol 102, 147-155

Meyer N, Penn LZ (2008): Reflecting on 25 years with MYC. Nat Rev Cancer $\underline{8}$, 976-990

Miller TW, Balko JM, Ghazoui Z, Dunbier A, Anderson H, Dowsett M, González-Angulo AM, Mills GB, Miller WR, Wu H, et al. (2011): A gene expression signature from human breast cancer cells with acquired hormone independence identifies MYC as a mediator of antiestrogen resistance. Clin Cancer Res 17, 2024-2034

Mohanti BK, Rath GK, Anantha N, Kannan V, Das BS, Chandramouli BA, Banerjee AK, Das S, Jena A, Ravichandran R, et al. (1996): Improving cancer radiotherapy with 2-deoxy-Dglucose: phase I/II clinical trials on human cerebral gliomas. Int J Radiat Oncol Biol Phys $\underline{35}$, 103-111 
Moskowitz CS, Chou JF, Wolden SL, Bernstein JL, Malhotra J, Novetsky Friedman D, Mubdi NZ, Leisenring WM, Stovall M, Hammond S, et al. (2014): Breast cancer after chest radiation therapy for childhood cancer. J Clin Oncol 32, 2217-2223

Patel HK, Bihani T (2018): Selective estrogen receptor modulators (SERMs) and selective estrogen receptor degraders (SERDs) in cancer treatment. Pharmacol Ther $\underline{186}$, 1-24

Pelicano H, Martin DS, Xu R-H, Huang P (2006): Glycolysis inhibition for anticancer treatment. Oncogene $\underline{25}, 4633-4646$

Perou CM, Sørlie T, Eisen MB, van de Rijn M, Jeffrey SS, Rees CA, Pollack JR, Ross DT, Johnsen $H$, Akslen LA, et al. (2000): Molecular portraits of human breast tumours. Nature $\underline{406}$, 747-752

Prat A, Parker JS, Karginova O, Fan C, Livasy C, Herschkowitz JI, He X, Perou CM (2010): Phenotypic and molecular characterization of the claudin-low intrinsic subtype of breast cancer. Breast Cancer Res $\underline{12}$, R68

Schuhmacher M, Staege MS, Pajic A, Polack A, Weidle UH, Bornkamm GW, Eick D, Kohlhuber $F$ (1999): Control of cell growth by c-Myc in the absence of cell division. Curr Biol $\underline{9}$, $1255-1258$

Seltzer MJ, Bennett BD, Joshi AD, Gao P, Thomas AG, Ferraris DV, Tsukamoto T, Rojas CJ, Slusher BS, Rabinowitz JD, et al. (2010): Inhibition of glutaminase preferentially slows growth of glioma cells with mutant IDH1. Cancer Res $\underline{70}$, 8981-8987

Shim H, Chun YS, Lewis BC, Dang CV (1998): A unique glucose-dependent apoptotic pathway induced by c-Myc. Proc Natl Acad Sci U S A 95, 1511-1516

Son J, Lyssiotis CA, Ying H, Wang X, Hua S, Ligorio M, Perera RM, Ferrone CR, Mullarky E, Shyh-Chang N, et al. (2013): Glutamine supports pancreatic cancer growth through a KRAS-regulated metabolic pathway. Nature 496, 101-105

Timmerman LA, Holton T, Yuneva M, Louie RJ, Padró M, Daemen A, Hu M, Chan DA, Ethier SP, van 't Veer LJ, et al. (2013): Glutamine sensitivity analysis identifies the XCT antiporter as a common triple-negative breast tumor therapeutic target. Cancer Cell 24, 450-465

Vander Heiden MG, Cantley LC, Thompson CB (2009): Understanding the Warburg Effect: the metabolic requirements of cell proliferation. Science $\underline{324}$, 1029-1033 
van den Heuvel APJ, Jing J, Wooster RF, Bachman KE (2012): Analysis of glutamine dependency in non-small cell lung cancer: GLS1 splice variant GAC is essential for cancer cell growth. Cancer Biol Ther $\underline{13}$, 1185-1194

Warburg O (1956): On the origin of cancer cells. Science $\underline{123}, 309-314$

Watson PH, Safneck JR, Le K, Dubik D, Shiu RP (1993): Relationship of c-myc amplification to progression of breast cancer from in situ to invasive tumor and lymph node metastasis. J Natl Cancer Inst $\underline{85}$, 902-907

Whiting S (2014): Study of the Glutaminase Inhibitor CB-839 in Solid Tumors ClinicalTrials.gov. https://clinicaltrials.gov/ct2/show/NCT02071862; Zugriff am 15.05.2018

Wise DR, Thompson CB (2010): Glutamine addiction: a new therapeutic target in cancer. Trends Biochem Sci $\underline{35}$, 427-433

Wokoun U, Hellriegel M, Emons G, Gründker C (2017): Co-treatment of breast cancer cells with pharmacologic doses of 2-deoxy-D-glucose and metformin: starving tumors.

Oncol Rep 37, 2418-2424

Woo YM, Shin Y, Lee EJ, Lee S, Jeong SH, Kong HK, Park EY, Kim HK, Han J, Chang M, Park J-H (2015): Inhibition of aerobic glycolysis represses Akt/mTOR/HIF-1 $\alpha$ axis and restores Tamoxifen sensitivity in antiestrogen-resistant breast cancer cells. PLOS ONE $\underline{10}$, e0132285

Yu L, Wang L, Mao C, Duraki D, Kim JE, Huang R, Helferich WG, Nelson ER, Park BH, Shapiro DJ (2019): Estrogen-independent Myc overexpression confers endocrine therapy resistance on breast cancer cells expressing ER $\alpha$ Y537S and ER $\alpha$ D538G mutations. Cancer Lett 442 , 373-382

Yuneva M, Zamboni N, Oefner P, Sachidanandam R, Lazebnik Y (2007): Deficiency in glutamine but not glucose induces MYC-dependent apoptosis in human cells. J Cell Biol $\underline{178}$, 93-105

Zhang F, Aft RL (2009): Chemosensitizing and cytotoxic effects of 2-deoxy-D-glucose on breast cancer cells. J Cancer Res Ther 5 Suppl 1, S41-S43

Zindy F, Eischen CM, Randle DH, Kamijo T, Cleveland JL, Sherr CJ, Roussel MF (1998): Myc signaling via the ARF tumor suppressor regulates p53-dependent apoptosis and immortalization. Genes Dev $\underline{12}$, 2424-2433 
Danksagung

Mein besonderer Dank gilt meinem Doktorvater Prof. Dr. rer. nat. Carsten Gründker für die Bereitstellung des Themas und die stets konstruktiv-kritische Betreuung. Außerdem danke ich Sonja Blume und Johanna Hellinger für die laborchemische und -technisch-methodische Unterstützung im Labor. 